Working Paper Series

$10 / 2020$

The Power of Sentiment: Irrational Beliefs of Households and Consumer Loan Dynamics

Zuzana Rakovská, Dominika Ehrenbergerová, Martin Hodula

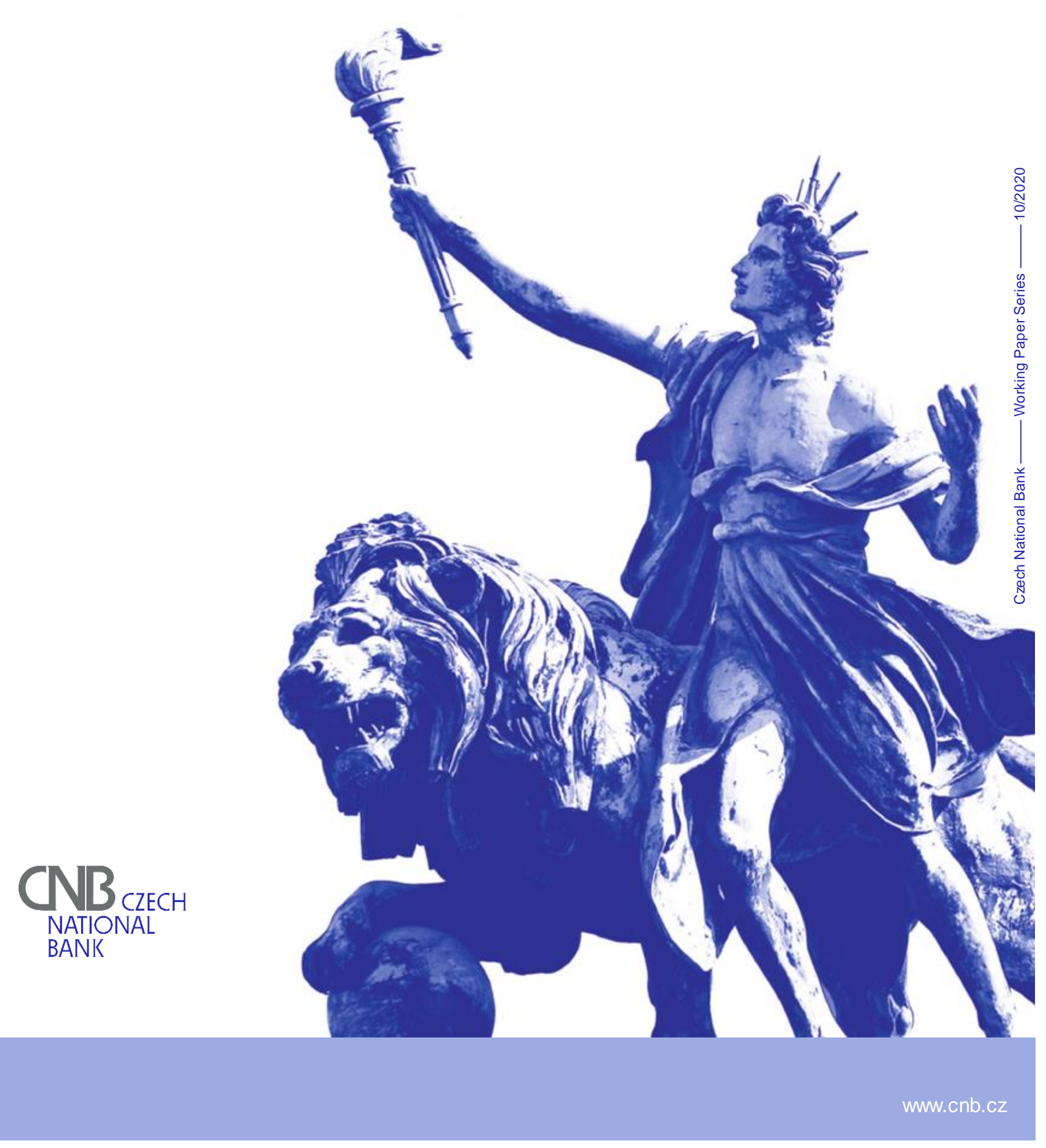


The Working Paper Series of the Czech National Bank (CNB) is intended to disseminate the results of the CNB's research projects as well as the other research activities of both the staff of the CNB and collaborating outside contributors, including invited speakers. The Series aims to present original research contributions relevant to central banks. It is refereed internationally. The referee process is managed by the CNB Economic Research Division. The working papers are circulated to stimulate discussion. The views expressed are those of the authors and do not necessarily reflect the official views of the CNB.

Distributed by the Czech National Bank, available at www.cnb.cz

\author{
Reviewed by: $\quad$ Jaroslav Borovička (New York University) \\ Jan Babecký (Czech National Bank) \\ Project Coordinator: Simona Malovaná \\ Issued by: $\quad$ C Czech National Bank, December 2020
}




\title{
The Power of Sentiment: Irrational Beliefs of Households and Consumer Loan Dynamics
}

\author{
Zuzana Rakovská, Dominika Ehrenbergerová, and Martin Hodula*
}

\begin{abstract}
We examine whether household sentiment can explain fluctuations in newly issued consumer loans. We construct a novel measure of household sentiment using detailed data from the harmonized consumer surveys conducted in European countries. We differentiate between rational sentiment, which mimics dynamics in macroeconomic fundamentals, and irrational sentiment, which proxies households' optimism/pessimism on top of their rationally sourced beliefs. We show that shocks to the sentiment of households do have a measurable impact on growth of consumer loans. Specifically, we assert a significantly positive role of irrational sentiment on top of the economic fundamentals identified in the literature. Moreover, a closer examination reveals that the studied relationship is not symmetric over the business cycle - the effect of irrational sentiment is present only in periods in which a country's output is well above its potential.
\end{abstract}

\begin{abstract}
Abstrakt
Zkoumáme, jestli sentiment domácností může vysvětlovat výkyvy nově poskytovaných spotřebitelských úvěrů. Sestavujeme nový ukazatel sentimentu domácností využívající podrobná data $\mathrm{z}$ harmonizovaných šetření mezi spotřebiteli v evropských zemích. Rozlišujeme mezi racionálním sentimentem, který odráží dynamiku fundamentálních makroekonomických veličin, a iracionálním sentimentem, který aproximuje optimismus či pesimismus domácností nad rámec jejich racionálně založených úsudků. Ukazujeme, že šokové změny sentimentu domácností mají měřitelný dopad do růstu spotřebitelských úvěrů. Konkrétně potvrzujeme významný kladný vliv iracionálního sentimentu nad rámec fundamentálních ekonomických veličin, který je popsán v odborné literatuře. Bližší zkoumání navíc ukazuje, že analyzovaný vztah není v průběhu hospodářského cyklu symetrický - efekt iracionálního sentimentu je prrítomen pouze v obdobích, kdy je produkt země výrazně nad svým potenciálem.
\end{abstract}

JEL Codes: D12, D84, E51, G41, G51.

Keywords: Consumer loans, consumer survey, expectations, optimism, sentiment.

\footnotetext{
* Zuzana Rakovská, Czech National Bank and Masaryk University, zuzana.rakovska@cnb.cz Dominika Ehrenbergerová, Czech National Bank and Charles University, dominika.ehrenbergerova@cnb.cz Martin Hodula, Czech National Bank and University of Economics in Prague, martin.hodula@cnb.cz The authors note that the paper represents their own views and not necessarily those of the Czech National Bank. We would like to thank Simona Malovaná, Jaroslav Borovička, Jan Babecký, Jan Frait, and seminar participants at the Czech National Bank for useful comments. All errors and omissions remain the fault of the authors.
} 


\section{Introduction}

The role of consumer (household) confidence in future real economic activity remains an open question in macroeconomics. There are studies that assign measures of consumer confidence a prominent role in forecasting consumption (Carroll et al., 1994) as well as studies arguing that such measures contain little (if any) additional information for the real economy (Ludvigson, 2004). This ambiguity found in the academic literature can be explained in various ways. For instance, sentiment may only reflect beliefs about current economic fundamentals. As a result, economic agents act on the basis of perceived macroeconomic conditions, which are gradually extrapolated into the future. In fact, positive shocks to sentiment are considered to be only temporary (Starr, 2012) if not met with an actual improvement in economic conditions (Barsky and Sims, 2012). It is also possible that positive shocks to economic agents' beliefs about future economic prospects can become self-fulfilling, to the extent that they constitute multiple rational expectations equilibria (Benhabib and Spiegel, 2019).

Unlike the implications of changes in sentiment on consumption, the role of sentiment as a potential determinant of the fluctuations in credit is rarely recognized or even tested. Since the ups and downs of bank credit are widely recognized to have serious consequences for the real economy (Jordà et al., 2011; Gourinchas and Obstfeld, 2012), it seems natural to analyze the missing link, i.e., the potential relationship between shocks to sentiment and credit dynamics. Such analysis may also complement the myriad of studies trying to answer the simple yet rather elusive question of what drives bank credit (Bernanke and Gertler, 1995; Jiménez et al., 2012, 2017).

In this paper, we analyze the role of economic agents' beliefs - their sentiment - in explaining fluctuations in new consumer loans. We define and understand sentiment from an economic perspective: the term "sentiment" describes economic agents' views arising from their anticipation of future economic developments and also as affected by the past and present economic situation. Thus, household sentiment can be described as an economic indicator that measures how optimistic (or pessimistic) households are about their personal financial situation, the current state of the economy, and the future economic outlook.

To cater for the ambiguity in defining and understanding sentiment, we calculate a novel household sentiment index using detailed data from the harmonized consumer surveys that are conducted locally in the individual European countries. We then differentiate between the part of household sentiment that can be explained by the underlying macroeconomic data, i.e., rational facts, and the part that proxies a mood of excessive optimism or pessimism which is irrational, i.e., cannot be explained solely by fundamentals. We go on to examine the empirical link between the rational and irrational components of household sentiment and growth of newly issued consumer loans. In the empirical verification, we rely on a panel of fifteen European countries spanning the period from January 2003 to March 2019. We believe our paper fills the gap in the existing literature on factors trying to explain fluctuations in bank consumer loans by linking behavioral aspects of finance to macroeconomic credit dynamics.

We find that shocks to the aggregate sentiment of households do have a measurable impact on fluctuations in newly issued consumer loans. Our estimation results point to a non-trivial sentiment channel that explains fluctuations in new loans. Apart from confirming the role of economic fundamentals (materialized in our rational sentiment measure), we assert that irrational sentiment has a significant influence as well. We subject our estimates to a battery of robustness tests. We discover that the impact of shocks to irrational sentiment is not symmetric across the business cycle. Specifically, we find that irrational beliefs about the current situation as well as future economic 
prospects affect growth of new consumer loans positively during boom times, whereas the impact seems to be reduced to zero in any other times. We do not identify any asymmetries in the case of rational sentiment.

Overall, our empirical assessment of the statistical relationship between household sentiment and growth of consumer loans relates to the theoretical literature in a number of ways. Our results are in line with the financial instability hypothesis formulated by Minsky (1977): positive shocks to sentiment are associated with faster growth of credit. Our findings also relate to the stream of literature modeling the contribution of behavioral factors to credit booms while leaving aside the assumption of rational behavior (Fuster et al., 2010; Gennaioli et al., 2015; Bordalo et al., 2018).

Our findings have some major implications for monetary and macroprudential policy conduct. We show that favorable macroeconomic conditions lay the ground for excessive household optimism to drive growth of consumer loans. In other words, our estimates suggest that during an economic upturn, households are prepared to tolerate a much higher level of indebtedness. In the absence of counter-cyclical policy, positive shocks to household sentiment can easily become self-fulfilling when increased demand for credit is met by supply. Excessive growth of household credit coupled with other imbalances or fragility in the financial system has contributed to strong adverse effects in a number of advanced economies several times in history, most notably during the Global Financial Crisis of 2007-2009.

The paper proceeds as follows. Section 2 summarizes the role of sentiment in economics by reviewing the existing literature and highlights our contribution. Section 3 discusses underlying facets of the construction of our novel measure of household sentiment and explains the derivation of the rational and irrational components. Section 4 presents our empirical strategy and data. Section 5 discusses the main results and robustness estimates, and Section 6 concludes.

\section{The Role of Sentiment: A Review}

Economic decisions, including the decision to borrow, are no longer viewed as fully rational decisions driven by information efficiency and utility maximization. Advances in the field of behavioral economics have changed the view on the decision-making process postulated by traditional theories. The early concepts of bounded rationality (Simon, 1957), prospect theory (Kahneman and Tversky, 1979), and numerous judgmental biases suggest that the way economic agents form their decisions is not fully rational but might follow simpler information-processing rules (rules of thumb) and even emotional wishful thinking. Decisions are made with respect to agents' perceptions of the current economic situation as well as their expectations about future prospects (Kamdar, 2018), but may also be affected by psychological biases (Tversky and Kahneman, 1974; Gennaioli and Shleifer, 2010).

Beliefs that are subject to the cognitive and emotional limitations of agents are referred to in many applications as sentiment. If those beliefs are optimistic, sentiment is positive; if they are pessimistic, sentiment is negative. In general, there is no unique definition of sentiment in the existing literature. For example, in the asset pricing literature, sentiment is usually understood as the aggregated beliefs of uninformed (not rational) market participants about the future movements of observed variables (prices, returns). Baker and Wurgler (2006) define investor sentiment as a "propensity to speculate" or "optimism or pessimism about stocks in general." In their next study, Baker and Wurgler (2007) define sentiment as "belief about future cash flows and investment risks that is not justified by the facts at hand." But the definition in the literature which concentrates on the 
effects of sentiment on macroeconomic variables is different. For example, Ewing and Payne (1998) define sentiment as a proxy for anticipated future income and/or economic well-being. Caglayan and $\mathrm{Xu}$ (2016) further state that sentiment captures the "aggregate perception of the business leaders and consumers on the economic outlook."

In our view, the overall economic sentiment of households represents the aggregate outcome of both their expectations and their assessment of the current situation. We create our sentiment index accordingly using data from harmonized consumer surveys (described in Section 3.1) as a measure that captures the respondents' assessment of the past, current, and future (expected) economic and financial situation. The process of forming expectations is essential in assessing the future economic situation, and, consequently, in building up sentiment. Numerous theoretical studies examine the role of expectations in explaining financial fluctuations. Some of the recent observations on credit booms build upon the concept of extrapolative expectations; examples of such studies include Fuster et al. (2010), Nofsinger (2012), Sordi and Vercelli (2012), and Bordalo et al. (2018). In general, economic agents tend to overestimate the persistence of favorable conditions and, as a result, overrate future outcomes.

In our paper, we examine whether there are any linkages between the sentiment of households and their decision to borrow. Credit booms have been known to become the prominent contributor to financial instability (Jordà et al., 2011; Schularick and Taylor, 2012). The role of euphoric periods in the expansion of households' leverage was recognized in Minsky (1977), who formulated a view on the factors causing instability of the financial system in the re-born financial instability hypothesis (FIH). Minsky warned that euphoria - a reflection of positive sentiment, optimism, or confidence - causes households to take on more debt than would be rational and to underestimate the risk of crisis. Sudden distress then causes much larger costs than expected, which, in turn, evokes a so-called Minsky moment - a massive collapse of the financial system. A number of authors have recognized the validity of the FIH and the associated Minsky moment in relation to the Global Financial Crisis (e.g., Schularick and Taylor, 2012; Shefrin, 2016; López-Salido et al., 2017).

Both the theoretical and empirical literature in the field of behavioral finance and economics suggests that economic agents tend to behave differently in times of relative market tranquility as opposed to periods of fear and uncertainty (Akerlof and Shiller, 2010; Garcia, 2013). Households tend to overestimate a consistent pattern of good news and, at the same time, ignore the possibility that the good times might end in the foreseeable future. In the model by Bordalo et al. (2018), agents over-weight the probability of a positive future state when the current conditions are good (diagnostic expectations). In addition, the authors suggest that credit expands in reaction to good news. Overreaction to a string of positive information can be further tracked down to Barberis et al. (1998), who, however, link good prospects to overly positive growth of stock prices rather than to growth of credit. Gennaioli et al. (2015) in their model of neglect of risk suggest that agents' estimates of the probability of a crisis in boom periods are too low because they view bad macroeconomic conditions as an abnormality in the otherwise positive environment. Similarly, Ambrocio (2020) asserts that agents remain optimistic during "good times" even though the macroeconomic news might point to worsening conditions. On the other hand, some theories suggest an opposite relation, especially in periods of distress: the theory of conservatism (Edwards, 1968) asserts that people tend to pick up on new evidence too slowly. Thus, we will also examine the hypothesis that the effects of household sentiment on credit growth differ in periods of economic expansion and in periods of economic distress, while allowing for different relationships for the rational and irrational components. 
There is a wide literature focusing on the effects of sentiment in financial markets, portfolio allocation, stock prices, and the like. However, the literature exploring sentiment in the macroeconomic context of real activity is rather underdeveloped. To our knowledge, there are two other papers that focus on the relationship between sentiment and credit. In the study most closely related to ours, Delis et al. (2014) examine bank lending behavior during anxious periods, which they proxy with three different confidence survey measures. They show that loan supply falls when consumers and analysts are anxious. ${ }^{1}$ They note that the estimated effects are less prevalent in the period after 2001. Similarly, Caglayan and Xu (2016) analyze how changes in various OECD survey measures and their volatility affect bank lending behavior. They estimate the effect of changes in sentiment on lending growth to be negative and more pronounced in periods of extreme sentiment volatility. The two studies make a worthy contribution to the literature, as they assert that anxious moods might affect the supply side of lending. This paper is also loosely related to the literature which investigates the relationship between sentiment - economic agents' beliefs - and other indicators of real activity. Multiple studies show that economic agents' beliefs are associated with real economic activity both contemporaneously and in the long term. Barsky and Sims (2012) find that confidence innovations have implications for consumption and income many periods in the future. Benhabib and Spiegel (2019) confirm that sentiment or consumer confidence shocks do have a measurable impact on output and consumption, certainly at one-year horizons and possibly over longer horizons.

We offer a different perspective to Delis et al. (2014) and Caglayan and Xu (2016) by differentiating between rational and irrational sentiment. We argue that sentiment, which is captured as the aggregate outcome of households' assessment of the current economic situation as well as their expectations about future economic prospects, contains two components. The first component reflects households' evaluation of macroeconomic fundamentals, which may be extrapolated into the future. We refer to this component as rational sentiment. The second component then represents the mood of optimism or pessimism on top of "rationally sourced" judgment, which is irrational, as it represents households' over-reaction or under-reaction to fundamental news. By distinguishing between rational and irrational sentiment, we follow the influential stream of literature on behavioral finance, which concentrates on the effects of sentiment and is clear of macroeconomic determinants. In their pioneering study, Baker and Wurgler (2006) orthogonalized sentiment proxies to several macroeconomic variables in order to remove the business cycle component. Such component, if not controlled for, might cause false inference in the analysis when the selected measure of sentiment co-moves with the business cycle for entirely rational reasons. Orthogonalization of financial proxies for sentiment has since been employed in several studies, for example, Baker and Wurgler (2007), Huang et al. (2015), and Han and Li (2017).

Differentiating between the rational part of sentiment (driven by macroeconomic prospects) and the irrational part (optimism or pessimism not caused by fundamental news) is particularly essential when considering survey-based sentiment measures. In general, these measures represent a numerical expression of how optimistic respondents are at the time the survey is conducted. If the macroeconomic prospects are sound and/or were sound in the past, the survey participants may extrapolate this information and deliver positive expectations in their responses. Similar argumentation is provided in Barsky and Sims (2012), who use the Michigan Survey of Consumers and distinguish between rational and irrational shifts using a VAR framework. They find that unexplained innovations to consumer confidence are the result of slowly building news about "apparently permanent" current and future economic fundamentals.

\footnotetext{
${ }^{1}$ Anxious periods are defined as in Fostel and Geanakoplos (2008) as situations when the perceptions and expectations of economic agents about economic conditions worsen, even though the economy is not in a recession.
} 


\section{The New Sentiment Index and Its Rational and Irrational Components}

Our aim is to examine how household sentiment calculated from surveys of the population affects credit growth. However, we are primarily interested in beliefs of households that are not informed by economic prospects. We argue that households' expectations revealed in the direct questionnaires that are, in turn, used to form consumer confidence measures - the popular proxies for sentiment - contain two components: (1) rational sentiment, which mimics households' (rational) reactions to the state of the economy, and (2) irrational sentiment, which proxies households' optimism/pessimism on top of their "rationally sourced" beliefs.

Thus, to obtain our measure of interest - irrational sentiment, we first collect a measure of households' beliefs using population surveys and label it the total sentiment index. We do not content ourselves with a pre-designed measure of total sentiment constructed from a population survey, such as the Consumer Confidence Indicator (CCI hereafter). Instead, we calculate a novel variable which we believe provides a better expression of households' expectations that might be linked to credit growth. We then employ a cleaning procedure in which we decompose this total measure of sentiment into two components: (1) rational and (2) irrational sentiment. The underlying analysis then concentrates primarily on irrational sentiment.

\subsection{The Total Measure of Household Sentiment}

To construct our total sentiment measure, we employ detailed data from the harmonized consumer surveys that are conducted locally in the individual European countries and then consolidated by the European Commission's Directorate-General for Economic and Financial Affairs (DG ECFIN). ${ }^{2}$ A part of the results of these consumer surveys is also used to construct CCIs for the individual European countries and for the European Union and the euro area as a whole. In particular, the CCI draws on the results of four questions from the survey, and the selection of questions is determined by the aim of the CCI to closely track private consumption growth (European Commission, 2019). The detailed data that we use report the non-seasonally adjusted balances for each country and for each question in the survey. ${ }^{3}$ We thus have an opportunity to construct a survey-based sentiment measure which contains not only the information reflected in the CCI, but also other potentially relevant information for explaining the growth of consumer loans.

We decided to calculate our total measure of sentiment using the same method as the one applied by DG ECFIN for the CCI. That is, we calculate total sentiment as the simple arithmetic average of the balances of the answers to the selected questions. European Commission (2019) defines the balance for each question as the difference between the weighted percentages of respondents giving positive answers and the weighted percentages of respondents giving negative answers. ${ }^{4}$ The weights are

\footnotetext{
${ }^{2}$ Consumer surveys are conducted together with business surveys under the Joint Harmonised EU Programme of Business and Consumer Surveys. The detailed data are freely available on the European Commission's website (https://ec.europa.eu). According to European Commission (2018), consumer surveys have two purposes: (1) to collect information on households' spending and savings intentions, and (2) to assess their perception of the factors influencing these decisions. Other background information regarding the consumer surveys can be found in Appendix E.

${ }^{3}$ We employ non-seasonally adjusted balances because seasonal adjustment of the series might remove relevant information about households' irrationality. We argue that households respond to the survey based on their current assessments and expectations, while they do not consider any seasonal effects. In fact, seasonality in the data might be a reflection of households' irrationality, which is of our primary interest in this paper.

${ }^{4}$ For a more detailed description of how the balances are constructed, see the easy-to-understand definition in Ambrocio (2019), who in his study calculated a measure of household uncertainty using the same data set as we do in this study.
} 
given by the "strength" of the positive/negative answers - strictly positive (negative) answers enter the calculation with weight one, while just positive (negative) answers enter with weight 0.5 .

As already mentioned, the CCI is designed in such a manner that it provides the best result ${ }^{5}$ for tracking private consumption growth at the level of the European Union (EU), the euro area, and the EU member states (European Commission, 2019). In contrast, our aim is to construct the total sentiment indicator so that it captures as much information as possible regarding households' beliefs that are relevant to their decisions to borrow. At this point, we do not attempt to construct the best leading indicator for credit growth, simply because the total sentiment indicator is not the variable of our primary concern. The construction of the total sentiment index is a necessary step for obtaining irrational sentiment (the part of the total index which is not driven by fundamental news and hence proxies households' optimism/pessimism on top of their "rationally sourced" beliefs), which is the explanatory variable we are actually interested in. Therefore, when selecting the set of questions to be included in our total sentiment index, we considered two criteria: (1) a consistent cross-country pattern of simple contemporaneous and leading correlations between the balances for the individual questions and growth of consumer loans (see Table A2 in the Appendix); and (2) the theoretical foundations of the individual questions.

Out of all the questions presented in the harmonized consumer survey, Table 1 lists the questions considered for our total sentiment measure. Figure A1 depicts the contribution of each question to the total sentiment index. In addition to the questions included in the CCI, which are all arguably relevant to households' borrowing decisions, we consider three additional questions from the harmonized consumer survey - the question on the assessment of the past economic situation, the question on households' major purchases, and the question on the current financial situation of households (questions 3, 8, and 12 in Table 1). Question 12 was selected mainly because of its direct link to households' indebtedness, while questions 3 and 8 are the current and backward-looking variants of the forward-looking questions 4 and 9 employed in the CCI. ${ }^{6}$

Even though the literature postulates that households' actions are driven by their expectations about the future (see, for example, Acemoglu and Scott, 1994), we believe that current and past economic experience also affects households' decisions to borrow. We acknowledge that the information contained in the answers to questions 3 and 8 might already be extrapolated in the responses to the forward-looking question 4 (general economic situation) and question 9 (major purchasing activities). Nevertheless, we argue that not all households form their replies to these two types of questions consistently, which means that households might not necessarily expect a positive (negative) future upon a positive (negative) assessment of the past and current situation. Moreover, the usefulness of these additional questions for explaining the dynamics of growth of consumer loans is demonstrated by a rather consistent pattern in their pairwise correlations across countries (see Table A2).

\footnotetext{
${ }^{5}$ The best result is achieved by correlation analysis, an ability to track directional change, two simple in-sample models, an out-of-sample forecasting exercise, and a volatility analysis (European Commission, 2018, p. 1).

${ }^{6}$ There are questions in the survey linked to inflation and savings as well; however, they were not considered for the total sentiment index for the same reasons for which the design of the CCI disregards them. Specifically, the impact of savings and inflation expectations on consumption and decisions to borrow is ambiguous. The question from the harmonized consumer survey which concentrates on unemployment expectations is also not included in our index, since we assert that expectations regarding the degree of unemployment are already included in the response to the question on expectations about the general economic situation. Table A1 in the Appendix lists the details of these questions.
} 


\section{Table 1: Questions Used for Calculation of the Total Sentiment}

\begin{tabular}{|c|c|c|c|}
\hline Q.No. & Short Description & Question & $\mathrm{CCI}$ \\
\hline 1 & $\begin{array}{l}\text { Financial situation over last } \\
12 \text { months }\end{array}$ & $\begin{array}{l}\text { How has the financial situation of your household } \\
\text { changed over the last } 12 \text { months? } \\
\text { Answers: (++) got a lot better, (+) got a little better, (=) } \\
\text { stayed the same, (-) got a little worse, (- -) got a lot worse, }(N) \\
\text { don't know }\end{array}$ & $\mathrm{Y}$ \\
\hline 2 & $\begin{array}{l}\text { Financial situation over next } \\
12 \text { months }\end{array}$ & $\begin{array}{l}\text { How do you expect the financial position of your } \\
\text { household to change over the next } 12 \text { months? } \\
\text { Answers: (++) get a lot better, (+) get a little better, (=) stay } \\
\text { the same, (-) get a little worse, (- -) get a lot worse, }(N) \text { don't } \\
\text { know }\end{array}$ & $\mathrm{Y}$ \\
\hline 3 & $\begin{array}{l}\text { General economic situation } \\
\text { over last } 12 \text { months }\end{array}$ & $\begin{array}{l}\text { How do you think the general economic situation in the } \\
\text { country has changed over the past } 12 \text { months? } \\
\text { Answers: }(++) \text { got a lot better, }(+) \text { got a little better, (=) } \\
\text { stayed the same, (-) got a little worse, }(--) \text { got a lot worse, }(N) \\
\text { don't know }\end{array}$ & $\mathrm{N}$ \\
\hline 4 & $\begin{array}{l}\text { General economic situation } \\
\text { over next } 12 \text { months }\end{array}$ & $\begin{array}{l}\text { How do you expect the general economic situation in } \\
\text { this country to develop over the next } 12 \text { months? } \\
\text { Answers: (++) get a lot better, (+) get a little better, (=) stay } \\
\text { the same, (-) get a little worse, (- -) get a lot worse, }(N) \text { don't } \\
\text { know }\end{array}$ & $\mathrm{Y}$ \\
\hline 8 & Major purchases at present & $\begin{array}{l}\text { In view of the general economic situation, do you think } \\
\text { that now it is the right moment for people to make major } \\
\text { purchases such as furniture, electrical/electronic devices, } \\
\text { etc.? } \\
\text { Answers: }(++) \text { yes, it is the right moment now, (=) it is neither } \\
\text { the right moment nor the wrong moment, (--) no, it is not the } \\
\text { right moment now, }(N) \text { don't know }\end{array}$ & $\mathrm{N}$ \\
\hline 9 & $\begin{array}{l}\text { Major purchases over next } \\
12 \text { months }\end{array}$ & $\begin{array}{l}\text { Compared to the past } 12 \text { months, do you expect to spend } \\
\text { more or less money on major purchases (furniture, } \\
\text { electrical/electronic devices, etc.) over the next } 12 \\
\text { months? } \\
\text { Answers: }(++) \text { much more, }(+) \text { a little more, }(=) \text { about the } \\
\text { same, (-) a little less, }(--) \text { much less, }(N) \text { don't know }\end{array}$ & $\mathrm{Y}$ \\
\hline 12 & $\begin{array}{l}\text { Statement on financial } \\
\text { situation of household }\end{array}$ & $\begin{array}{l}\text { Which of these statements best describes the current } \\
\text { financial situation of your household? } \\
\text { Answers: }(++) \text { we are saving a lot, }(+) \text { we are saving a little, } \\
(=) \text { we are just managing to make ends meet on our income, (-) } \\
\text { we are having to draw on our savings, (- -) we are running into } \\
\text { debt, }(N) \text { don't know }\end{array}$ & $\mathrm{N}$ \\
\hline
\end{tabular}

Note: This table lists the questions from the harmonized consumer surveys administered by DG ECFIN that are employed in the calculation of the total sentiment index. The set of possible answers is placed below each question and indicates which answer is considered to be strictly positive (++), just positive (+), neutral (=), just negative $(-)$, and strictly negative (- -). Just positive (negative) answers enter the calculation of the question balances with weight 0.5 , while strictly positive (negative) answers enter with weight 1 . The last column indicates whether the results for the given question are $(\mathrm{Y})$ or are not $(\mathrm{N})$ used in the calculation of the CCI.

Source: European Commission (2019). 
Figure 1 compares the dynamics of our total sentiment and the country-level min-max structure of the CCI. The strong resemblance of the two measures is implied by the fact that the total sentiment index contains all the information included in the CCI (questions 1, 2, 4, and 9). The difference, which is most evident around the year 2010, is caused by additionally included questions 3, 8, and 12. We acknowledge that the min-max envelopes of the two measures are very similar; however, it was not our intention to create a total sentiment measure that ignores the well-established performance of consumer confidence as proxied by the CCI and is necessarily distinct. Instead, we aimed to include the information that is the most relevant to households' borrowing - the selection of the questions and the related reasoning was described above.

\section{Figure 1: Total Sentiment and Min-Max of CCI}

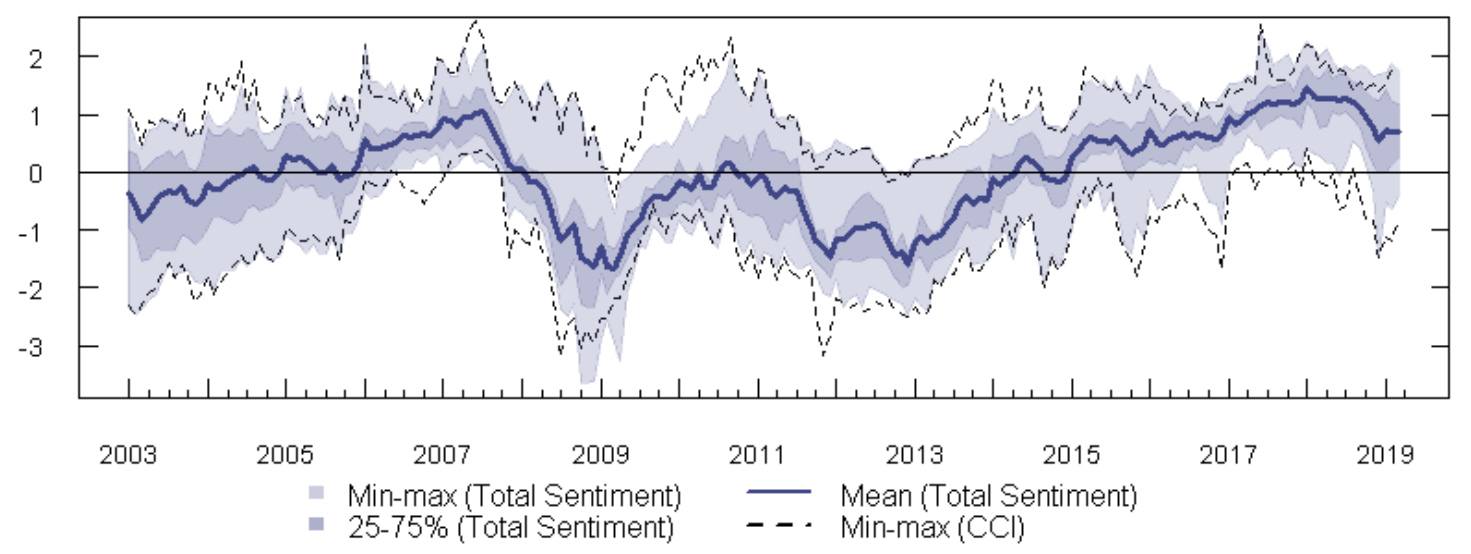

Note: The indices are standardized using their sample mean and standard deviation; the vertical axis shows the standard deviations.

\subsection{Sentiment Decomposition}

As described above, we argue that household sentiment contains a rational and an irrational part. As a simple demonstration, suppose that the measure of households' confidence is represented by the answers to a single question "How do you expect the general economic situation in this country to develop over the next 12 months?" First, an average household might respond to this inquiry simply by extrapolating the current (or past) economic prospects. In other words, if the current macroeconomic situation is good (bad), households form positive (negative) views about the future 12 months. We refer to such views as rational sentiment simply because such behavior is rational from the point of view of traditional theories. Second, households might also reveal other types of information in their responses. For example, they might get too optimistic (or pessimistic) compared to the "rationally sourced" reaction - in the case of extensive enthusiasm, one might think of it as Shiller's irrational exuberance in the general population. Alternatively, households might provide dishonest or wrong answers simply because they are prone to moral hazard and biases that arise from financial illiteracy or the rules of thumb they use when answering complex questions (Gouret and Hollard, 2011). Any such answer then contains a certain portion of noise, ${ }^{7}$ which might be expressed by differencing it with the degree to which the rationally sourced answer tends to be optimistic, neutral, or pessimistic. Therefore, we argue that the responses households provide in

\footnotetext{
${ }^{7}$ Michis et al. (2010) emphasize that common measures of sentiment contain a "noise" component on top of the respondents' expectations.
} 
the questionnaire contain not only expectations driven by fundamentals, but also expectations that are flawed by the emotional or cognitive limitations of the respondents. We refer to this additional component on top of "rationally sourced" beliefs as irrational sentiment.

To decompose total sentiment into its rational and irrational parts, we employed the variant of the orthogonalization procedure proposed in Baker and Wurgler (2006). In their framework, they regressed individual sentiment proxies (various measures of total sentiment) on a set of individual macroeconomic variables to obtain irrational (orthogonalized) sentiment measures as the residuals of these regressions. In our approach, we regress the total measures of sentiment calculated for each country in our sample on the modified growth version of the Households Macroeconomic Environment (HOME) index developed in Hodula et al. (2021). ${ }^{8}$ The methodology for constructing the modified version of the HOME index strictly follows the methodology in Hodula et al. (2021, p. 6), that is, we performed factor model estimation. The description of the individual constituents of the HOME index and its dynamics can be found in Appendix B (Table B1 and Figure B1). We argue that households tend to view the state of the economy on the overall level rather than through its individual facets. Their assessment of the present and anticipation of the future state of the economy reacts to the combination of factors rather than to changes of the individual macro variables. Therefore, using a composite indicator for the macroeconomic conditions instead of the set of individual macroeconomic variables is likely to provide a better approximation of the fundamental factors that affect the total sentiment of households.

Hence, the decomposition of total sentiment into its rational and irrational components was performed by running the following regression for each country $i$ in our sample:

$$
\text { Sentiment }_{i, t}=\underbrace{\beta_{i} \times H O M E_{i, t}}_{\text {rational sentiment }}+\underbrace{\varepsilon_{i, t}}_{\text {irrational sentiment }}
$$

where Sentiment represents total sentiment (standardized to have zero mean and unit variance), HOME represents the modified growth version of the HOME index (Hodula et al., 2021), and $t$ is the monthly subscript. The irrational sentiment for each country $i$ is then formed by the residuals $\varepsilon_{i, t}$, while the rational sentiment is obtained by calculating the fitted values of this regression equation. Equation (1) is estimated separately for each country. The average R-squared of these regressions is around 0.45 .

Figure 2 depicts the aggregate dynamics of both rational (Panel A) and irrational (Panel B) sentiment, while the country-level graphs can be found in Figure B2 in Appendix B. As already discussed at the beginning of this section, rational sentiment is created so that it captures the part of the total sentiment index which is driven by macroeconomic fundamentals. We use the modified HOME index as a proxy for the state of the economy; therefore, it is of no surprise that rational sentiment mimics the path of this composite macroeconomic index (see Figure B1). Next, irrational sentiment is designed to capture the portion of the total sentiment index which cannot

\footnotetext{
${ }^{8}$ We modified the growth version of the HOME index (Hodula et al., 2021) in two respects. Firstly, we calculated the HOME index using monthly data instead of quarterly data, because our total sentiment measure has monthly frequency. Secondly, we replaced the annual growth rate of gross domestic product by two variables - the annual growth rate of the industrial production index and the annual growth rate of the retail trade index. The reason for this modification is that the data on GDP are available only at quarterly frequency while the data on the two replacement variables are available monthly. Even though we interpolated the other quarterly variables that make up the index to monthly data using cubic spline interpolation (e.g., gross disposable income), we replaced GDP because we believe that the combination of the two replacement measures provides more valid monthly information than the interpolated version of GDP.
} 
be explained by the HOME index. Its value then represents the over-optimistic or over-pessimistic mood of households on top of their "rationally sourced" beliefs, or simply the noise that arises from the emotional or cognitive limitations of the respondents. Hence, both the volatility and the cross-sectional variation are more pronounced for this measure compared to its rational counterpart.

\section{Figure 2: Rational and Irrational Sentiment}

(A) Rational

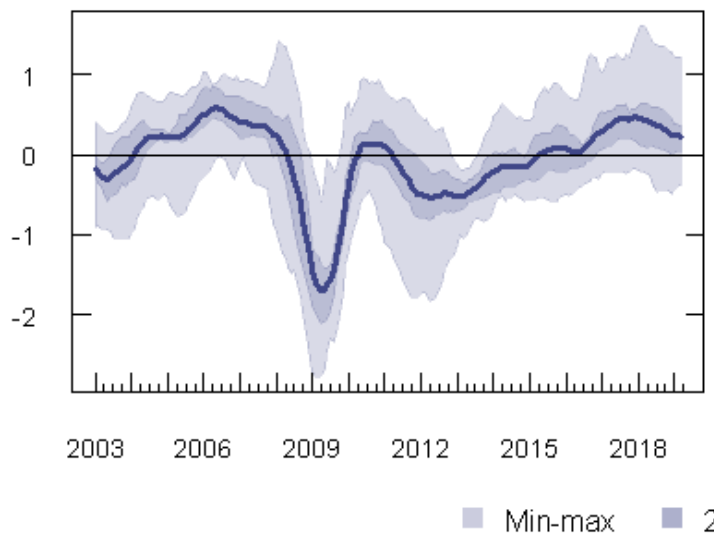

(B) Irrational

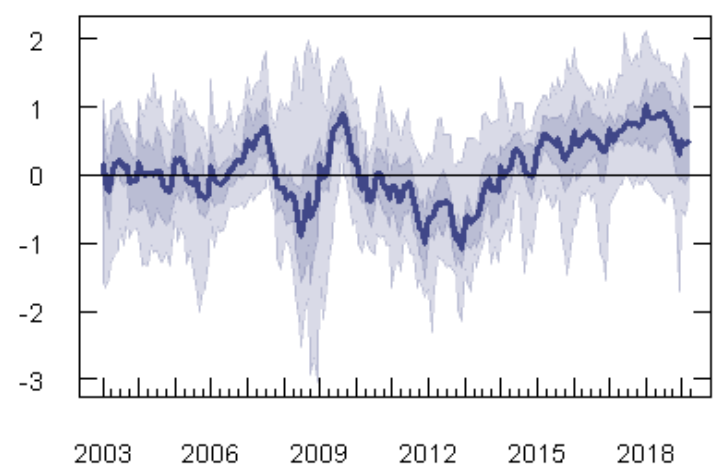

Note: The indices are standardized using their sample mean and standard deviation; the vertical axis shows the standard deviations.

\subsubsection{Biases Related to the Sentiment Decomposition}

We acknowledge that our decomposition of overall sentiment into its rational and irrational parts is a statistical procedure based on a simple regression equation and as such may differ from the true irrational or rational sentiment or the irrational and rational sentiment as understood in theory. The decomposition constructed in the paper is unbiased only if the HOME index used for the decomposition is able to isolate exactly all fluctuations in total sentiment that are due to fundamental factors only. Two sources of bias may arise. First, if the HOME index does not exhaust all the variation in the total sentiment measure that is due to fundamental shocks, then the residuals will contain these fundamental fluctuations and hence will not be entirely irrational. Second, if the HOME index is constructed from variables that are also affected by non-fundamental shocks, then the fitted values of the regression will also be affected by these non-fundamental fluctuations and hence will not be entirely rational.

Despite these reservations, we argue that it is reasonable to assume that the HOME index isolates exactly all fundamentals-related fluctuations in total sentiment and that using the regression approach as in Equation (1) is a suitable way to separate the rational and irrational components. First, the HOME index contains twelve input variables, making it an exhaustive and complex index for capturing macroeconomic conditions. Second, by using dynamic factor analysis to calculate the HOME index, we isolate the common factor behind the movement of the macroeconomic variables. Factor analysis can thus filter out the irrational information contained in some of the variables, if this information is not included in the remaining portion. Third, Hodula et al. (2021) show that consumer confidence as captured in the CCI reflects current or very recent economic information that forms the HOME index. Similarly, Hodula et al. (2019) provide time series evidence linking improved macroeconomic conditions as depicted by the HOME index to increasing household 
indebtedness. Last but not least, to deal with any remaining uncertainty around the suitability of the regression in Equation (1) and the potential bias, we estimate the regression with individual macroeconomic variables instead of the composite HOME index (see Section 5.2).

We adopt the terms "rational" and "irrational" sentiment from the behavioral asset pricing literature, such as Verma and Soydemir (2009), Verma et al. (2008), and Das et al. (2020). They all regress sentiment on macroeconomic variables and consider the residuals to be irrational sentiment, all of them following the idea of separating sentiment into its rational and irrational parts as in Baker and Wurgler (2006, 2007) and Brown and Cliff (2004). In particular, Verma and Soydemir (2009) and Verma et al. (2008) use a set of twelve fundamentals in a simple regression, while Das et al. (2020) use a similar number of fundamentals in a principal component analysis. ${ }^{9}$

\subsection{The Index of (Irrational) Optimism and Pessimism}

The question balances represent the difference between the weighted proportion of positive answers and the weighted proportion of negative answers. A positive balance then indicates that the proportion of households that responded positively exceeds the proportion of households with negative responses. As described in Section 3.1, we created the total sentiment index as a simple arithmetic average of the balances for selected questions. As a result, we can infer the same association of the sign of total sentiment with the proportions of positively or negatively responding households as we did for the single balances above.

Nevertheless, an increase in total sentiment does not necessarily mean an increase in the proportion of optimistic households. This is because the sample also contains neutral households and households who responded with "I don't know" (see Table 1 for more details). Therefore, an increase in total sentiment might simply be caused by part of households who previously responded negatively now responding with a neutral or "I don't know" answer. Even though the proportion of pessimistic households decreases in this case, one might object that if the proportion of positively responding households remains the same, it is not legitimate to call such movements "increased optimism."

To control for this potential discrepancy in the interpretation of the results, we decided to construct two additional indices: a positive responses index and a negative responses index. Firstly, for each question which was employed in the construction of total sentiment, we calculated the weighted proportion of households with positive answers and the weighted proportion of households with negative answers. As before, we use a weight of 0.5 for just positive/negative answers, while strictly positive/negative answers are weighted with a coefficient of one. Secondly, instead of averaging the balances for the individual questions, we calculated the positive (negative) responses index as the simple arithmetic average of the weighted proportions of optimistic (pessimistic) households across the set of desired questions. ${ }^{10}$ Lastly, we applied the decomposition procedure described in Section 3.2 to extract the irrational parts of both indices.

\footnotetext{
${ }^{9}$ Specifically, Verma and Soydemir (2009) and Verma et al. (2008) use a set of twelve fundamentals, including economic growth, short-term interest rates, economic risk premiums, future economic variables, business conditions, dividend yield, and inflation, and since they are primarily interested in the effect on asset pricing, they also include excess returns on the market portfolio and premia on the portfolio of small stocks relative to large stocks, high book/market stocks relative to low book/market stocks, momentum factor, and currency fluctuations. The macroeconomic variables used by Das et al. (2020) differ depending on whether sentiment across housing, commercial property, or stock markets is considered.

${ }^{10}$ The difference between these two indices then produces the total sentiment index (see Figure A2).
} 
Figure 3 depicts the aggregate dynamics of irrational optimism and pessimism across countries. It provides a clear picture of how excessive (irrational) optimism peaks in the post-crisis period after 2009 and in the last five years. Similarly, excessive pessimism peaks around 2008 and 2012, which are both associated with the distressed times of the Global Financial Crisis. Even though it might be tempting, one should not infer an immediate increase in one measure in reaction to a decrease in the other. ${ }^{11}$

\section{Figure 3: Irrational Optimism and Pessimism}

(A) Ir.Optimism

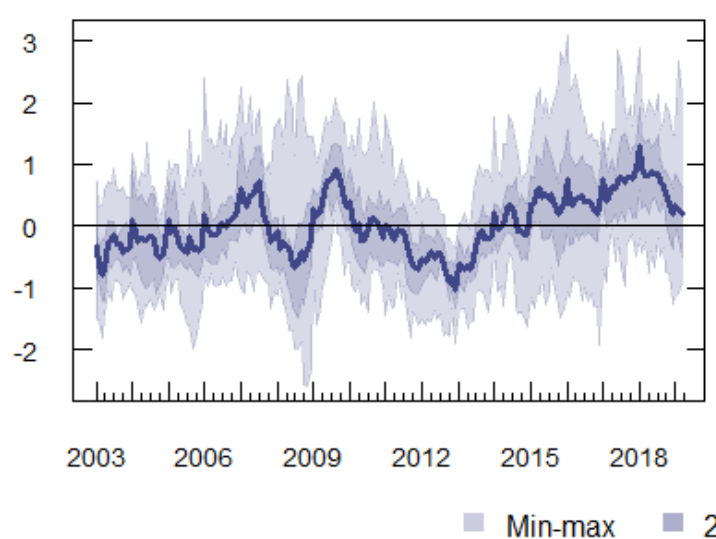

(B) Ir.Pessimism

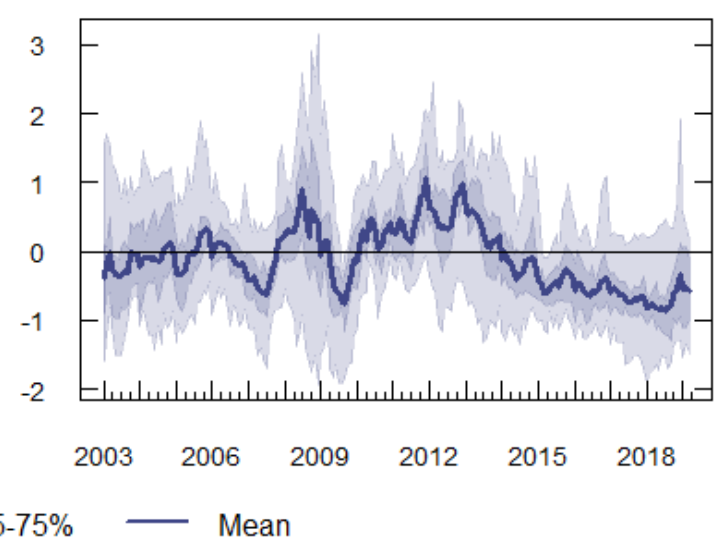

Note: The indices are standardized using their sample mean and standard deviation; the vertical axis shows the standard deviations.

\section{The Effect of Sentiment on Consumer Loan Growth}

\subsection{Methodology}

After creating our own index of sentiment and decomposing it into its rational and irrational parts, we continue with the main goal of our paper - an examination of the relationship between sentiment and fluctuations in newly issued consumer loans. In this regard, we employ a fixed-effects model with monthly panel data from 15 European countries (described in Section 4.2 below). In order to motivate our hypothesis about the effect of irrational and rational sentiment on consumer loan growth, we start with a naïve specification which looks as follows:

$$
\Delta \ln \left(\text { ConsumerLoans }_{i, t}\right)=\beta_{1} \text { IrSentiment }_{i, t-1}+\beta_{2} \text { RSentiment }_{i, t-1}+v_{i}+\varepsilon_{i, t}
$$

where $\Delta \ln \left(\right.$ ConsumerLoans $\left._{i, t}\right)$ stands for annual growth of consumer loans (in log-differences, smoothed by the 3-month moving average); RSentiment $_{i, t-1}$ stands for the rational part and IrSentiment $_{i, t-1}$ for the irrational part of total sentiment. The subscript $i$ denotes the countries in our sample, $v_{i}$ is a fixed-effects term, and $\varepsilon_{i, t}$ is an error term. We use this equation to simply check whether there is a potential relationship between the components of sentiment and consumer loan growth while being aware that the specification in Equation (2) apparently misses other determinants of consumer loan growth. Thus, the full baseline specification is as follows:

$$
\Delta \ln \left(\text { ConsumerLoans }_{i, t}\right)=\beta_{1} \text { IrSentiment }_{i, t-1}+\gamma \mathbf{X}_{i, t-1}+v_{i}+\varepsilon_{i, t}
$$

where vector $\mathbf{X}_{i, t-1}$ is a vector of control variables (see Section 4.2 for more information).

\footnotetext{
${ }^{11}$ Note that because of the cleaning procedure, the overall irrational sentiment is not proportional to the difference between irrational optimism and irrational pessimism.
} 
All the control variables are included in lagged values for two reasons: first, because some of the macroeconomic and demand-side controls affect credit growth with a lag; second, in order to eliminate potential endogeneity of the bank supply-side controls.

The approach of using sentiment in levels allows us to retain the full information included in the index and echoes the view that shifts in sentiment, such as positive shocks to expectations concerning future output or future output growth, can be self-fulfilling and long-lasting. By redacting the level information, we would lose the information about the size of the effect of sentiment on consumer loan fluctuations. Moreover, we would need to explicitly assume that shocks to sentiment have only temporary effects on consumer loan growth in equilibrium. Our approach contrasts with that of Caglayan and Xu (2016), who track down the effects of year-onyear changes in sentiment on loan supply. ${ }^{12}$ The sentiment variables are included in levels lagged by one month. The use of sentiment in the first lag allows us to examine whether households' beliefs affect the future dynamics of newly issued consumer loans. ${ }^{13}$

In subsequent specifications, we include interaction terms in order to control for various time periods. By doing so, we aim to verify the hypothesis that sentiment plays a different role in booms vs. busts ("good" vs. "bad" times). The intuition behind this comes from extrapolative expectations linked to the financial instability hypothesis: the former notion suggests that households extrapolate the current macroeconomic conditions (good or bad) into the future; the latter suggests that in good times, households take on more debt than would be rational, which might be driven by positive sentiment. Nevertheless, the financial instability hypothesis does not claim that in bad times, households take on less debt than would be rational. This leads us to the hypothesis that the strength of the link between sentiment and credit dynamics differs in different time periods, which we aim to examine further on. The simple motivation for that is also depicted in Figure 4. When we plot annual growth of consumer loans and both rational and irrational sentiment, we find relations of different strength in different time periods. We differentiate between the boom period of 20062008 and the bust period of 2009-2011. ${ }^{14}$ While the relationship is positive for rational sentiment in both periods (even though less strong for the crisis period), the relationship between irrational sentiment and growth of consumer loans is positive only in boom periods, and insignificant or even slightly negative in crisis periods.

\footnotetext{
${ }^{12}$ Note that it is possible that sentiment shocks affect output growth rates only temporarily. Our analysis does not rule out such possibility.

${ }^{13}$ The lag structure of order one was selected based on the adjusted $R^{2}$, which showed weak or no signs of improvement when a richer lag structure was considered. We run two series of tests to justify the selection of the first lag as the optimal lag length. First, we estimated Equations (2) and (3) where the first lag of the sentiment variables was replaced each time by one of the second to the twelfth lag. Second, we re-estimated Equations (2) and (3) including all additional lags up to the twelfth lag at once. When we compared the adjusted $R^{2}$ from each of these regressions, the specification with the first lag showed superior performance.

${ }^{14}$ The distinction between time periods is arbitrary and chosen only for illustrative purposes. It is chosen in accordance with the development of the output gap in most countries, but obviously, it could differ for different countries and with respect to different criteria.
} 
Figure 4: Relationship between Sentiment and Growth of Consumer Loans

(A) Subsample 2006-2008
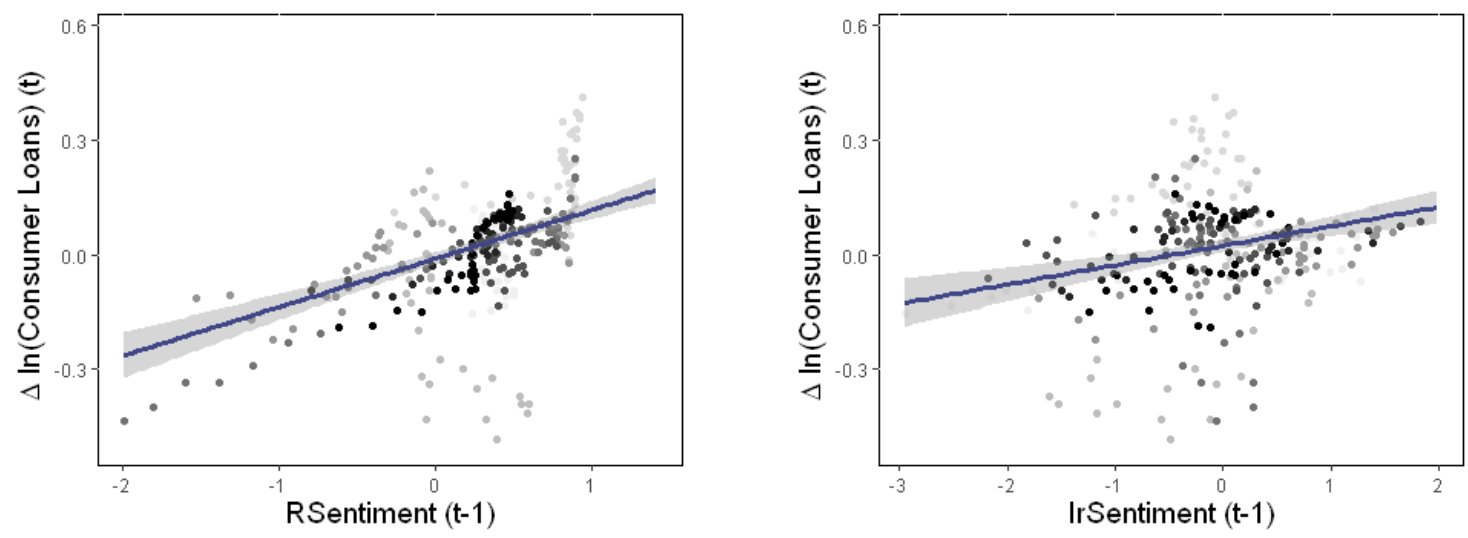

(B) Subsample 2009-2011
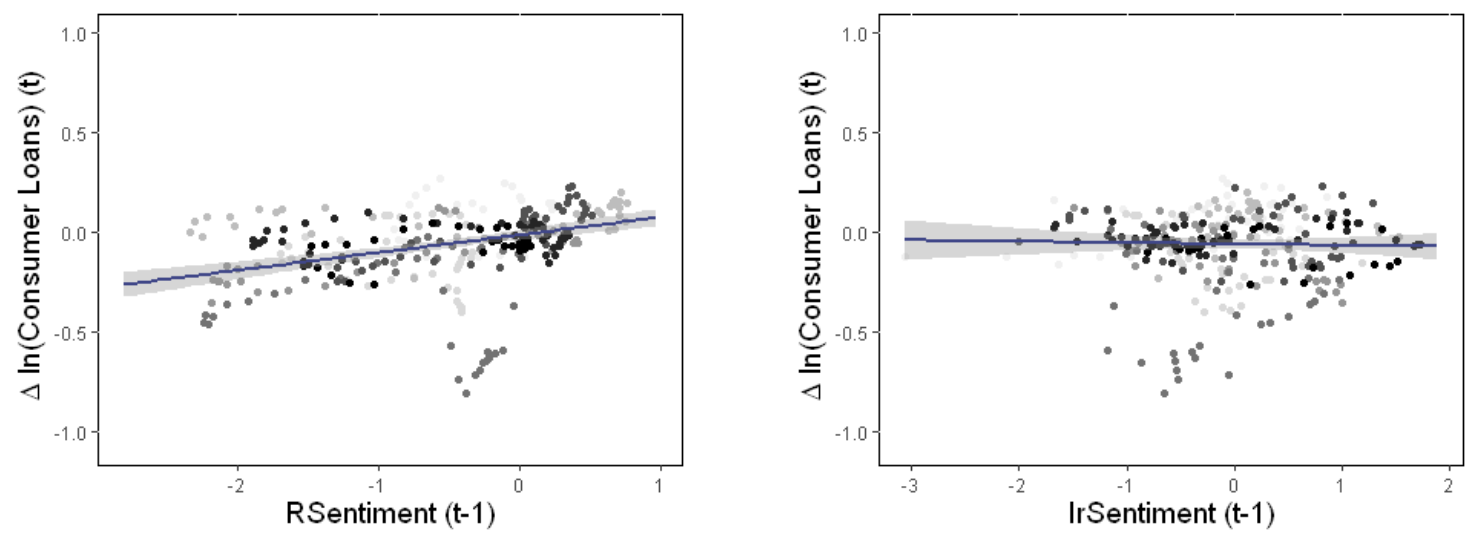

Note: The horizontal axis is in standard deviations. The blue line refers to the overall sample of countries.

In the estimation equation, however, we offer a more sophisticated distinction between good and bad times than simple sub-samples of time periods. As the distinction criterion for good and bad times we use the output gap (described in more detail in Section 4.2.1 below). We create two dummies, equal to one if (i) the value of the output gap is higher than the upper threshold, and if (ii) it is below the lower threshold, respectively. With that we can distinguish between three periods - GoodTimes, BadTimes, and NormalTimes, according to the level of the output gap. We use these dummies to create interaction terms to enhance Equation (3) as follows:

$$
\begin{aligned}
\Delta \ln \left(\text { ConsumerLoans }_{i, t}\right) & =\beta_{1} \text { IrSentiment }_{i, t-1} * \text { GoodTimes }_{i, t-1}+ \\
& +\beta_{2} \text { IrSentiment }_{i, t-1} * \text { BadTimes }_{i, t-1}+ \\
& +\beta_{3} \text { IrSentiment }_{i, t-1} * \text { NormalTimes }_{i, t-1}+\gamma \mathbf{X}_{i, t-1}+v_{i}+\varepsilon_{i, t}
\end{aligned}
$$

For Equation (4) we provide several robustness checks, as will be shown in Section 5.2. Last but not least, instead of the index of total sentiment and its subsequent decomposition into its rational and irrational parts, we construct separate indices of optimism and pessimism (see Section 3.3), then decompose them into their rational and irrational parts, and then estimate the equivalents of 
Equations (3) and (4) with the index of irrational optimism and pessimism separately:

$$
\Delta \ln \left(\text { ConsumerLoans }_{i, t}\right)=\beta_{1} \operatorname{Ir}_{i, t-1}+\gamma \mathbf{X}_{i, t-1}+v_{i}+\varepsilon_{i, t}
$$

and

$$
\begin{aligned}
\Delta \ln \left(\text { ConsumerLoans }_{i, t}\right) & =\beta_{1} \operatorname{IrZ}_{i, t-1} * \text { GoodTimes }_{i, t-1}+ \\
& +\beta_{2} \operatorname{IrZ}_{i, t-1} * \text { BadTimes }_{i, t-1}+ \\
& +\beta_{3} \operatorname{IrZ}_{i, t-1} * \text { NormalTimes }_{i, t-1}+\gamma \mathbf{X}_{i, t-1}+v_{i}+\varepsilon_{i, t}
\end{aligned}
$$

where $\operatorname{IrZ}_{i, t-1}$ stands for either irrational optimism (IrOptimism $\left.{ }_{i, t-1}\right)$ or pessimism $\left(\right.$ IrPessimism $\left._{i, t-1}\right)$.

As far as the econometric approach is concerned, we apply a weighted fixed-effects regression with wild cluster bootstrap inference. First, as weights, we use a measure of financial inclusion: the share of the country's adult population who have borrowed from a financial institution. The measure is sourced from data in the Global Findex Database compiled by the World Bank from national surveys (Demirguc-Kunt et al., 2018). The weight for each country is determined by the variable Borrowed from a financial institution (\% age 15+) and averaged across three waves of surveys - 2011, 2014, and 2017 (see Table C3). We use these weights in order to put more emphasis on countries where financial inclusion is higher, as those countries are of greater interest to us. Materially, if sentiment is to have an effect on credit growth, then we can expect it to have a higher real impact in countries where more people engage in borrowing.

Second, wild cluster bootstrap inference is employed for the standard errors on the regression coefficients in order to deal with the relatively small number of cross-sectional units - clusters. We cannot assume that the error terms in Equation (3) are uncorrelated within countries; thus, we prefer to use clustered, heteroskedasticity-robust standard errors. However, as pointed out by Cameron et al. (2008), Cameron and Miller (2015), and Roodman et al. (2019), conventional inference methods are not suitable, because the large-sample properties which they utilize do not hold if the number of clusters is small. As a remedy, they suggest using the wild cluster bootstrap. ${ }^{15}$ For that, we employ the post-estimation boottest ${ }^{16}$ command in Stata, whose inference is based on the bootstrapped p-values implied by the t-statistic from the Wald test. Across all the regression tables, we thus report bootstrap p-values instead of the more typically reported standard errors.

\subsection{Data}

In this paper we study how (irrational) sentiment affects consumer loan growth in a panel of 15 countries of the European Union, namely, Austria, Belgium, the Czech Republic, Denmark, Finland, France, Germany, Italy, the Netherlands, Poland, Portugal, Slovakia, Sweden, and the United Kingdom. The observation period spans between January 2003 and March 2019. We use monthly panel data from various European and international sources. Table $\mathrm{C} 2$ provides basic summary statistics of all the variables that enter the analysis.

\footnotetext{
15 The idea of any procedure based on a bootstrap is to generate a large number of bootstrap pseudo-samples and to calculate the desired statistic from each of them. The distribution of these statistics is then used to infer the distribution of the original sample. The bootstrap p-values then represent the proportion of statistics that are more extreme than the statistic from the original sample.

${ }^{16}$ We employ the default function, which generates 999 cluster bootstrap samples using the Rademacher distribution, with the null hypothesis imposed. It reports the t-statistic from the Wald test and its bootstrapped p-values. Standard errors are not used, as they do not provide asymptotic refinement (for more information about asymptotic refinement and the boottest algorithm, see Roodman et al. (2019)).
} 
Our dependent variable, $\Delta \ln$ (Consumer Loans), is represented by annual growth in newly issued consumer loans calculated as the change in the natural logarithm of consumer loans over the previous year, smoothed by its 3-month moving average. The data on new consumer loans are obtained from the European Central Bank or from national central banks (the Czech Republic, the Netherlands, and Slovakia), all in national currencies. We consider only newly issued loans ${ }^{17}$ (new business) to households and non-profit institutions serving households, because we expect this category of loans to be affected the most by movements in household sentiment. Delis et al. (2014) employed a similar dependent variable; however, they concentrated on bank-level data instead of aggregate banking sector data. Figure 5 depicts the aggregate dynamics of our dependent variable. When tracking the panel mean, we identify one full credit cycle and a total of two expansionary phases during the 2006-2007 and 2015-2018 periods. A contraction in credit during the 2008-2010 period was caused by the Global Financial Crisis.

\section{Figure 5: Annual Growth in New Consumer Loans}

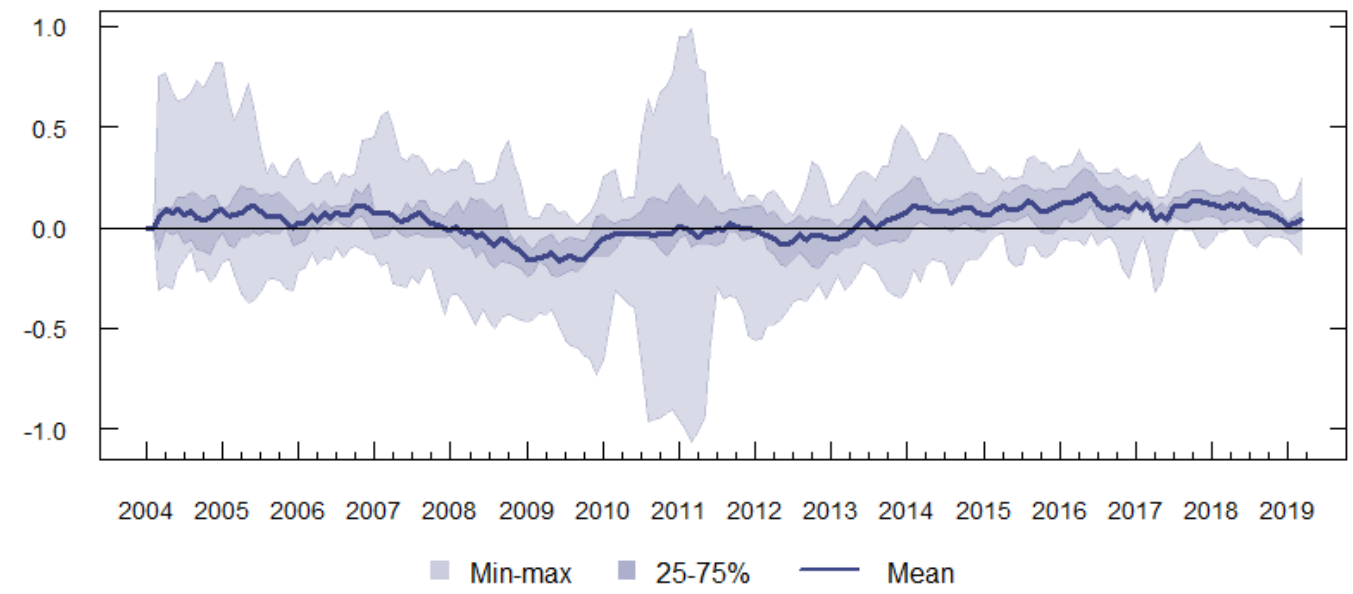

Note: Annual growth in new consumer loans is calculated as the change in the natural logarithm of new consumer loans over the previous year, smoothed by its 3-month moving average.

The main explanatory variable is irrational sentiment (IrSentiment). This variable represents the portion of households' optimism or pessimism on top of beliefs that are formed based on macroeconomic prospects. Formally, it is expressed as the residual from regressing the total sentiment index (see Section 3.1) on the modified version of the Households Macroeconomic Environment Index (HOME index, Hodula et al., 2021). We consider irrational sentiment to be a measure of households' excessive optimism or pessimism that arises from their cognitive and emotional limitations. Simultaneously, we claim that the other part of the total sentiment index - rational sentiment - only reflects the information already contained in the composition of the macroeconomic controls. Moreover, such information can be more precisely represented by actual macroeconomic variables. As a result, we employ rational sentiment only in our naïve specification (see Equation 2) and replace it with a more rigorous set of various macroeconomic controls further on.

\footnotetext{
${ }^{17}$ More precisely, we used the time series category for loans for consumption excluding revolving loans and overdrafts, convenience and extended credit card debt.
} 
We group the set of control variables into four categories. We name the first category baseline macroeconomic controls and include three variables there: annual growth of industrial production ( $\triangle$ Industrial prod.), inflation measured by annual growth of the harmonized index of consumer prices ( $\triangle$ CPI inflation), and the 3-month money market interest rate (Short-term rate). These three initial controls are motivated by Barsky and Sims (2012), who used the real interest rate, inflation, real GDP, and real consumption in their VAR model. We replace GDP with the index of industrial production due to its availability at monthly frequency and the fact that these series are fundamentally very similar (their correlation is 0.65 on average in our sample). We disregard the variable capturing real consumption in the group of baseline controls and instead include annual growth in the retail trade index in the additional set of macroeconomic controls as discussed below. Again, the rationale is that the retail series is available at monthly frequency and its correlation with consumption as measured by the final consumption expenditure of households is 0.64 on average. A similar set of baseline controls was employed in Delis et al. (2014), who studied how anxious periods affect bank lending. Moreover, all the baseline variables are used as common determinants of household debt in the existing literature (Debelle, 2004; Meng et al., 2013).

The second group, additional macroeconomic controls, accompanies the first three variables in capturing the overall state of the economy. Annual growth in the retail trade index ( $\Delta$ Retail trade) is included to complement the index of industrial production in its role of approximating GDP growth. The second additional macroeconomic control, Term spread, proxies the financial market term premium and is measured as the difference between the 10-year government bond yield and the 3-month money market rate.

Bank controls represent the third group of explanatory variables. Their aim is to capture the heterogeneity of the overall banking sector. For this purpose we selected two ratios: capital and reserves to total assets (Capital to Assets) and non-performing loans to gross loans (NPL to Loans). ${ }^{18}$ The former variable represents a simple measure of capitalization in the country's banking sector, while the latter controls for credit risk. One can think of these variables as supplyside factors which affect banks' availability of funding and hence also credit growth.

The last group of controls was designed to cover the factors that are at work when households actually apply for loans. These demand-side controls are annual growth of the unemployment rate $(\Delta$ Unemployment rate $)$ and annual growth of disposable income $(\Delta$ Disp. income $) .{ }^{19}$ In fact, the inclusion of such explanatory variables contributes to the debate on whether it is supply (the availability of funding) or demand (households' decisions to take on debt) that causes the accumulation of debt. This simultaneity problem arises because it is extremely difficult to disentangle the roles of credit demand and supply from one another. Specifically, we can only analyze the credit volume that was actually granted, not knowing whether credit availability (supply) or demand played a role. Some progress has been made in this area by using matched bank-firm lending datasets in single countries (Khwaja and Mian, 2008; Amiti and Weinstein, 2018). Jiménez et al. (2017) exploit the Spanish credit registry and collect information on loan applications to analyze the demand side and loan contracts to analyze supply. The approach of Jiménez et al.

\footnotetext{
${ }^{18}$ We used three sources of data to construct the NPL to Loans variable. The primary source was the Financial Soundness Indicators database (https://data.imf.org/), which, however, offered only quarterly data and/or for some countries only annual or semi-annual observations. We decided to fill the gaps at the beginning of the sample with annual data from the FRED database (https://fred.stlouisfed.org/). The last source we employed was Bloomberg, which served as a last resort repository of quarterly or annual data if the previous two sources lacked the given record. For each country in our sample we ended up with mixed-frequency data starting in 2002:Q4 and ending in 2019:Q1. The monthly observations used in the final analysis were obtained by cubic spline interpolation.

${ }^{19}$ We used cubic spline interpolation to obtain the disposable income series in monthly frequency.
} 
(2017) would be the natural choice. However, given the unavailability of such rich data for our large panel of countries, we decided to approach the issue by identifying and controlling for the factors that drive the supply and demand for credit. $^{20}$

\subsubsection{Definitions of Good and Bad Times}

Motivated by a simple analysis of how our measure of irrational sentiment affects credit growth in the pre- and post-crisis subsamples (see Figure 4), we decided to enhance the baseline model and examine the strength of the underlying relation during the ups and downs of the business cycle. Our goal is to detect possible asymmetric effects of sentiment throughout our sample. As mentioned in Section 2, the literature suggests that economic agents might react differently in times of positive and negative news. While households might view macroeconomic conditions as informative for their decisions, it is reasonable to look at the effects of irrational sentiment conditional on the situation in the economy.

To identify periods of economic expansion on the one hand and economic distress on the other, we employed a simple rule for each country based on the value of the output gap. We constructed a measure of the output gap as a cyclical component of the national GDP series using the HodrickPrescott (HP) filter with the smoothing parameter $\lambda$ set to 1,600 . As the next step we designed two dummy variables conditional on the values of potential output for each country separately: (i) a GoodTimes dummy which is equal to 1 if the value of the output gap lies above the upper threshold and 0 otherwise, and (ii) a BadTimes dummy which is equal to 1 if the value of the output gap lies below the lower threshold and 0 otherwise. We set the upper (lower) threshold to be equal to the sample mean of the country's output gap plus (minus) 0.5 of its standard deviation. ${ }^{21}$ With these two dummies in hand we were able to proxy three types of periods - "good," "bad," and "normal," where NormalTimes can be formally expressed as (1-GoodTimes - BadTimes). Finally, we included the interactions of these dummies with irrational sentiment in our enhanced model as specified in Equation (4) (see also Figure C1, which depicts the country-level dynamics of these interaction terms together with the values of the output gap). Similarly, we examined the asymmetric effects for the indices of irrational optimism and pessimism (Equation 6).

\section{Empirical Results}

We first examine the naïve model, where growth in new consumer loans is gradually regressed first on total sentiment (Sentiment $t_{-1}$ ) and then on its two components, rational sentiment (RSentiment $t_{t-1}$ ) and irrational sentiment (IrSentiment $\left.t_{-1}\right)$. This is just to demonstrate that we have a strong case for our subsequent analysis.

All the coefficients on the sentiment variables turn out to be positive and significant at a $1 \%$ or $5 \%$ confidence level. This result is consistent with the theory that shocks to the confidence of consumers increase their appetite to consume products (Mishkin et al., 1978; Acemoglu and Scott, 1994; Garrett et al., 2005), one of which, potentially, is loans. With total sentiment, we find a positive one standard deviation shock to be associated with a $6.1 \mathrm{pp}$ increase in new consumer loan growth (Table 2, column 1). When we distinguish between the two components of sentiment, the effect becomes more pronounced for rational sentiment driven by fundamentals, where the point

\footnotetext{
${ }^{20}$ Meng et al. (2013) claims that the household debt level is jointly determined by supply and demand, while both sides are ultimately determined by macroeconomic variables.

${ }^{21}$ The selection of this criteria was affected by the minimum-maximum structure of the output gap series, which resulted in too few observations for GoodTimes and BadTimes under the rule of one standard deviation (see Table C1).
} 
estimate reaches almost $10 \mathrm{pp}$. Irrational sentiment scores lower, at about $4 \mathrm{pp}$ when no other controls are included in the naïve model (Table 2, column 2). Even though they are just outcomes of a simple model, these point estimates are already interesting, as they show that in their decision to borrow, households are not fully rational and there is room for "animal spirit." However, one has to keep in mind that the sentiment indices on the right-hand side are standardized to have zero mean and a variance of one, so a one unit shock represents a one standard deviation increase, which is a materially very significant change. ${ }^{22}$

Table 2: Motivation - Effects of Total, Rational, and Irrational Sentiment on Annual Growth in Consumer Loans

\begin{tabular}{|c|c|c|c|}
\hline & \multicolumn{3}{|c|}{ Dependent variable: $\Delta \ln \left(\right.$ Consumer Loans $\left._{t}\right)$} \\
\hline & (1) & (2) & (3) \\
\hline Sentiment $_{t-1}$ & $\begin{array}{c}\mathbf{0 . 0 6 1} \\
{[0.000]}\end{array}$ & & \\
\hline RSentiment $_{t-1}$ & & $\begin{array}{c}\mathbf{0 . 0 9 7} \\
{[0.002]}\end{array}$ & \\
\hline IrSentiment $_{t-1}$ & & $\begin{array}{c}\mathbf{0 . 0 3 9} \\
{[0.011]} \\
\end{array}$ & $\begin{array}{c}\mathbf{0 . 0 2 8} \\
{[0.047]} \\
\end{array}$ \\
\hline$\Delta$ Industrial prod $_{t-1}$ & & & $\begin{array}{c}\mathbf{0 . 0 0 8} \\
{[0.003]}\end{array}$ \\
\hline$\Delta$ CPI inflation ${ }_{t-1}$ & & & $\begin{array}{l}-0.009 \\
{[0.147]}\end{array}$ \\
\hline Short-term rate $_{t-1}$ & & & $\begin{array}{c}\mathbf{- 0 . 0 1 4} \\
{[0.039]}\end{array}$ \\
\hline Observations & 2,544 & 2,457 & 2,457 \\
\hline Adjusted $\mathrm{R}^{2}$ & 0.115 & 0.166 & 0.126 \\
\hline
\end{tabular}

Note: $p$-values (in brackets) are estimated using the wild cluster bootstrap resampling method developed by Cameron et al. (2008). Estimates in bold determine significance up to the $10 \%$ level. The table lists estimates based on panel data regression with country fixed effects and clusters, weighted by the financial inclusion proxy.

In the last column of Table 2, we include baseline macroeconomic controls which may affect new consumer loan growth as suggested in Barsky and Sims (2012). ${ }^{23}$ In this case, the effect of irrational sentiment on credit growth remains significant - a one unit improvement in irrational sentiment increases consumer loan growth by $2.8 \mathrm{pp}$. The coefficient on the economic activity proxy (industrial production) is of the expected positive direction and statistically significant; the short-term interest rate is significantly and negatively related to growth of consumer loans, which is in line with general intuition as well as the empirical literature on the monetary policy credit channel (Bernanke and Gertler, 1995). Altogether, the naïve model supports a non-trivial sentiment channel for fluctuations in bank credit. A positive (negative) shift in sentiment results in an increase (decrease) in newly issued consumer loans. More importantly, it is not just sentiment backed up by fundamentals that matters for consumer loan growth; irrational sentiment plays a significant role as well.

\footnotetext{
${ }^{22} \mathrm{~A}$ one standard deviation increase in sentiment variables is extremely rare. For example, a month-over-month increase of one standard deviation in irrational sentiment can be observed only in $3 \%$ of the month-over-month movements on average.

${ }^{23}$ When including macroeconomic controls, rational sentiment, RSentiment $t_{-1}$, is no longer employed, as it itself is a linear combination of the modified HOME index (Hodula et al., 2021) - the composite indicator which results from running a dynamic factor analysis on the set of 13 macroeconomic variables.
} 
In the next section, we test whether the established empirical link between irrational sentiment and growth of consumer loans can survive increasingly demanding model specifications. We introduce additional control variables into the model and we account for the presence of possible asymmetries in the relationship associated with economic boom/bust periods.

\subsection{Asymmetric Effects of Sentiment}

We examine whether the established relationship suggesting that irrational sentiment has a direct impact on new consumer loan growth is symmetric through the business cycle. To this end, we differentiate between good, bad, and normal macroeconomic environments underpinned by the evolution of the output gap (see Section 4.2.1 for details) as specified in Equation (4). At the same time, we include a wider set of control variables as specified in Section 4. We subsequently add baseline macroeconomic controls, additional macroeconomic controls, banking sector (supplyside) variables, and demand-side proxies. Estimates are shown in Table 3.

At first, in terms of rational sentiment, we do not find any asymmetries and hence confirm the robust effect of rational sentiment on consumer loan growth from the previous section. However, we find the impact of irrational sentiment to be conditional on the prevailing macroeconomic conditions. We discover that irrational beliefs about future economic effects impact consumer loan growth positively during good times, whereas the impact seems to be reduced to zero at any other time (bad times or normal times) after adding macroeconomic and financial controls (Table 3, columns 3-5). In almost all of the specifications, the effect of irrational sentiment is statistically significant at a 5\% confidence level, with bootstrapped p-values reported. The point estimate of approximately $5 \mathrm{pp}$ is largely invariant to perturbations in our specification. The effect is more pronounced than the one estimated in the naïve model.

The reported estimates are in accordance with both our expectations and the theory behind the financial instability hypothesis (Minsky, 1977), diagnostic expectations (Bordalo et al., 2018), and with the overreaction hypothesis from the literature on stock prices (De Bondt and Thaler, 1987; Clare and Thomas, 1995). In good times, households tend to overestimate the persistence of a positive economic situation into the future and then, based on the optimistic prospects, take on more debt than would be rational. The positive relation found between irrational sentiment and consumer loan growth thus further enhances consumer loan growth beyond the level supported by fundamentals, i.e., it pulls consumer loan growth beyond the levels dictated by the traditional theories and possibly contributes to a credit spiral. However, this happens only in good times, as the significance of irrational sentiment in normal times gradually declines when we add more controls.

Interestingly, we report insignificant estimates of irrational sentiment effects on consumer loan growth when the economy is in bad shape. This can be explained in several ways. It may be an empirical manifestation of the under-reaction hypothesis, which states that even if the optimism of households increases, it is not reflected in increased credit growth if the surrounding economic conditions are bad. This is also in line with the theory of conservatism as described in Section 2. It may also be the outcome of significant supply-side constraints for which we cannot fully control. Specifically, during periods of high market uncertainty, banks are more likely to cut back on lending regardless of consumers' intention to borrow (Ivashina and Scharfstein, 2010; De Haas and Van Horen, 2013).

On the other hand, the effect of rational sentiment continues to be significant across all time periods, and in all periods the effect seems to be materially similar. In bad times, if consumer loan growth decreases or increases because of sentiment, it is because of its rational component 
linked to fundamentals; no irrational swings in consumer loan growth appear. In all the models, the performance of most of the control variables is as expected. Growth of industrial production positively affects consumer loan growth, while it is negatively related to both the short-term interest rate and the term spread (the difference between the long-term and short-term interest rate). The rest of the control variables have the expected sign but are not statistically significant.

Table 3: Baseline - Effects of Irrational Sentiment on Annual Growth in Consumer Loans in Booms (GoodTimes), Busts (BadTimes), and "Normal" Periods (NormalTimes)

\begin{tabular}{|c|c|c|c|c|c|}
\hline & \multicolumn{5}{|c|}{ Dependent variable: $\Delta \ln \left(\right.$ Consumer Loans $\left.{ }_{t}\right)$} \\
\hline & (1) & $(2)$ & (3) & (4) & (5) \\
\hline \multirow{2}{*}{ RSentiment $_{t-1} \times$ GoodTimes $_{t-1}$} & 0.101 & & & & \\
\hline & [0.007] & & & & \\
\hline \multirow{2}{*}{ RSentiment $_{t-1} \times$ NormalTimes $_{t-1}$} & 0.088 & & & & \\
\hline & {$[0.010]$} & & & & \\
\hline \multirow{2}{*}{ RSentiment $_{t-1} \times$ BadTimes $_{t-1}$} & 0.092 & & & & \\
\hline & {$[0.002]$} & & & & \\
\hline \multirow{2}{*}{ IrSentiment $_{t-1} \times$ GoodTimes $_{t-1}$} & 0.057 & 0.046 & 0.045 & 0.048 & 0.046 \\
\hline & {$[0.017]$} & {$[0.060]$} & {$[0.048]$} & {$[0.023]$} & {$[0.018]$} \\
\hline \multirow{2}{*}{ IrSentiment $_{t-1} \times$ NormalTimes $_{t-1}$} & 0.046 & 0.036 & 0.017 & 0.018 & 0.016 \\
\hline & [0.004] & {$[0.020]$} & [0.205] & [0.206] & {$[0.195]$} \\
\hline \multirow{2}{*}{ IrSentiment $_{t-1} \times$ BadTimes $_{t-1}$} & -0.004 & -0.017 & -0.020 & -0.015 & -0.015 \\
\hline & {$[0.833]$} & {$[0.392]$} & {$[0.295]$} & {$[0.451]$} & [0.478] \\
\hline \multirow[t]{2}{*}{$\Delta$ Industrial prod $_{t-1}$} & & 0.007 & 0.005 & 0.005 & 0.004 \\
\hline & & {$[0.005]$} & [0.002] & {$[0.000]$} & {$[0.007]$} \\
\hline \multirow[t]{2}{*}{$\Delta$ Retail trade $_{t-1}$} & & & 0.006 & 0.006 & 0.005 \\
\hline & & & {$[0.286]$} & {$[0.230]$} & {$[0.331]$} \\
\hline \multirow[t]{2}{*}{$\Delta$ CPI inflation ${ }_{t-1}$} & & -0.010 & -0.009 & -0.007 & -0.008 \\
\hline & & {$[0.175]$} & [0.222] & {$[0.233]$} & {$[0.174]$} \\
\hline \multirow[t]{2}{*}{ Short-term rate t $_{t-1}$} & & -0.014 & -0.028 & -0.024 & -0.026 \\
\hline & & [0.039] & {$[0.005]$} & [0.033] & {$[0.023]$} \\
\hline \multirow[t]{2}{*}{ Term spread $_{t-1}$} & & & -0.034 & -0.034 & -0.032 \\
\hline & & & {$[0.020]$} & {$[0.025]$} & {$[0.036]$} \\
\hline \multirow[t]{2}{*}{ Capital to Assets ${ }_{t-1}$} & & & & 0.006 & 0.007 \\
\hline & & & & {$[0.611]$} & {$[0.505]$} \\
\hline \multirow[t]{2}{*}{ NPL to Loans ${ }_{t-1}$} & & & & 0.004 & 0.003 \\
\hline & & & & {$[0.375]$} & [0.396] \\
\hline \multirow[t]{2}{*}{ Unemployment rate $_{t-1}$} & & & & & 0.001 \\
\hline & & & & & {$[0.837]$} \\
\hline \multirow[t]{2}{*}{$\Delta$ Disp. income $t-1$} & & & & & 0.006 \\
\hline & & & & & {$[0.142]$} \\
\hline Observations & 2,457 & 2,457 & 2,457 & 2,454 & 2,454 \\
\hline Adjusted $\mathrm{R}^{2}$ & 0.174 & 0.136 & 0.189 & 0.191 & 0.194 \\
\hline
\end{tabular}

Note: $p$-values (in brackets) are estimated using the wild cluster bootstrap resampling method developed by Cameron et al. (2008). GoodTimes, BadTimes, and NormalTimes denote dummy variables that are equal to 1 if the GDP gap for the given country in the given month $t$ is 0.5 standard deviation above, below, and around its mean, respectively, and 0 otherwise. Estimates in bold determine significance up to the $10 \%$ level. The table lists estimates based on panel data regression with country fixed effects and clusters, weighted by the financial inclusion proxy.

Our results contradict those of Caglayan and Xu (2016), who estimate change in sentiment to have a negative impact on banks' loan growth. They explain the negative impact of an increase in sentiment through the lens of monetary policy tightening, which is more likely to take place during economic upturns. However, such argumentation is troublesome for several reasons. First, the model they estimate is contemporaneous and a lagged monetary policy response is not considered. Second, 
the model does not include any monetary policy proxy. Third, as the authors also note, they do not report a uniformly negative impact across the various model specifications; in fact, the reported parameter estimate turns positive when they consider the OECD CCI as the main sentiment variable.

\subsection{Robustness Check}

We provide several robustness checks of the results described above. First, we examine an extended version of Equation (4) and differentiate between the phases of the business cycle in more detail, as periods of good and bad times are divided into their increasing and decreasing phases. Altogether, by using interaction dummies we can examine the effect of irrational sentiment in periods of: (i) a very positive and increasing output gap (expansion), (ii) a very positive and decreasing output gap (recession), (iii) a non-extreme output gap, (iv) a very negative and decreasing output gap (depression), and (v) a very negative and increasing output gap (recovery). The results, reported in Table D1 in the Appendix, show that regardless of whether there is expansionary or recessionary phase with a positive output gap, irrational sentiment remains positively and significantly related to consumer loan growth, with the magnitude lying consistently in the range of 4-5 pp. Similarly, in both the depression and recovery phases with a negative output gap, irrational sentiment does not have a significant role in explaining consumer loan growth. Thus, the results confirm those in Table 3 .

Second, we estimate Equations (5) and (6) where, instead of the rational and irrational indices of overall sentiment, we include the indices of irrational optimism and pessimism separately, as described in Section 3.3. The results are reported in Table 4. Irrational optimism significantly affects consumer loan growth, increasing it by $2.3 \mathrm{pp}$ (column 1) on average, or by $5.9 \mathrm{pp}$ and $2.0 \mathrm{pp}$ in good times and normal times, respectively (column 3). Again, there is no significant relationship estimated in bad times. On the other hand, irrational pessimism is never significant (columns 2 and 4). The full set of controls is included. Thus, we assert that irrationally optimistic beliefs are those that matter and lead to an increase in consumer loan growth. Previously, we looked at good and bad times from the point of view of the economic cycle, and good periods proved to be significant. Here, we have distinguished between optimistic and pessimistic beliefs, and the optimistic ones have proved to be those which are significant.

Third, we provide robustness checks from the methodological point of view. We estimate a variant of Table 3 with a different threshold for the interaction dummies separating good, normal, and bad times: instead of the threshold of 0.5 standard deviation above/below the mean, we use one standard deviation above/below the mean. Due to the scarcity of one standard deviation changes in the output gap (see Table C1) we can interpret this as extremely good or bad times with respect to the output gap measure. The results are reported in Table D2 in the Appendix. Again, they remain robust: a shock to irrational sentiment of one standard deviation leads to a 4-5 pp increase in annual consumer loan growth during alternatively defined good times. The effect is not significant in other time periods. The effect of rational sentiment is the same as before: significant and equal to around 8-10 pp across all time periods. Next, we estimate a non-weighted version of the regressions (Table D3 in the Appendix) instead of the weighted fixed effects. The results turn out to be robust (qualitatively as well as quantitatively) under this alternative specification as well.

We then provide the robustness in terms of the decomposition of the sentiment index. In our original specification, the total sentiment index was decomposed into the rational and irrational indices by using the modified version of the HOME index (Hodula et al., 2021) as described in Section 3.2. In contrast to that, Table D4 in the Appendix reports the results with rational and irrational sentiment decomposed by using individual macroeconomic variables instead of the composite HOME index. 
The results are very much in line with the previous ones, proving that they are robust with respect to the method of decomposition of the total sentiment index.

Table 4: Diverse Effects of Households' Optimism and Pessimism

\begin{tabular}{|c|c|c|c|c|}
\hline & \multicolumn{4}{|c|}{ Dependent variable: $\Delta \ln \left(\right.$ Consumer Loans $\left.{ }_{t}\right)$} \\
\hline & $(1)$ & $(2)$ & (3) & $(4)$ \\
\hline Ir.optimism $_{t-1}$ & $\begin{array}{c}\mathbf{0 . 0 2 3} \\
{[0.016]}\end{array}$ & & & \\
\hline Ir.pessimism $_{t-1}$ & & $\begin{array}{c}-0.010 \\
{[0.544]}\end{array}$ & & \\
\hline Ir.Optimism $_{t-1} \times$ GoodTimes $_{t-1}$ & & & $\begin{array}{c}\mathbf{0 . 0 5 9} \\
{[0.003]}\end{array}$ & \\
\hline Ir.Optimism $_{t-1} \times$ NormalTimes $_{t-1}$ & & & $\begin{array}{c}\mathbf{0 . 0 2 0} \\
{[0.056]}\end{array}$ & \\
\hline Ir.Optimism $_{t-1} \times$ BadTimes $_{t-1}$ & & & $\begin{array}{c}-0.018 \\
{[0.233]}\end{array}$ & \\
\hline Ir.Pessimism $_{t-1} \times$ GoodTimes $_{t-1}$ & & & & $\begin{array}{l}-0.028 \\
{[0.264]}\end{array}$ \\
\hline Ir.Pessimism $_{t-1} \times$ NormalTimes $_{t-1}$ & & & & $\begin{array}{l}-0.008 \\
{[0.618]}\end{array}$ \\
\hline Ir.Pessimism $_{t-1} \times$ BadTimes $_{t-1}$ & & & & $\begin{array}{c}0.009 \\
{[0.671]}\end{array}$ \\
\hline Baseline Macro Controls & yes & yes & yes & yes \\
\hline Additional Macro Controls & yes & yes & yes & yes \\
\hline Bank Controls & yes & yes & yes & yes \\
\hline Demand-side Controls & yes & yes & yes & yes \\
\hline Observations & 2,454 & 2,454 & 2,454 & 2,454 \\
\hline Adjusted $\mathrm{R}^{2}$ & 0.194 & 0.183 & 0.210 & 0.186 \\
\hline
\end{tabular}

Note: $p$-values (in brackets) are estimated using the wild cluster bootstrap resampling method developed by Cameron et al. (2008). GoodTimes, BadTimes, and NormalTimes denote dummy variables that are equal to 1 if the GDP gap for the given country in the given month $t$ is 0.5 standard deviation above, below, and around its mean, respectively, and 0 otherwise. Estimates in bold determine significance up to the $10 \%$ level. The table lists estimates based on panel data regression with country fixed effects and clusters, weighted by the financial inclusion proxy.

Last but not least, we test the robustness of our results by splitting the sample into two subsamples of countries - high-debt and low-debt countries, categorized based on their average credit-to-GDP ratios - to see whether our sample is systematically heterogeneous in this respect. ${ }^{24}$ The results in Table D5 in the Appendix show that regardless of whether one considers a subset of high-debt or low-debt countries, irrational sentiment matters in good times (even though the effect is less significant than in the full sample) and its effect on consumer loan growth in bad times is negligible. This is in line with our main results. The effect of rational sentiment in low-debt countries seems to disappear, while it remains strong in the other subset.

While the panel regressions for both the full sample and the two subsamples give us no indication that a relationship exists between irrational sentiment and consumer loan fluctuations in bad times, there may be a connection in some countries. In fact, there may be statistically significant relationships in all countries, but with differing signs. To this end, we re-estimate the model as it

\footnotetext{
${ }^{24}$ We employed data on credit-to-GDP ratios, where credit is represented by total credit granted to households and non-profit institutions serving households, from the BIS Statistical Warehouse and from the ECB Statistical Data Warehouse in the case of Slovakia. We calculated their average values in the period from 2003:Q1 to 2019:Q1 and considered the seven countries with the highest average credit-to-GDP ratios as high-debt countries (DK, NL, GB, PT, SE, ES, DE) and the remaining eight countries as low-debt countries (FI, BE, FR, AT, IT, PL, SK, CZ).
} 
appears in Equation (4) for each individual country. The results of these country-level regressions are reported in Table D6. ${ }^{25}$ We observe that shocks to irrational sentiment appear to explain consumer loan fluctuations during bad times in five to seven of the countries studied depending on the model specification. The effect is positive as expected in large, high-income countries such as Germany, France, and Italy, but is negative in Spain (which might be due to local supply constraints during and after the crisis), and, surprisingly, Denmark. Nevertheless, the effect differs across countries, making some of the aggregate panel results insignificant. On the other hand, the results for irrational sentiment in good times remain consistent in the panel and the country-by-country analysis: if the effect is significant, it is positive.

\section{Conclusion}

We contributed with novel empirical evidence to an as yet unresolved question in economics: what is the role of household sentiment in real economic activity? In the paper, we tested the empirical link between sentiment and consumer loan fluctuations using panel data covering 15 European countries over the 2003-2019 period. To this end, we created a new index of household sentiment using harmonized consumer survey data from the European Commission. We employed a variant of the orthogonalization procedure proposed in Baker and Wurgler (2006) to decompose the novel index of sentiment into a rational and an irrational component.

We began by linking shocks to sentiment to changes in new consumer loans. Our estimates suggest that increased sentiment of households generally increases consumer loan growth. In this respect, we identified a non-trivial sentiment channel that explains fluctuations in consumer loans. Furthermore, we showed that decisions of households to borrow are not backed up solely by macroeconomic fundamentals (i.e., rational sentiment), but the irrational part of sentiment also has a significant influence.

We proceeded by verifying the link identified between the rational and irrational sentiment of households and the dynamics of new consumer loans with respect to business cycle fluctuations. We confirmed that the role of sentiment that is backed up by macroeconomic fundamentals is robust across the business cycle, as we did not identify any asymmetries in boom or bust times. On the other hand, we discovered that our irrational sentiment variable, which proxies for households' optimism or pessimism on top of their rationally sourced beliefs, impacts consumer loan growth positively only during economic upturns. In other words, shocks to irrational sentiment, regardless of whether they are positive or negative, do not have a significant impact on consumer loan dynamics when the economy is in bad shape. These findings were further verified when we considered indices of optimism and pessimism only. We complemented our analyses with a battery of robustness tests.

The presented set of results provides empirical support for the rich theoretical body of literature on behavioral factors and their role in explaining credit fluctuations (Fuster et al., 2010; Gennaioli et al., 2015; Bordalo et al., 2018). We provided empirical evidence that consumer loan growth might be a joint outcome of both rational and irrational beliefs about the current and future economic situation. Moreover, we showed that during boom times, excessive optimism leads households to take on more debt than implied by the dynamics of macroeconomic factors. This produces some important implications for financial stability conduct, especially if the credit supply matches the increasing demand.

\footnotetext{
${ }^{25}$ We performed the country-level analysis on a sample of 12 countries instead of 15 because the data on the dependent variable for three countries (Poland, Sweden, and the United Kingdom) contain too few observations to be used for the country-specific analysis.
} 


\section{References}

Acemoglu, D. And A. ScotT (1994): "Consumer Confidence and Rational Expectations: Are Agents' Beliefs Consistent with the Theory?" The Economic Journal, 104(422):1-19.

Akerlof, G. A. And R. J. Shiller (2010): Animal Spirits: How Human Psychology Drives the Economy, and Why It Matters for Global Capitalism. Princeton University Press.

Ambrocio, G. (2019): "Measuring Household Uncertainty in EU Countries." Research Discussion Papers 17/2019, Bank of Finland.

Ambrocio, G. (2020): "Rational Exuberance Booms." Review of Economic Dynamics, 35 : 263-282.

Amiti, M. And D. E. Weinstein (2018): "How Much Do Idiosyncratic Bank Shocks Affect Investment? Evidence from Matched Bank-Firm Loan Data." Journal of Political Economy, 126(2):525-587.

BAKer, M. AND J. WuRgler (2006): "Investor Sentiment and the Cross-Section of Stock Returns.” Journal of Finance, 61(4):1645-1680.

BAKER, M. AND J. Wurgler (2007): "Investor Sentiment in the Stock Market." Journal of Economic Perspectives, 21(2):129-151.

BARberis, N., A. Shleifer, AND R. Vishny (1998): “A Model of Investor Sentiment.” Journal of Finacial Economics, 49:307-343.

BARSKY, R. B. AND E. R. Sims (2012): "Information, Animal Spirits, and the Meaning of Innovations in Consumer Confidence." American Economic Review, 102(4):1343-77.

Benhabib, J. And M. M. Spiegel (2019): "Sentiments and Economic Activity: Evidence from US States." The Economic Journal, 129(618):715-733.

Bernanke, B. S. And M. Gertler (1995): "Inside the Black Box: The Credit Channel of Monetary Policy Transmission.” Journal of Economic Perspectives, 9(4):27-48.

Bordalo, P., N. Gennaioli, AND A. Shleifer (2018): "Diagnostic Expectations and Credit Cycles." The Journal of Finance, 73(1):199-227.

BRown, G. W. AND M. T. Cliff (2004): "Investor Sentiment and the Near-term Stock Market." Journal of Empirical Finance, 11(1):1-27.

Caglayan, M. AND B. XU (2016): "Sentiment Volatility and Bank Lending Behavior." International Review of Financial Analysis, 45:107-120.

Cameron, A. C. And D. L. Miller (2015): “A Practitioner's Guide to Cluster-Robust Inference." Journal of Human Resources, 50(2):317-372.

Cameron, A. C., J. B. Gelbach, And D. L. Miller (2008): "Bootstrap-Based Improvements for Inference with Clustered Errors." The Review of Economics and Statistics, 90(3):414427.

Carroll, C. D., J. C. Fuhrer, And D. W. Wilcox (1994): "Does Consumer Sentiment Forecast Household Spending? If So, Why?" The American Economic Review, 84(5): 1397-1408.

Clare, A. And S. Thomas (1995): "The Overreaction Hypothesis and the UK Stock Market." Journal of Business Finance and Accounting, 22:961-961. 
DAS, P., R. FÜss, B. HANLE, AND I. N. Russ (2020): "The Cross-Over Effect of Irrational Sentiments in Housing, Commercial Property, and Stock Markets." Journal of Banking \& Finance, 114:1-14.

De Bondt, W. F. AND R. H. ThaleR (1987): "Further Evidence on Investor Overreaction and Stock Market Seasonality.” The Journal of Finance, 42(3):557-581.

De HAAs, R. AND N. VAN HoRen (2013): "Running for the Exit? International Bank Lending During a Financial Crisis." The Review of Financial Studies, 26(1):244-285.

Debelle, G. (2004): "Household Debt and the Macroeconomy." BIS Quarterly Review March 2004, Bank for International Settlements.

Delis, M. D., G. P. Kouretas, And C. Tsoumas (2014): “Anxious Periods and Bank Lending." Journal of Banking \& Finance, 38:1-13.

Demirguc-Kunt, A., L. Klapper, D. Singer, S. Ansar, And J. Hess (2018): The Global Findex Database 2017: Measuring Financial Inclusion and the Fintech Revolution. The World Bank.

EDWARDS, W. (1968): Conservatism in Human Information Processing. In Kleinmutz, B., editors, Formal Representation of Human Judgment, pages 17-52. John Wiley and Sons, New York.

European Commission (2018): “A Revised Consumer Confidence Indicator.” (https://ec. europa.eu/info/sites/info/files/new_cci.pdf).

European Commission (2019): "The Joint Harmonised EU Programme Of Business And Consumer Surveys: User Guide.” (https://ec.europa.eu/info/sites/info/files/bcs_user_guide_ en_0.pdf).

Ewing, B. T. And J. E. PAyne (1998): “The Long-Run Relation Between the Personal Savings Rate and Consumer Sentiment." Journal of Financial Counseling and Planning, 9(1):8996.

Fostel, A. And J. Geanakoplos (2008): "Leverage Cycles and the Anxious Economy." American Economic Review, 98(4):1211-44.

Fuster, A., D. Laibson, AND B. Mendel (2010): "Natural Expectations and Macroeconomic Fluctuations.” Journal of Economic Perspectives, 24(4):67-84.

Garcia, M. J. R. (2013): "Financial Education and Behavioral Finance: New Insights into the Role of Information in Financial Decisions.” Journal of Economic Surveys, 27(2):297-315.

Garrett, T. A., R. Hernández-Murillo, M. T. Owyang, et Al. (2005): "Does Consumer Sentiment Predict Regional Consumption." Federal Reserve Bank of St. Louis Review, 87 (2):123-135.

Gennaioli, N. And A. Shleifer (2010): “What Comes to Mind." The Quarterly Journal of Economics, 125(4):1399-1433.

Gennaioli, N., A. Shleifer, And R. Vishny (2015): "Neglected Risks: The Psychology of Financial Crises." American Economic Review, 105(5):310-314.

Gouret, F. AND G. Hollard (2011): "When Kahneman Meets Manski: Using Dual Systems of Reasoning to Interpret Subjective Expectations of Equity Returns." Journal of Applied Econometrics, 26(3):371-392. 
Gourinchas, P.-O. AND M. ObstFeld (2012): "Stories of the Twentieth Century for the Twenty-First." American Economic Journal: Macroeconomics, 4(1):226-265.

Han, X. AND Y. Li (2017): "Can Investor Sentiment Be a Momentum Time-Series Predictor? Evidence from China." Journal of Empirical Finance, 42:212-239.

Hodula, M., S. Malovana, And J. Frait (2019): "Too Much of a Good Thing? Households' Macroeconomic Conditions and Credit Dynamics.” CNB Working Paper 11/2019, Czech National Bank.

Hodula, M., S. Malovana, And J. Frait (2021): "What Does Really Drive Consumer Confidence?" Social Indicators Research, forthcoming.

Huang, D., F. Jiang, J. Tu, And G. Zhou (2015): "Investor Sentiment Aligned: A Powerful Predictor of Stock Returns." The Review of Financial Studies, 28(3):791-837.

IVAShina, V. AND D. Scharfstein (2010): "Bank Lending During the Financial Crisis of 2008." Journal of Financial Economics, 97(3):319-338.

Jiménez, G., S. Ongena, J.-L. Peydró, And J. SAurina (2012): "Credit Supply and Monetary Policy: Identifying the Bank Balance-Sheet Channel with Loan Applications." American Economic Review, 102(5):2301-26.

Jiménez, G., S. Ongena, J.-L. Peydró, And J. Saurina Salas (2017): "Do Demand or Supply Factors Drive Bank Credit, in Good and Crisis Times?" Economic Working Paper Series, No. 1567, Universitat Pompeu Fabra, Department of Economics and Business, Barcelona.

JordÀ, Ò., M. Schularick, AND A. M. TAYlor (2011): "Financial Crises, Credit Booms, and External Imbalances: 140 Years of Lessons." IMF Economic Review, 59(2):340-378.

Kahneman, D. And A. TVersky (1979): "Prospect Theory: An Analysis of Decision Under Risk.” Econometrica, 47(2):263-291.

KAMDAR, R. (2018): “The Inattentive Consumer: Sentiment and Expectations.” Unpublished manuscript.

KhwajA, A. I. AND A. MiAn (2008): "Tracing the Impact of Bank Liquidity Shocks: Evidence from an Emerging Market." American Economic Review, 98(4):1413-42.

López-SAlido, D., J. C. Stein, And E. ZakrajŠEK (2017): "Credit-Market Sentiment and the Business Cycle." The Quarterly Journal of Economics, 132(3):1373-1426.

Ludvigson, S. C. (2004): “Consumer Confidence and Consumer Spending." Journal of Economic Perspectives, 18(2):29-50.

Meng, X., N. T. Hoang, and M. Siriwardana (2013): "The Determinants of Australian Household Debt: A Macro Level Study.” Journal of Asian Economics, 29:80-90.

Michis, A. A. ET AL. (2010): "Denoised Least Squares Forecasting of GDP Changes Using Indexes of Consumer and Business Sentiment." IFC Bulletin, 25:383.

MiNSKY, H. P. (1977): "The Financial Instability Hypothesis: An Interpretation of Keynes and an Alternative to "Standard" Theory." Challenge, 20(1):20-27.

Mishinin, F. S., R. Hall, J. Shoven, T. Juster, And M. Lovell (1978): “Consumer Sentiment and Spending on Durable Goods." Brookings Papers on Economic Activity, 1978 (1):217-232. 
Newey, W. K. AND K. D. West (1987): “A Simple, Positive Semi-Definite, Heteroskedasticity and Autocorrelation Consistent Covariance Matrix." Econometrica, 55(3):703-708.

Nofsinger, J. R. (2012): “Household Behavior and Boom/Bust Cycles.” Journal of Financial Stability, 8(3):161-173.

Roodman, D., M. Ø. Nielsen, J. G. MacKinnon, And M. D. Webb (2019): "Fast and Wild: Bootstrap Inference in Stata Using Boottest.” The Stata Journal, 19(1):4-60.

Schularick, M. AND A. M. TAYlor (2012): "Credit Booms Gone Bust: Monetary Policy, Leverage Cycles, and Financial Crises, 1870-2008." American Economic Review, 102(2): 1029-61.

Shefrin, H. (2016): Behavioral Risk Management: Managing the Psychology that Drives Decisions and Influences Operational Risk. Palgrave Macmillan.

Simon, H. A. (1957): Models of Man; Social and Rational. Wiley.

Sordi, S. AND A. Vercelli (2012): "Heterogeneous Expectations and Strong Uncertainty in a Minskyian Model of Financial Fluctuations." Journal of Economic Behavior \& Organization, 83(3):544-557.

StARR, M. A. (2012): “Consumption, Sentiment, and Economic News.” Economic Inquiry, 50 (4):1097-1111.

TVErsky, A. AND D. Kahneman (1974): "Judgment Under Uncertainty: Heuristics and Biases." Science, 185(4157):1124-1131.

Verma, R. And G. SOYdemir (2009): “The Impact of Individual and Institutional Investor Sentiment on the Market Price of Risk." The Quarterly Review of Economics and Finance, 49(3):1129-1145.

VERMA, R., H. BAKLACI, AND G. SOYDEMIR (2008): "The Impact of Rational and Irrational Sentiments of Individual and Institutional Investors on DJIA and S\&P500 Index Returns." Applied Financial Economics, 18(16):1303-1317.

Zellner, A. (1962): "An Efficient Method of Estimating Seemingly Unrelated Regressions and Tests for Aggregation Bias.” Journal of the American Statistical Association, 57(298):348368. 


\section{Appendix A: Total Sentiment Index}

Table A1: Questions NOT Employed in Total Sentiment Index

\begin{tabular}{|c|c|c|c|}
\hline Q.No. & Short Description & Question & $\mathrm{CCI}$ \\
\hline 5 & $\begin{array}{l}\text { Price trends over last } 12 \\
\text { months }\end{array}$ & $\begin{array}{l}\text { How do you think that consumer prices have developed } \\
\text { over the last } 12 \text { months? } \\
\text { Answers: }(++) \text { risen a lot, }(+) \text { risen moderately, }(=) \text { risen } \\
\text { slightly, }(-) \text { stayed about the same, }(--) \text { fallen, }(N) \text { don't know }\end{array}$ & $\mathrm{N}$ \\
\hline 6 & $\begin{array}{l}\text { Price trends over next } 12 \\
\text { months }\end{array}$ & $\begin{array}{l}\text { By comparison with the past } 12 \text { months, how do you } \\
\text { expect that consumer prices will develop in the next } \\
12 \text { months? } \\
\text { Answers: (++) increase more rapidly, (+) increase at the same } \\
\text { rate, (=) increase at a slower rate, (-) stay about the same, (- -) } \\
\text { fall, }(N) \text { don't know }\end{array}$ & $\mathrm{N}$ \\
\hline 7 & $\begin{array}{l}\text { Unemployment } \\
\text { expectations over next } 12 \\
\text { months }\end{array}$ & $\begin{array}{l}\text { How do you expect the number of people unemployed in } \\
\text { this country to change over the next } 12 \text { months? } \\
\text { Answers: (++) increase sharply, (+) increase slightly, (=) } \\
\text { remain the same, (-) fall slightly, (- -) fall sharply, (N) don't } \\
\text { know }\end{array}$ & $\mathrm{N}$ \\
\hline 11 & $\begin{array}{l}\text { Savings over next } 12 \\
\text { months }\end{array}$ & $\begin{array}{l}\text { Over the next } 12 \text { months, how likely is it that you save } \\
\text { any money? } \\
\text { Answers: }(++) \text { very likely, (+) fairly likely, (-) not likely, (--) } \\
\text { not at all likely, }(N) \text { don't know }\end{array}$ & $\mathrm{N}$ \\
\hline
\end{tabular}

Note: This table lists the questions from the harmonized consumer surveys administered by DG ECFIN that were NOT considered in the calculation of the total sentiment index. Note that we do not report question 10 (Q10) either in this table or in Table 1. This is because the responses to Q10 are not harmonized across the EU and so DG ECFIN does not provide detailed data for it. See also the notes to Table 1.

Source: European Commission (2019). 
Table A2: Contemporaneous and Leading Correlations between Consumer Loans and Balances of Individual Survey Questions

\begin{tabular}{|c|c|c|c|c|c|c|c|c|c|c|c|c|c|c|c|c|}
\hline Question & AT & $\mathbf{B E}$ & $\mathbf{C Z}$ & DK & FI & FR & $\overline{\mathrm{DE}}$ & IT & NL & PL & PT & SK & ES & SE & UK & Mean \\
\hline \multicolumn{17}{|c|}{ Panel A: Contemporaneous (t) Correlations } \\
\hline Q1 & 0.48 & 0.16 & 0.22 & 0.13 & 0.06 & 0.25 & 0.51 & 0.59 & -0.16 & 0.27 & 0.35 & 0.09 & 0.57 & 0.53 & 0.49 & 0.30 \\
\hline Q2 & 0.30 & 0.06 & 0.14 & 0.02 & -0.06 & 0.31 & 0.52 & 0.65 & 0.04 & 0.31 & 0.44 & 0.14 & 0.65 & 0.21 & 0.34 & 0.27 \\
\hline Q3 & 0.39 & 0.44 & 0.35 & 0.54 & 0.23 & 0.52 & 0.23 & 0.76 & 0.11 & 0.23 & 0.49 & 0.27 & 0.71 & 0.64 & 0.25 & 0.41 \\
\hline Q4 & 0.24 & 0.40 & 0.20 & 0.27 & -0.04 & 0.44 & 0.32 & 0.65 & 0.12 & 0.23 & 0.49 & 0.30 & 0.64 & -0.13 & -0.09 & 0.27 \\
\hline Q5 & -0.11 & -0.28 & 0.16 & -0.10 & -0.20 & -0.44 & -0.64 & -0.48 & 0.31 & -0.21 & -0.37 & -0.16 & 0.03 & -0.02 & -0.50 & -0.20 \\
\hline Q6 & 0.40 & 0.07 & 0.13 & 0.42 & 0.10 & -0.12 & -0.22 & -0.45 & 0.19 & -0.31 & -0.36 & -0.18 & 0.15 & 0.39 & -0.12 & 0.01 \\
\hline Q7 & -0.28 & -0.41 & -0.36 & -0.55 & -0.22 & -0.39 & -0.09 & -0.81 & -0.17 & -0.13 & -0.56 & -0.17 & -0.66 & -0.58 & -0.12 & -0.37 \\
\hline Q8 & 0.51 & 0.31 & 0.41 & 0.15 & -0.16 & 0.58 & 0.67 & 0.62 & -0.11 & 0.05 & 0.32 & 0.19 & 0.32 & 0.57 & 0.42 & 0.32 \\
\hline Q9 & 0.45 & 0.05 & 0.38 & 0.25 & 0.04 & 0.46 & 0.56 & 0.08 & -0.15 & -0.11 & 0.11 & 0.04 & 0.67 & 0.42 & 0.46 & 0.25 \\
\hline Q11 & -0.30 & 0.01 & 0.12 & 0.07 & 0.08 & 0.19 & 0.44 & 0.64 & 0.08 & 0.14 & 0.09 & -0.11 & 0.35 & 0.08 & 0.42 & 0.15 \\
\hline Q12 & 0.11 & -0.07 & -0.02 & 0.17 & 0.09 & -0.28 & 0.47 & 0.44 & -0.08 & 0.22 & 0.14 & -0.16 & 0.20 & 0.05 & 0.53 & 0.12 \\
\hline \multicolumn{17}{|c|}{ Panel B: Leading $(t+1)$ Correlations } \\
\hline Q1 & 0.49 & 0.18 & 0.21 & 0.12 & 0.05 & 0.25 & 0.49 & 0.57 & -0.14 & 0.25 & 0.33 & 0.06 & 0.55 & 0.59 & 0.51 & 0.30 \\
\hline Q2 & 0.32 & 0.09 & 0.13 & 0.01 & -0.02 & 0.32 & 0.51 & 0.65 & 0.07 & 0.27 & 0.44 & 0.12 & 0.68 & 0.25 & 0.38 & 0.28 \\
\hline Q3 & 0.36 & 0.45 & 0.36 & 0.54 & 0.24 & 0.52 & 0.18 & 0.75 & 0.12 & 0.20 & 0.48 & 0.25 & 0.70 & 0.66 & 0.29 & 0.41 \\
\hline Q4 & 0.23 & 0.44 & 0.18 & 0.29 & 0.00 & 0.45 & 0.26 & 0.65 & 0.15 & 0.20 & 0.49 & 0.30 & 0.68 & -0.07 & -0.03 & 0.28 \\
\hline Q5 & -0.15 & -0.34 & 0.15 & -0.11 & -0.23 & -0.48 & -0.66 & -0.49 & 0.27 & -0.18 & -0.39 & -0.15 & 0.03 & -0.12 & -0.52 & -0.22 \\
\hline Q6 & 0.40 & 0.00 & 0.15 & 0.40 & 0.10 & -0.16 & -0.26 & -0.48 & 0.16 & -0.29 & -0.39 & -0.18 & 0.12 & 0.37 & -0.23 & -0.02 \\
\hline Q7 & -0.25 & -0.37 & -0.36 & -0.55 & -0.23 & -0.36 & -0.04 & -0.79 & -0.17 & -0.13 & -0.55 & -0.17 & -0.67 & -0.62 & -0.15 & -0.36 \\
\hline Q8 & 0.50 & 0.32 & 0.42 & 0.17 & -0.11 & 0.59 & 0.67 & 0.62 & -0.11 & 0.02 & 0.32 & 0.14 & 0.34 & 0.65 & 0.44 & 0.33 \\
\hline Q9 & 0.44 & 0.06 & 0.35 & 0.23 & 0.06 & 0.48 & 0.55 & 0.04 & -0.13 & -0.08 & 0.09 & 0.02 & 0.66 & 0.48 & 0.48 & 0.25 \\
\hline Q11 & -0.31 & 0.00 & 0.10 & 0.09 & 0.06 & 0.19 & 0.42 & 0.63 & 0.11 & 0.12 & 0.05 & -0.14 & 0.36 & 0.11 & 0.46 & 0.15 \\
\hline Q12 & 0.08 & -0.07 & -0.04 & 0.14 & 0.08 & -0.30 & 0.46 & 0.40 & -0.02 & 0.22 & 0.12 & -0.20 & 0.20 & 0.07 & 0.56 & 0.11 \\
\hline \multicolumn{17}{|c|}{ Panel C: Leading $(t+3)$ Correlations } \\
\hline Q1 & 0.52 & 0.22 & 0.18 & 0.09 & 0.02 & 0.22 & 0.46 & 0.53 & -0.13 & 0.17 & 0.30 & 0.01 & 0.51 & 0.64 & 0.53 & 0.28 \\
\hline Q2 & 0.38 & 0.13 & 0.09 & -0.01 & 0.06 & 0.35 & 0.46 & 0.63 & 0.10 & 0.17 & 0.42 & 0.08 & 0.70 & 0.36 & 0.42 & 0.29 \\
\hline Q3 & 0.33 & 0.44 & 0.35 & 0.53 & 0.23 & 0.51 & 0.11 & 0.72 & 0.10 & 0.14 & 0.46 & 0.19 & 0.67 & 0.68 & 0.35 & 0.39 \\
\hline Q4 & 0.26 & 0.47 & 0.15 & 0.35 & 0.08 & 0.46 & 0.17 & 0.66 & 0.18 & 0.12 & 0.49 & 0.28 & 0.71 & 0.07 & 0.08 & 0.30 \\
\hline Q5 & -0.23 & -0.43 & 0.14 & -0.12 & -0.30 & -0.54 & -0.65 & -0.49 & 0.21 & -0.10 & -0.43 & -0.09 & 0.03 & -0.31 & -0.52 & -0.25 \\
\hline Q6 & 0.32 & -0.09 & 0.24 & 0.38 & 0.08 & -0.28 & -0.32 & -0.52 & 0.08 & -0.24 & -0.45 & -0.15 & 0.06 & 0.29 & -0.36 & -0.06 \\
\hline Q7 & -0.19 & -0.27 & -0.34 & -0.54 & -0.23 & -0.30 & 0.03 & -0.76 & -0.15 & -0.12 & -0.52 & -0.14 & -0.66 & -0.65 & -0.19 & -0.34 \\
\hline Q8 & 0.50 & 0.35 & 0.40 & 0.17 & -0.04 & 0.59 & 0.62 & 0.58 & -0.11 & 0 & 0.30 & 0.05 & 0.31 & 0.72 & 0.47 & 0.33 \\
\hline Q9 & 0.43 & 0.10 & 0.34 & 0.22 & 0.08 & 0.50 & 0.51 & -0.03 & -0.14 & -0.03 & 0.06 & -0.03 & 0.62 & 0.58 & 0.47 & 0.25 \\
\hline Q11 & -0.32 & -0.01 & 0.07 & 0.15 & 0.09 & 0.15 & 0.36 & 0.63 & 0.14 & 0.10 & 0.01 & -0.17 & 0.32 & 0.16 & 0.56 & 0.15 \\
\hline Q12 & 0.01 & -0.11 & -0.07 & 0.16 & 0.07 & -0.31 & 0.44 & 0.35 & 0.04 & 0.18 & 0.07 & -0.20 & 0.16 & 0.10 & 0.59 & 0.10 \\
\hline
\end{tabular}

Note: Panel A shows the pairwise correlations between annual growth in new consumer loans (the dependent variable) at time $t$ and the balances of the individual survey questions at time $t$. Panels B and C report the pairwise correlations between the leading dependent variable at time $t+1$ and $t+3$, respectively, and the balances of the individual survey questions at time $t$. The sample spans from January 2003 to March 2019 . The results for Question 10 (Q10) are not included because the responses to this question are not harmonized across the EU and so DG ECFIN does not provide detailed data for it. 
Figure A1: Total Sentiment Index and Contributions of Individual Questions
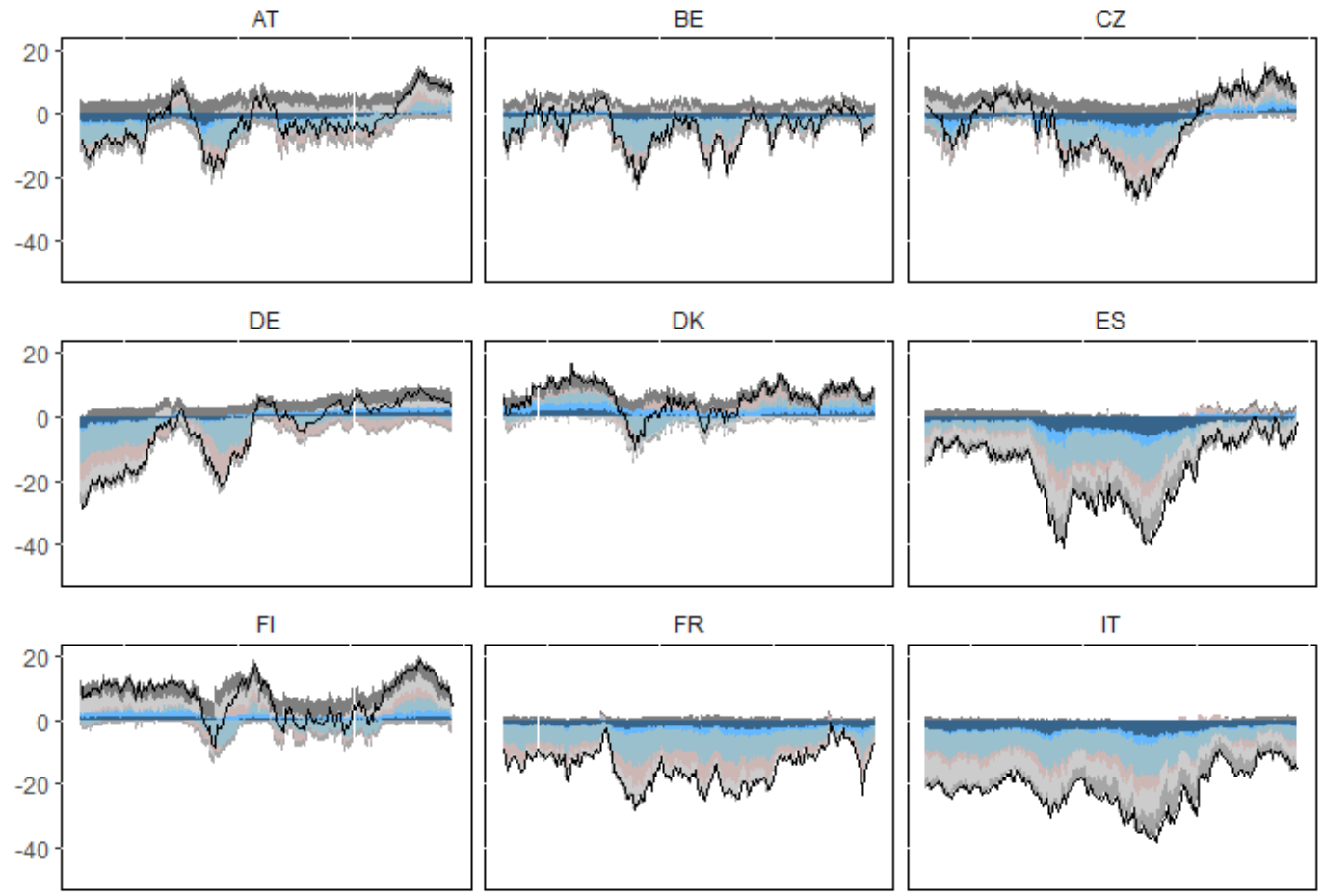

FR

IT
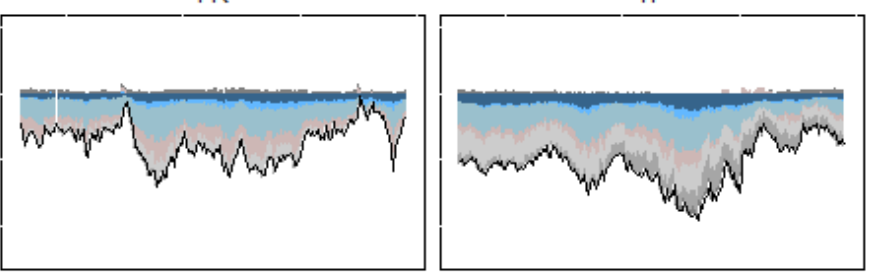

NL

PL
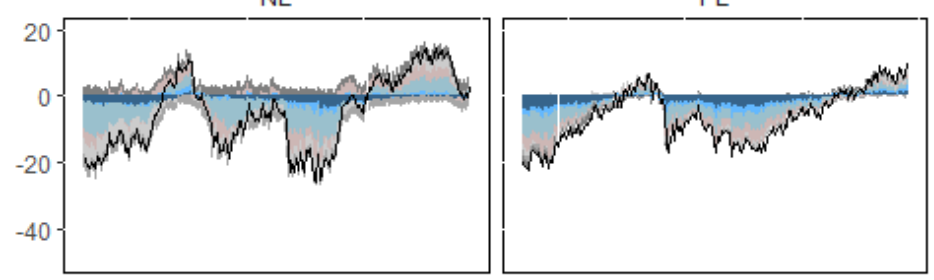

PT
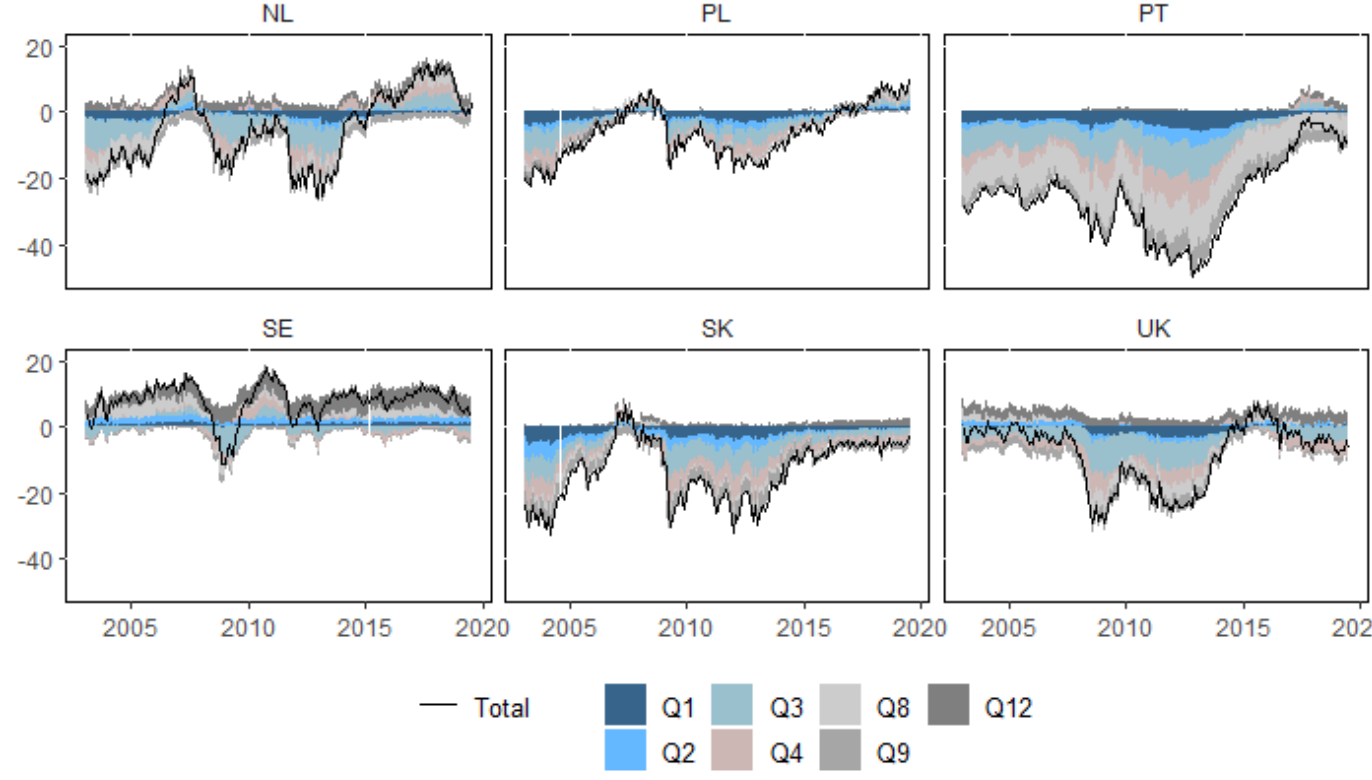

UK

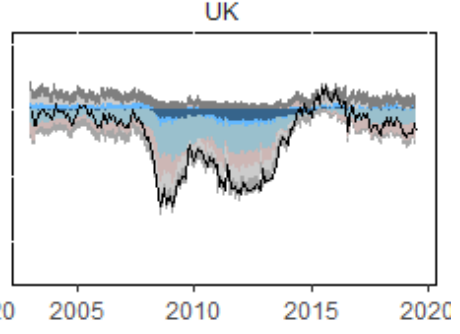

Q12

Note: The total sentiment index is calculated as the simple arithmetic average of the balances for the selected questions. In order to visualize the contributions of the individual questions to the total sentiment index, each question balance was divided by the questions count. 
Figure A2: Total Sentiment Index, Positive Responses Index, and Negative Responses Index
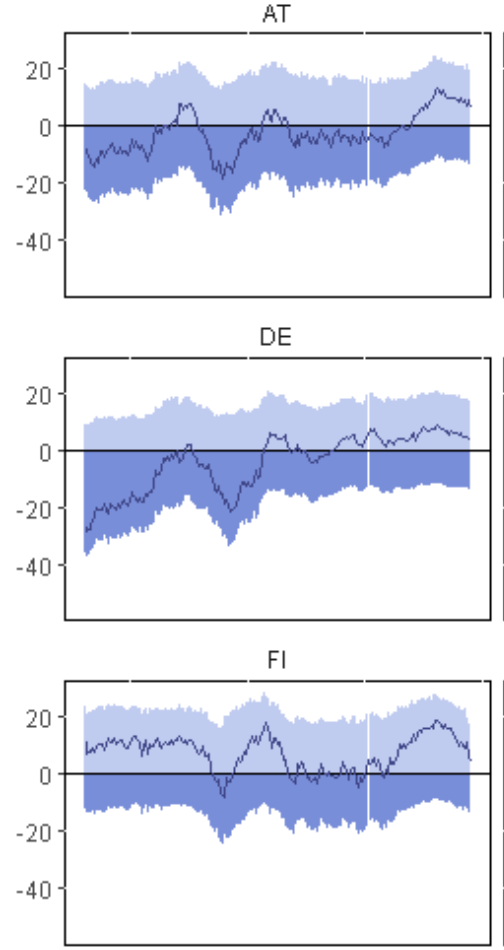

NL
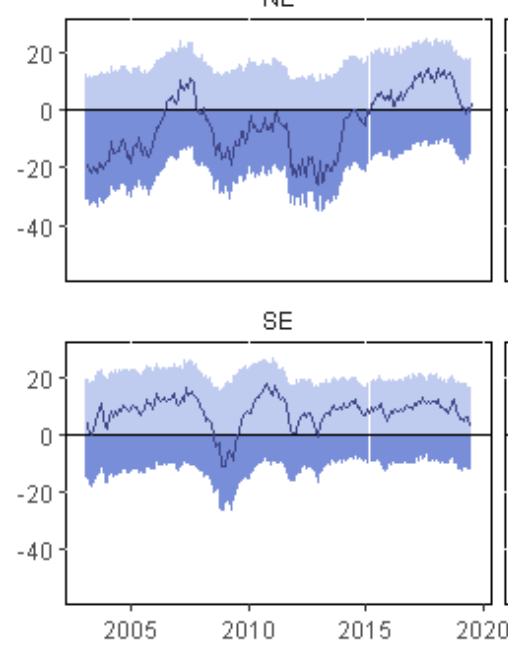

$(-1) \times$ Negative
$\mathrm{BE}$

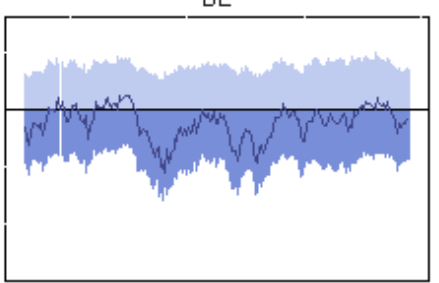

DK

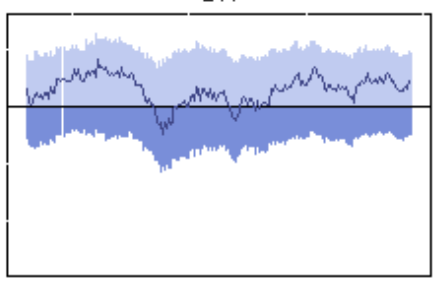

FR

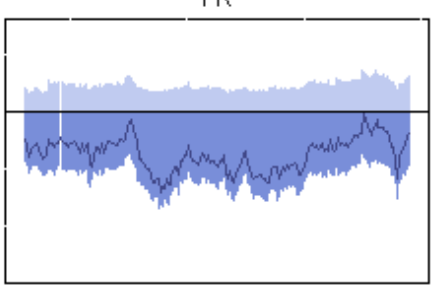

PL

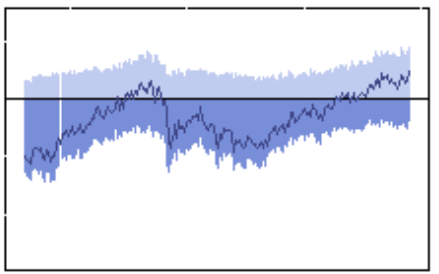

SK

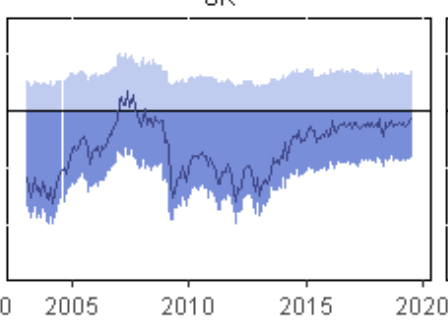

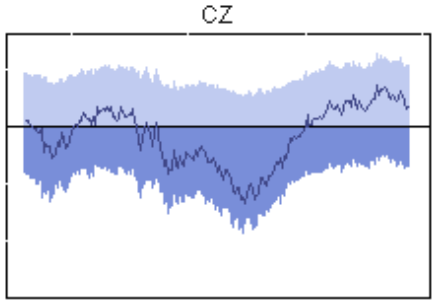

ES

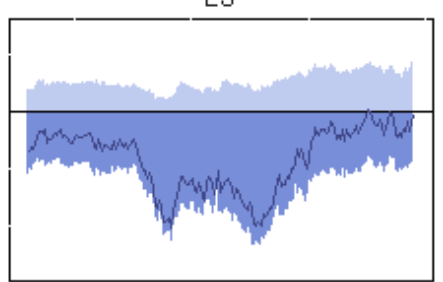

IT

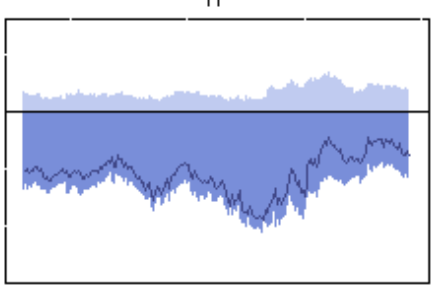

PT

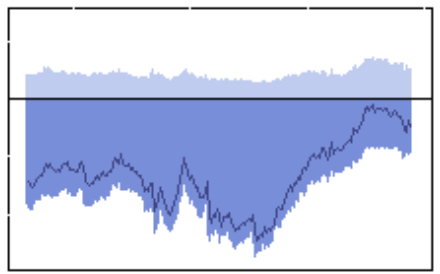

UK

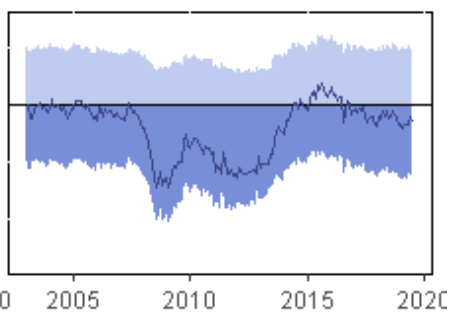

— Total (Positive - Negative)

Note: The total sentiment index represents the simple arithmetic average of the balances for the selected questions. The positive (negative) responses index represents the simple arithmetic average of the balances for the selected questions that take into account positive (negative) answers only. 


\section{Appendix B: Decomposition of Total Sentiment}

\section{Table B1: Constituents of Modified HOME Index}

\begin{tabular}{|c|c|c|c|c|c|}
\hline ID & Description & $\overline{\text { SA }^{\mathrm{a}}}$ & Freq. & Transf. $^{b}$ & Source \\
\hline 1 & Industrial production index $(2015=100)$ & $\bar{Y}$ & $\overline{\mathrm{M}}$ & YoY $\Delta(\%)$ & Eurostat \\
\hline 2 & $\begin{array}{l}\text { Retail trade; index of turnover - total, except motor vehicles } \\
\text { and motorcycles }(2015=100)\end{array}$ & Y & M & YoY $\Delta(\%)$ & Eurostat \\
\hline 3 & $\begin{array}{l}\text { Gross disposable income; households and non-profit } \\
\text { institutions serving households; current prices; national } \\
\text { currency; millions }\end{array}$ & $\mathrm{Y}$ & Q & $\begin{array}{l}\text { CSI \& YoY } \\
\Delta(\%)\end{array}$ & $\begin{array}{l}\text { Eurostat, } \\
\text { Datacube (SK) }\end{array}$ \\
\hline 4 & $\begin{array}{l}\text { Gross savings; households and non-profit institutions serving } \\
\text { households; current prices; national currency; millions }\end{array}$ & $\mathrm{Y}$ & Q & $\begin{array}{l}\text { CSI \& YoY } \\
\Delta(\%)\end{array}$ & $\begin{array}{l}\text { Eurostat, } \\
\text { Datacube (SK) }\end{array}$ \\
\hline 5 & $\begin{array}{l}\text { Compensation of employees; households, non-profit } \\
\text { institutions serving households; national currency; millions }\end{array}$ & Y & Q & $\begin{array}{l}\text { CSI \& YoY } \\
\Delta(\%)\end{array}$ & $\begin{array}{l}\text { Eurostat, } \\
\text { Datacube (SK) }\end{array}$ \\
\hline 6 & $\begin{array}{l}\text { Total employment (resident population concept - LFS); from } \\
15 \text { to } 64 \text { years; thousand persons }\end{array}$ & Y & Q & $\begin{array}{l}\text { CSI \& YoY } \\
\Delta(\%)\end{array}$ & Eurostat \\
\hline 7 & $\begin{array}{l}\text { Bank interest rate (per annum) on loans to households for } \\
\text { consumption (excluding revolving loans and overdrafts, } \\
\text { convenience and extended credit card debt); new business; in \% }\end{array}$ & $\mathrm{N}$ & M & $x_{1}, y_{1}$ & $\begin{array}{l}\text { ECB, national } \\
\text { central bank } \\
(\mathrm{UK}, \mathrm{SE}, \mathrm{PL} \\
\mathrm{CZ})\end{array}$ \\
\hline 8 & $\begin{array}{l}\text { Bank interest rate (per annum) on loans to households for } \\
\text { house purchase (excluding revolving loans and overdrafts, } \\
\text { convenience and extended credit card debt); new business; in \% }\end{array}$ & $\mathrm{N}$ & M & - & $\begin{array}{l}\text { ECB, national } \\
\text { central bank } \\
\text { (UK, SE, PL, } \\
\text { CZ) }\end{array}$ \\
\hline 9 & Residential property prices; nominal $(2015=100)$ & $\mathrm{N}$ & Q & $\begin{array}{l}\text { CSI \& YoY } \\
\Delta(\%)\end{array}$ & $\begin{array}{l}\text { BIS, ECB (PL, } \\
\text { PT) }\end{array}$ \\
\hline 10 & Share price index $(2015=100)$ & $\mathrm{Y}$ & $\mathrm{M}$ & YoY $\Delta(\%)$ & OECD \\
\hline 11 & $\begin{array}{l}\text { BIS effective exchange rate; nominal; broad basket }(2015= \\
100)\end{array}$ & $\mathrm{N}$ & M & YoY $\Delta(\%)$ & BIS \\
\hline 12 & $\begin{array}{l}\text { Terms of trade (export to import prices); exports and imports } \\
\text { of goods and services; in } \%\end{array}$ & $\mathrm{Y}$ & Q & $\begin{array}{l}\text { CSI \& YoY } \\
\Delta(\%)\end{array}$ & OECD \\
\hline
\end{tabular}

${ }^{a}$ SA - seasonal adjustment

${ }^{\mathrm{b}}$ YoY $\Delta(\%)$ - year-on-year changes in $\%$; CSI - conversion of the quarterly data to monthly data using cubic spline interpolation

Figure B1: Modified HOME Index - Growth Version (Hodula et al., 2021)

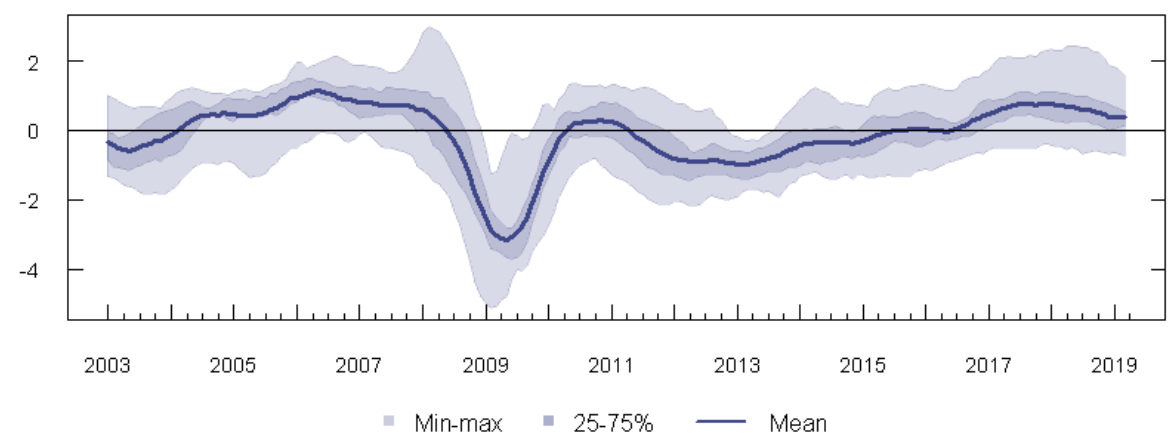

Note: For each country, the modified HOME index is standardized using its sample mean and standard deviation; the vertical axis shows the standard deviations. 
Figure B2: Total, Rational and Irrational Sentiment - Individual Countries

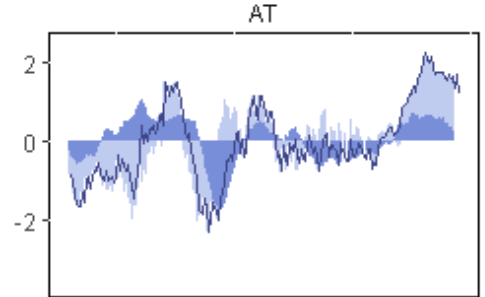

DE

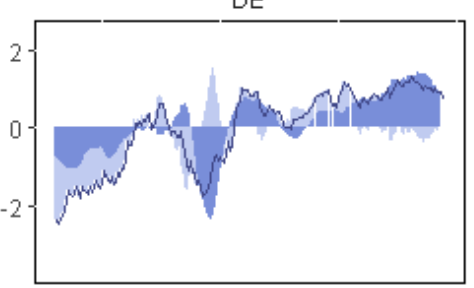

$\mathrm{FI}$

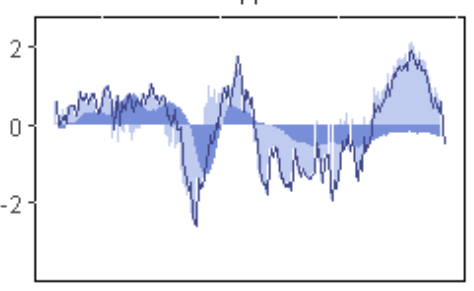

NL

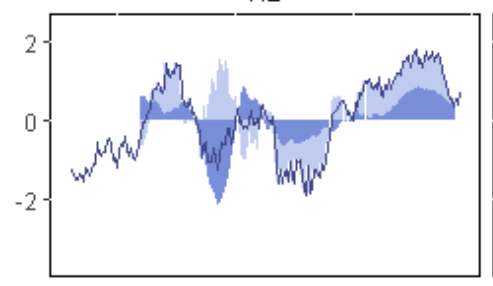

SE

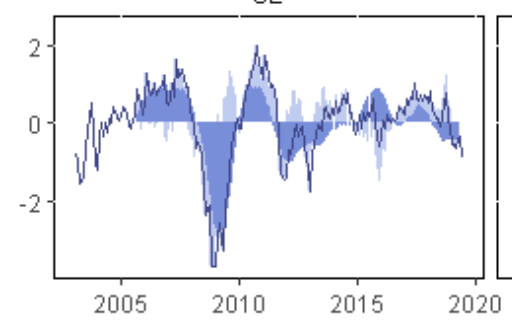

$\mathrm{BE}$

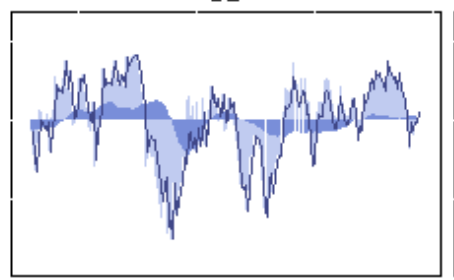

DK

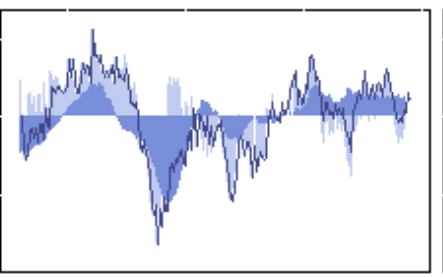

FR

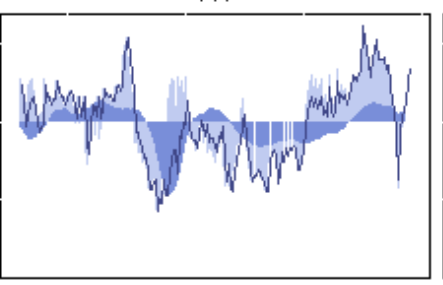

PL

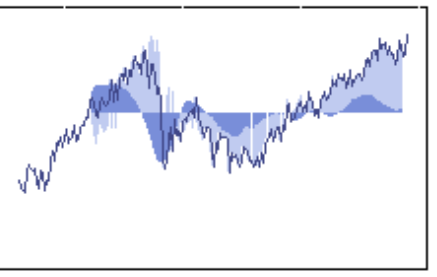

SK

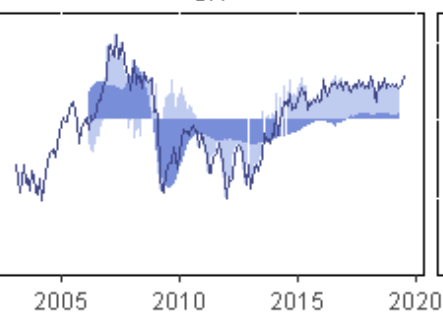

$\mathrm{CZ}$

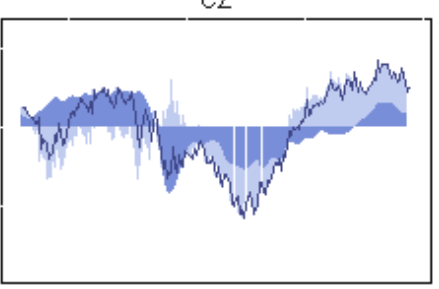

ES

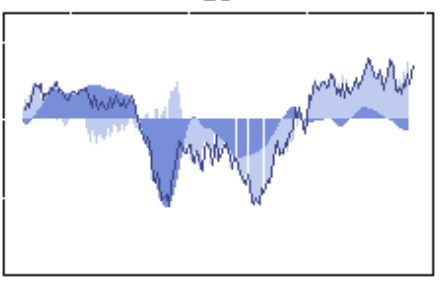

IT

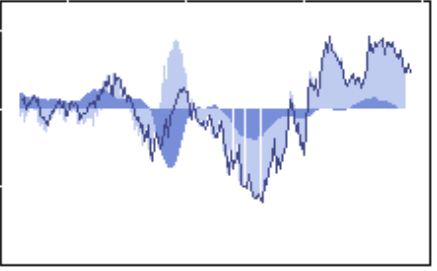

PT

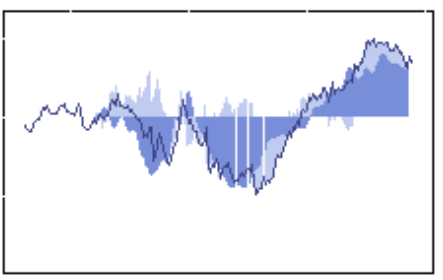

UK

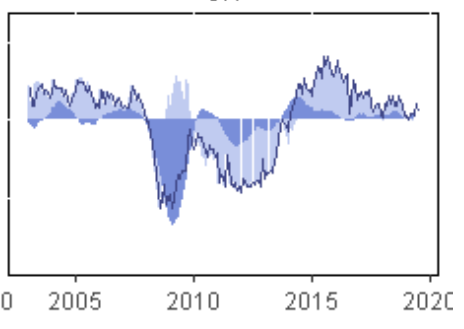

Rational Irrational - Total (z-score)

Note: The total sentiment index is standardized using its sample mean and standard deviation. The rational and irrational parts of the total sentiment index come from the cleaning procedure as described in Section 3.2. 


\section{Appendix C: Data}

\section{C.1 Good, Bad, and Normal Times}

Table C1: Output Gap - Summary Statistics \& Frequency of Good, Normal, and Bad Times under Different Rules

\begin{tabular}{|c|c|c|c|c|c|c|c|c|c|c|c|}
\hline \multirow[b]{2}{*}{ Sample } & \multirow[b]{2}{*}{ Min } & \multirow[b]{2}{*}{ Max } & \multirow[b]{2}{*}{ Mean } & \multirow[b]{2}{*}{ SD } & \multirow[b]{2}{*}{ Obs } & \multicolumn{3}{|c|}{ Rule $=0.5 S D$} & \multicolumn{3}{|c|}{ Rule $=1 S D$} \\
\hline & & & & & & $\begin{array}{c}\text { Good } \\
\text { Times } \\
(\% \text { Obs })\end{array}$ & $\begin{array}{c}\text { Normal } \\
\text { Times } \\
(\% \text { Obs })\end{array}$ & $\begin{array}{c}\text { Bad } \\
\text { Times } \\
(\% \text { Obs })\end{array}$ & $\begin{array}{c}\text { Good } \\
\text { Times } \\
(\% \text { Obs })\end{array}$ & $\begin{array}{c}\text { Normal } \\
\text { Times } \\
(\% \text { Obs })\end{array}$ & $\begin{array}{c}\text { Bad } \\
\text { Times } \\
\text { (\% Obs) }\end{array}$ \\
\hline Total & -5.7 & 7.64 & -0.09 & 1.67 & 2745 & 23 & 50 & 27 & 14 & 74 & 12 \\
\hline AT & -2.72 & 4.66 & -0.09 & 1.37 & 195 & 23 & 49 & 28 & 12 & 72 & 16 \\
\hline $\mathrm{BE}$ & -3.28 & 2.84 & -0.05 & 1.19 & 195 & 19 & 61 & 20 & 12 & 74 & 13 \\
\hline $\mathrm{CZ}$ & -3.96 & 6.02 & -0.13 & 2.03 & 195 & 19 & 49 & 32 & 13 & 74 & 13 \\
\hline $\mathrm{DE}$ & -4.35 & 3.69 & -0.08 & 1.52 & 195 & 21 & 57 & 22 & 12 & 74 & 14 \\
\hline DK & -4.61 & 4.02 & -0.1 & 1.6 & 195 & 22 & 54 & 25 & 11 & 76 & 13 \\
\hline ES & -3.22 & 4.99 & -0.04 & 1.89 & 195 & 25 & 41 & 34 & 13 & 70 & 17 \\
\hline FI & -4.81 & 6.04 & -0.14 & 2.13 & 195 & 18 & 52 & 30 & 12 & 79 & 9 \\
\hline FR & -2.79 & 3.46 & -0.05 & 1.18 & 195 & 15 & 55 & 29 & 12 & 78 & 10 \\
\hline IT & -2.68 & 3.57 & 0.00 & 1.31 & 195 & 27 & 39 & 34 & 17 & 73 & 10 \\
\hline NL & -2.59 & 4.38 & -0.14 & 1.52 & 159 & 23 & 57 & 19 & 15 & 79 & 6 \\
\hline PL & -3.83 & 3.32 & -0.30 & 1.57 & 157 & 30 & 50 & 20 & 20 & 71 & 9 \\
\hline $\mathrm{PT}$ & -3.73 & 3.49 & -0.12 & 1.68 & 159 & 43 & 30 & 27 & 23 & 64 & 13 \\
\hline SE & -3.55 & 3.96 & -0.05 & 1.57 & 163 & 28 & 43 & 29 & 21 & 63 & 17 \\
\hline SK & -5.7 & 7.64 & -0.04 & 2.54 & 157 & 22 & 58 & 20 & 13 & 80 & 7 \\
\hline UK & -2.79 & 4.43 & 0.03 & 1.35 & 195 & 22 & 50 & 29 & 11 & 80 & 9 \\
\hline
\end{tabular}

Note: Under the rule $=0.5$ SD (1 SD), Good Times, Bad Times, and Normal Times are represented by those observations for which the output gap is 0.5 standard deviation ( 1 standard deviation) above, below, and around its mean, respectively. 
Figure C1: Irrational Sentiment Conditional on Output Gap Values (Good Times, Bad Times, and Normal Times) - Individual Countries
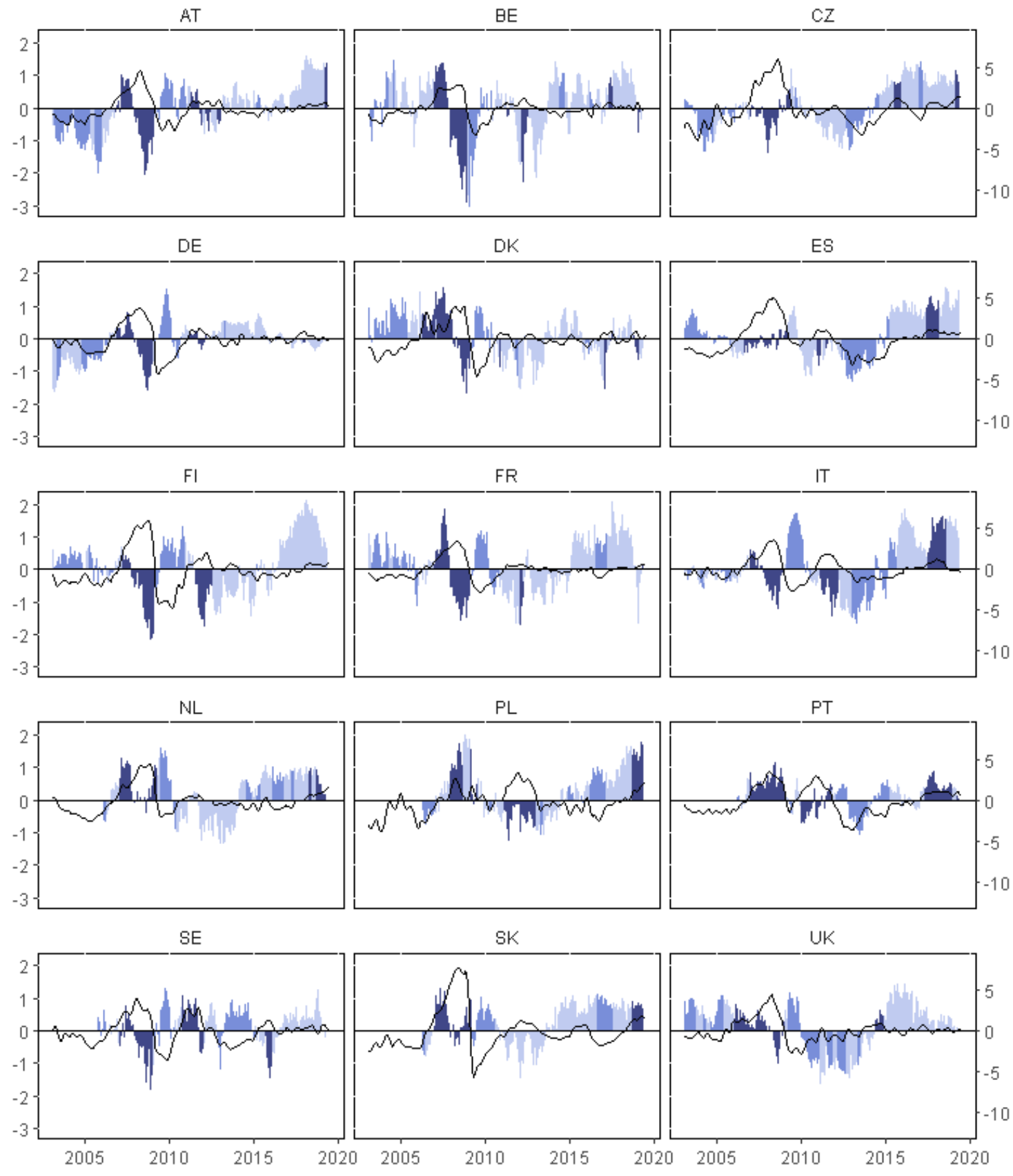

ir. sent $\times$ GoodTimes (lhs)

ir. sent $x$ BadTimes (lhs)

- Output gap (rhs)

ir.sent $x$ NormalTimes (lhs)

Note: The figure shows the values of irrational sentiment in good times, bad times, and normal times, these periods being defined as periods in which the GDP gap for the given country is 0.5 standard deviation above, below, and around its mean, respectively. The value of the GDP gap that corresponds to the underlying periods is plotted on the right-hand scale. 


\section{C.2 Summary Statistics}

Table C2: Summary Statistics and Data Sources

\begin{tabular}{|c|c|c|c|c|c|c|c|}
\hline & $\mathbf{N}$ & Mean & St. Dev. & Min & Max & $\begin{array}{l}\text { Type of } \\
\text { control var. }\end{array}$ & Source \\
\hline \multicolumn{8}{|l|}{ Dependent variable } \\
\hline$\Delta \ln ($ Consumer Loans $)$ & 2,502 & 0.028 & 0.192 & -1.070 & 0.993 & - & $\begin{array}{l}\text { ECB, NCBs (CZ, } \\
\text { NL, SK) }\end{array}$ \\
\hline \multicolumn{8}{|l|}{ Sentiment } \\
\hline Sentiment & 2,925 & 0.000 & 0.998 & -3.663 & 2.436 & - & \multirow{5}{*}{ DG ECFIN } \\
\hline RSentiment & 2,745 & -0.065 & 0.661 & -2.797 & 1.614 & - & \\
\hline IrSentiment & 2,745 & 0.092 & 0.747 & -3.055 & 2.121 & - & \\
\hline IrOptimism & 2,745 & 0.060 & 0.843 & -2.606 & 3.102 & - & \\
\hline IrPessimism & 2,745 & -0.099 & 0.734 & -1.952 & 3.161 & - & \\
\hline \multicolumn{8}{|l|}{ Control Variables } \\
\hline$\Delta$ Industrial prod. & 2,925 & 1.448 & 6.108 & -25.816 & 38.316 & Baseline & Eurostat \\
\hline$\triangle C P I$ inflation & 2,925 & 1.795 & 1.365 & -1.787 & 9.516 & Baseline & Eurostat \\
\hline Short-term rate & 2,925 & 1.600 & 1.723 & -0.610 & 7.120 & Baseline & Eurostat \\
\hline$\Delta$ Retail trade & 2,853 & 2.481 & 3.603 & -13.372 & 21.719 & Add. Macro & Eurostat \\
\hline Term spread & 2,925 & 1.476 & 1.383 & -2.023 & 12.629 & Add. Macro & OECD, Eurostat \\
\hline Capital to Assets & 2,877 & 8.011 & 3.007 & 3.374 & 15.891 & Bank & \multirow{4}{*}{$\begin{array}{l}\text { ECB } \\
\text { IMF (FSI), FRED, } \\
\text { Bloomberg } \\
\text { Eurostat } \\
\text { Eurostat, Datacube } \\
\text { (SK) }\end{array}$} \\
\hline NPL to Loans & 2,919 & 3.939 & 3.586 & 0.065 & 21.521 & Bank & \\
\hline$\Delta$ Unemployment rate & 2,925 & 8.432 & 4.011 & 1.900 & 26.300 & Demand-side & \\
\hline$\Delta$ Disp. income & 2,925 & 3.239 & 2.672 & -6.159 & 14.784 & Demand-side & \\
\hline \multicolumn{8}{|c|}{ Other Auxiliary Variables } \\
\hline HOME index & 2,745 & -0.126 & 1.173 & -5.142 & 2.992 & - & see Table B1 \\
\hline GDP gap & 2,925 & -0.088 & 1.668 & -5.698 & 7.640 & - & \multirow{4}{*}{$\begin{array}{l}\text { GDP data from } \\
\text { Eurostat (see also } \\
\text { Table C1) }\end{array}$} \\
\hline GoodTimes dummy & 2,910 & 0.221 & 0.415 & 0.000 & 1.000 & - & \\
\hline NormalTimes dummy & 2,910 & 0.486 & 0.500 & 0.000 & 1.000 & - & \\
\hline BadTimes dummy & 2,910 & 0.293 & 0.455 & 0.000 & 1.000 & - & \\
\hline
\end{tabular}

Note: $\Delta$ represents the year-on-year change. The mean of irrational sentiment (IrSentiment, IrOptimism, or IrPessimism) is not equal to zero because Equation (1) is estimated as a linear regression without an intercept. The specification was selected because both the dependent and explanatory variables are standardized to have zero mean and unit variance. Nevertheless, an intercept set to zero means that the linear fit of the data does not necessarily yield a zero mean of the residuals. Second, the mean of GDP gap is not zero because this series was filtered using a different time window (January 1995-June 2019). We employ a longer observation period for filtering the national GDP data because we assume that a longer time span of data yields improved performance of the filter. 
Table C3: Weights - Shares of Adult Population Who Borrowed from Financial Institutions

\begin{tabular}{lcccc|lcccc}
\hline \hline Country & $\begin{array}{c}\mathbf{2 0 1 1} \\
\text { (in \%) }\end{array}$ & $\begin{array}{c}\mathbf{2 0 1 4} \\
\text { (in \%) }\end{array}$ & $\begin{array}{c}\mathbf{2 0 1 7} \\
\text { (in \%) }\end{array}$ & $\begin{array}{c}\text { Mean } \\
\text { (in \%) }\end{array}$ & Country & $\begin{array}{c}\mathbf{2 0 1 1} \\
\text { (in \%) }\end{array}$ & $\begin{array}{c}\mathbf{2 0 1 4} \\
\text { (in \%) }\end{array}$ & $\begin{array}{c}\mathbf{2 0 1 7} \\
\text { (in \%) }\end{array}$ & $\begin{array}{c}\text { Mean } \\
\text { (in \%) }\end{array}$ \\
\hline SE & 23.40 & 27.71 & 21.49 & 24.20 & ES & 11.43 & 18.01 & 18.35 & 15.93 \\
FI & 23.88 & 21.58 & 20.10 & 21.85 & BE & 10.51 & 15.76 & 15.85 & 14.04 \\
DK & 18.80 & 21.63 & 20.60 & 20.34 & CZ & 9.47 & 13.02 & 14.92 & 12.47 \\
FR & 18.65 & 15.11 & 18.32 & 17.36 & NL & 12.56 & 12.59 & 12.13 & 12.43 \\
PL & 9.61 & 18.86 & 23.38 & 17.28 & AT & 8.25 & 13.3 & 14.15 & 11.90 \\
DE & 12.55 & 18.61 & 19.58 & 16.91 & IT & 4.59 & 13.46 & 16.22 & 11.42 \\
UK & 11.85 & 21.12 & 17.55 & 16.84 & PT & 8.26 & 9.48 & 8.93 & 8.89 \\
SK & 11.43 & 17.70 & 19.53 & 16.22 & & & & & \\
\hline \hline
\end{tabular}

Note: The table lists the values of the variable Borrowed from a financial institution (\% age 15+) reported in the Global Findex Database for all three waves of surveys - 2011, 2014, and 2017. The countries are sorted based on Mean. The value of Mean was used to determine the weights in all the weighted fixed-effects regressions. Source: World Bank. 


\section{Appendix D: Additional Results}

Table D1: Effects of Irrational Sentiment During Five Phases of Economic Cycle

\begin{tabular}{|c|c|c|c|c|c|}
\hline & \multicolumn{5}{|c|}{ Dependent variable: $\Delta \ln \left(\right.$ Consumer Loans $\left.{ }_{t}\right)$} \\
\hline & $(1)$ & $(2)$ & $(3)$ & $(4)$ & $(5)$ \\
\hline RSentiment $_{t-1} \times \uparrow$ GoodTimes $_{t-1}$ & $\begin{array}{c}\mathbf{0 . 0 7 8} \\
{[0.012]}\end{array}$ & & & & \\
\hline RSentiment $_{t-1} \times \downarrow$ GoodTimes $_{t-1}$ & $\begin{array}{c}\mathbf{0 . 1 2 6} \\
{[0.026]}\end{array}$ & & & & \\
\hline RSentiment $_{t-1} \times$ NormalTimes $_{t-1}$ & $\begin{array}{c}\mathbf{0 . 0 8 9} \\
{[0.007]}\end{array}$ & & & & \\
\hline RSentiment $_{t-1} \times \uparrow$ BadTimes $_{t-1}$ & $\begin{array}{c}0.054 \\
{[0.182]}\end{array}$ & & & & \\
\hline RSentiment $_{t-1} \times \downarrow$ BadTimes $_{t-1}$ & $\begin{array}{c}\mathbf{0 . 1 0 6} \\
{[0.000]}\end{array}$ & & & & \\
\hline IrSentiment $_{t-1} \times \uparrow$ GoodTimes $_{t-1}$ & $\begin{array}{c}\mathbf{0 . 0 5 4} \\
{[0.043]}\end{array}$ & $\begin{array}{c}\mathbf{0 . 0 4 6} \\
{[0.100]}\end{array}$ & $\begin{array}{c}\mathbf{0 . 0 4 3} \\
{[0.071]}\end{array}$ & $\begin{array}{c}\mathbf{0 . 0 4 4} \\
{[0.057]}\end{array}$ & $\begin{array}{c}\mathbf{0 . 0 4 1} \\
{[0.063]}\end{array}$ \\
\hline IrSentiment $_{t-1} \times \downarrow$ GoodTimes $_{t-1}$ & $\begin{array}{c}\mathbf{0 . 0 6 1} \\
{[0.033]}\end{array}$ & $\begin{array}{c}\mathbf{0 . 0 4 5} \\
{[0.031]}\end{array}$ & $\begin{array}{c}\mathbf{0 . 0 4 9} \\
{[0.030]}\end{array}$ & $\begin{array}{c}\mathbf{0 . 0 5 5} \\
{[0.014]}\end{array}$ & $\begin{array}{c}\mathbf{0 . 0 5 3} \\
{[0.022]}\end{array}$ \\
\hline IrSentiment $_{t-1} \times$ NormalTimes $_{t-1}$ & $\begin{array}{c}\mathbf{0 . 0 4 5} \\
{[0.005]}\end{array}$ & $\begin{array}{c}\mathbf{0 . 0 3 6} \\
{[0.021]}\end{array}$ & $\begin{array}{c}0.017 \\
{[0.222]}\end{array}$ & $\begin{array}{c}0.018 \\
{[0.187]}\end{array}$ & $\begin{array}{c}0.016 \\
{[0.228]}\end{array}$ \\
\hline IrSentiment $_{t-1} \times \uparrow$ BadTimes $_{t-1}$ & $\begin{array}{l}-0.011 \\
{[0.443]}\end{array}$ & $\begin{array}{l}-0.011 \\
{[0.611]}\end{array}$ & $\begin{array}{c}-0.006 \\
{[0.724]}\end{array}$ & $\begin{array}{l}-0.000 \\
{[0.994]}\end{array}$ & $\begin{array}{c}0.001 \\
{[0.988]}\end{array}$ \\
\hline IrSentiment $_{t-1} \times \downarrow$ BadTimes $_{t-1}$ & $\begin{array}{l}-0.005 \\
{[0.795]}\end{array}$ & $\begin{array}{l}-0.021 \\
{[0.393]}\end{array}$ & $\begin{array}{l}-0.027 \\
{[0.194]}\end{array}$ & $\begin{array}{l}-0.022 \\
{[0.291]}\end{array}$ & $\begin{array}{l}-0.023 \\
{[0.325]}\end{array}$ \\
\hline Baseline Macro Controls & & yes & yes & yes & yes \\
\hline Additional Macro Controls & & & yes & yes & yes \\
\hline $\begin{array}{l}\text { Bank Controls } \\
\text { Demand-side Controls }\end{array}$ & & & & yes & $\begin{array}{l}\text { yes } \\
\text { yes }\end{array}$ \\
\hline Observations & 2457 & 2457 & 2457 & 2454 & 2454 \\
\hline Adjusted $\mathrm{R}^{2}$ & 0.178 & 0.135 & 0.188 & 0.191 & 0.194 \\
\hline
\end{tabular}

Note: $p$-values (in brackets) are estimated using the wild cluster bootstrap resampling method developed by Cameron et al. (2008). $\uparrow$ GoodTimes and $\downarrow$ GoodTimes Goo $_{t-1}$ ( $\uparrow$ BadTimes and $\downarrow$ BadTimes Ba $_{t-1}$ ) denote dummy variables that are equal to 1 if the GDP gap for the given country in the given month $t$ is 0.5 standard deviation above (below) its mean and at the same time its value increased $(\uparrow)$ or decreased $(\downarrow)$ compared to the value in the previous quarter $(t-3)$, and 0 otherwise. NormalTimes denotes a dummy variable which is equal to 1 if the GDP gap for the given country in the given month $t$ is 0.5 standard deviation around its mean, and 0 otherwise. Baseline Macro Controls include: $\Delta$ Industrial prod $_{t-1}, \Delta \mathrm{CPI}_{\text {inflation }_{t-1}}$, Short-term rate ${ }_{t-1}$; Additional Macro Controls include: $\Delta$ Retail trade $_{t-1}$ and Term spread $t_{t-1}$; Bank Controls include: Capital to Assets B $_{t-1}$, NPL to Loans L $_{t-1}$; and Demand-side Controls include: Unemployment rate $t_{t-1}, \Delta$ Disp. income ${ }_{t-1}$. Estimates in bold determine significance up to the $10 \%$ level. The table lists estimates based on panel data regression with country fixed effects and clusters, weighted by the financial inclusion proxy. 
Table D2: Weighted Baseline Regression with One Standard Deviation Threshold for Defining Good Times, Bad Times, and Normal Times

\begin{tabular}{|c|c|c|c|c|c|}
\hline & \multicolumn{5}{|c|}{ Dependent variable: $\Delta \ln \left(\right.$ Consumer Loans $\left.{ }_{t}\right)$} \\
\hline & (1) & $(2)$ & (3) & (4) & (5) \\
\hline RSentiment $_{t-1} \times$ GoodTimes $_{t-1}$ & $\begin{array}{c}\mathbf{0 . 0 8 1} \\
{[0.043]}\end{array}$ & & & & \\
\hline RSentiment $_{t-1} \times$ NormalTimes $_{t-1}$ & $\begin{array}{c}\mathbf{0 . 1 0 0} \\
{[0.001]}\end{array}$ & & & & \\
\hline RSentiment $_{t-1} \times$ BadTimes $_{t-1}$ & $\begin{array}{c}\mathbf{0 . 0 8 2} \\
{[0.020]}\end{array}$ & & & & \\
\hline IrSentiment $_{t-1} \times$ GoodTimes $_{t-1}$ & $\begin{array}{c}\mathbf{0 . 0 5 7} \\
{[0.021]}\end{array}$ & $\begin{array}{c}0.035 \\
{[0.136]}\end{array}$ & $\begin{array}{c}\mathbf{0 . 0 4 1} \\
{[0.072]}\end{array}$ & $\begin{array}{c}\mathbf{0 . 0 4 7} \\
{[0.023]}\end{array}$ & $\begin{array}{c}\mathbf{0 . 0 4 4} \\
{[0.031]}\end{array}$ \\
\hline IrSentiment $_{t-1} \times$ NormalTimes $_{t-1}$ & $\begin{array}{c}\mathbf{0 . 0 4 3} \\
{[0.007]}\end{array}$ & $\begin{array}{c}\mathbf{0 . 0 3 7} \\
{[0.024]}\end{array}$ & $\begin{array}{c}0.020 \\
{[0.172]}\end{array}$ & $\begin{array}{c}0.021 \\
{[0.108]}\end{array}$ & $\begin{array}{c}0.019 \\
{[0.131]}\end{array}$ \\
\hline IrSentiment $_{t-1} \times$ BadTimes $_{t-1}$ & $\begin{array}{l}-0.024 \\
{[0.337]}\end{array}$ & $\begin{array}{l}-0.037 \\
{[0.241]}\end{array}$ & $\begin{array}{c}-0.031 \\
{[0.291]}\end{array}$ & $\begin{array}{l}-0.024 \\
{[0.421]}\end{array}$ & $\begin{array}{l}-0.023 \\
{[0.486]}\end{array}$ \\
\hline Baseline Macro Controls & & yes & yes & yes & yes \\
\hline Additional Macro Controls & & & yes & yes & yes \\
\hline Bank Controls & & & & yes & yes \\
\hline Demand-side Controls & & & & & yes \\
\hline Observations & 2,457 & 2,457 & 2,457 & 2,454 & 2,454 \\
\hline Adjusted $\mathrm{R}^{2}$ & 0.173 & 0.135 & 0.186 & 0.189 & 0.192 \\
\hline
\end{tabular}

Note: $p$-values (in brackets) are estimated using the wild cluster bootstrap resampling method developed by Cameron et al. (2008). GoodTimes, BadTimes, and NormalTimes denote dummy variables that are equal to 1 if the GDP gap for the given country in the given month $t$ is one standard deviation above, below, and around its mean, respectively, and 0 otherwise. Estimates in bold determine significance up to the $10 \%$ level. The table lists estimates based on panel data regression with country fixed effects and clusters, weighted by the financial inclusion proxy. See also the notes to Table D1 for additional information regarding the control variables. 
Table D3: Unweighted Baseline Regression

\begin{tabular}{|c|c|c|c|c|c|}
\hline & \multicolumn{5}{|c|}{ Dependent variable: $\Delta \ln \left(\right.$ Consumer Loans $\left.s_{t}\right)$} \\
\hline & $(1)$ & $(2)$ & (3) & (4) & (5) \\
\hline Sentiment $_{t-1} \times$ GoodTimes $_{t-1}$ & $\begin{array}{c}\mathbf{0 . 0 9 9} \\
{[0.007]}\end{array}$ & & & & \\
\hline Sentiment $_{t-1} \times$ NormalTimes $_{t-1}$ & $\begin{array}{c}\mathbf{0 . 0 9 7} \\
{[0.010]}\end{array}$ & & & & \\
\hline Sentiment $_{t-1} \times$ BadTimes $_{t-1}$ & $\begin{array}{c}\mathbf{0 . 0 9 7} \\
{[0.004]}\end{array}$ & & & & \\
\hline IrSentiment $_{t-1} \times$ GoodTimes $_{t-1}$ & $\begin{array}{c}\mathbf{0 . 0 6 1} \\
{[0.008]}\end{array}$ & $\begin{array}{c}\mathbf{0 . 0 4 9} \\
{[0.035]}\end{array}$ & $\begin{array}{c}\mathbf{0 . 0 4 4} \\
{[0.052]}\end{array}$ & $\begin{array}{c}\mathbf{0 . 0 4 7} \\
{[0.038]}\end{array}$ & $\begin{array}{c}\mathbf{0 . 0 4 5} \\
{[0.043]}\end{array}$ \\
\hline IrSentiment $_{t-1} \times$ NormalTimes $_{t-1}$ & $\begin{array}{c}\mathbf{0 . 0 4 6} \\
{[0.016]}\end{array}$ & $\begin{array}{c}\mathbf{0 . 0 3 8} \\
{[0.010]}\end{array}$ & $\begin{array}{c}0.016 \\
{[0.236]}\end{array}$ & $\begin{array}{l}0.018 \\
{[0.165]}\end{array}$ & $\begin{array}{l}0.016 \\
{[0.222]}\end{array}$ \\
\hline IrSentiment $_{t-1} \times$ BadTimes $_{t-1}$ & $\begin{array}{c}-0.002 \\
{[0.912]}\end{array}$ & $\begin{array}{l}-0.015 \\
{[0.478]}\end{array}$ & $\begin{array}{l}-0.021 \\
{[0.299]}\end{array}$ & $\begin{array}{l}-0.016 \\
{[0.437]}\end{array}$ & $\begin{array}{l}-0.014 \\
{[0.556]}\end{array}$ \\
\hline$\Delta$ Industrial prod. $_{t-1}$ & & $\begin{array}{c}\mathbf{0 . 0 0 8} \\
{[0.004]}\end{array}$ & $\begin{array}{c}\mathbf{0 . 0 0 5} \\
{[0.006]}\end{array}$ & $\begin{array}{c}\mathbf{0 . 0 0 5} \\
{[0.005]}\end{array}$ & $\begin{array}{c}\mathbf{0 . 0 0 4} \\
{[0.013]}\end{array}$ \\
\hline$\Delta$ CPI inflation ${ }_{t-1}$ & & $\begin{array}{c}-0.009 \\
{[0.318]}\end{array}$ & $\begin{array}{l}-0.007 \\
{[0.307]}\end{array}$ & $\begin{array}{l}-0.005 \\
{[0.409]}\end{array}$ & $\begin{array}{l}-0.006 \\
{[0.374]}\end{array}$ \\
\hline Short-term rate t-1 $_{t}$ & & $\begin{array}{r}-\mathbf{0 . 0 1 5} \\
{[0.033]}\end{array}$ & $\begin{array}{c}-\mathbf{0 . 0 3 1} \\
{[0.005]}\end{array}$ & $\begin{array}{l}-\mathbf{0 . 0 2 7} \\
{[0.025]}\end{array}$ & $\begin{array}{l}\mathbf{- 0 . 0 2 9} \\
{[0.010]}\end{array}$ \\
\hline$\Delta$ Retail $\operatorname{trade}_{t-1}$ & & & $\begin{array}{l}0.007 \\
{[0.212]}\end{array}$ & $\begin{array}{c}0.007 \\
{[0.189]}\end{array}$ & $\begin{array}{l}0.006 \\
{[0.281]}\end{array}$ \\
\hline Term spread $_{t-1}$ & & & $\begin{array}{l}-\mathbf{0 . 0 3 4} \\
{[0.005]}\end{array}$ & $\begin{array}{r}\mathbf{- 0 . 0 3 4} \\
{[0.011]}\end{array}$ & $\begin{array}{r}\mathbf{- 0 . 0 3 3} \\
{[0.028]}\end{array}$ \\
\hline Capital to Assets A $_{t-1}$ & & & & $\begin{array}{c}0.005 \\
{[0.603]}\end{array}$ & $\begin{array}{l}0.007 \\
{[0.476}\end{array}$ \\
\hline NPL to Loans ${ }_{t-1}$ & & & & $\begin{array}{c}0.004 \\
{[0.393]}\end{array}$ & $\begin{array}{c}0.002 \\
{[0.584]}\end{array}$ \\
\hline 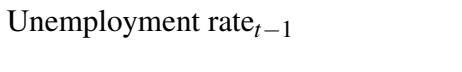 & & & & & $\begin{array}{c}0.003 \\
{[0.593]}\end{array}$ \\
\hline$\Delta$ Disp. $_{\text {income }} t-1$ & & & & & $\begin{array}{c}\mathbf{0 . 0 0 7} \\
{[0.078]}\end{array}$ \\
\hline Observations & 2,544 & 2,457 & 2,457 & 2,457 & 2,454 \\
\hline Adjusted $\mathrm{R}^{2}$ & 0.180 & 0.139 & 0.204 & 0.208 & 0.212 \\
\hline
\end{tabular}

Note: This table lists estimates based on unweighted panel data regression with country fixed effects and clusters. $p$-values (in brackets) are estimated using the wild cluster bootstrap resampling method developed by Cameron et al. (2008). GoodTimes, BadTimes, and NormalTimes denote dummy variables that are equal to 1 if the GDP gap for the given country in the given month $t$ is 0.5 standard deviation above, below, and around its mean, respectively, and 0 otherwise. Estimates in bold determine significance up to the $10 \%$ level. 
Table D4: Decomposition of Total Sentiment Using Individual Variables Instead of Composite HOME Index à la Hodula et al. (2021)

\begin{tabular}{|c|c|c|c|c|c|}
\hline & \multicolumn{5}{|c|}{ Dependent variable: $\Delta \ln \left(\right.$ Consumer Loans $\left.{ }_{t}\right)$} \\
\hline & (1) & $(2)$ & $(3)$ & (4) & (5) \\
\hline RSentiment $_{t-1} \times$ GoodTimes $_{t-1}$ & $\begin{array}{c}\mathbf{0 . 0 9 6} \\
{[0.000]}\end{array}$ & & & & \\
\hline RSentiment $_{t-1} \times$ NormalTimes $_{t-1}$ & $\begin{array}{c}\mathbf{0 . 0 7 5} \\
{[0.001]}\end{array}$ & & & & \\
\hline RSentiment $_{t-1} \times$ BadTimes $_{t-1}$ & $\begin{array}{c}\mathbf{0 . 0 7 2} \\
{[0.000]}\end{array}$ & & & & \\
\hline IrSentiment $_{t-1} \times$ GoodTimes $_{t-1}$ & $\begin{array}{l}0.024 \\
0.200\end{array}$ & $\begin{array}{c}\mathbf{0 . 0 3 9} \\
{[0.024]}\end{array}$ & $\begin{array}{c}\mathbf{0 . 0 3 9} \\
{[0.027]}\end{array}$ & $\begin{array}{c}\mathbf{0 . 0 4 0} \\
{[0.028]}\end{array}$ & $\begin{array}{c}\mathbf{0 . 0 3 8} \\
{[0.025]}\end{array}$ \\
\hline IrSentiment $_{t-1} \times$ NormalTimes $_{t-1}$ & $\begin{array}{c}\mathbf{0 . 0 3 5} \\
{[0.010]}\end{array}$ & $\begin{array}{l}0.024 \\
{[0.11}\end{array}$ & $\begin{array}{c}0.017 \\
{[0.317]}\end{array}$ & $\begin{array}{c}0.017 \\
{[0.279]}\end{array}$ & $\begin{array}{c}0.015 \\
{[0.366]}\end{array}$ \\
\hline IrSentiment $_{t-1} \times$ BadTimes $_{t-1}$ & $\begin{array}{l}-0.018 \\
{[0.427]}\end{array}$ & $\begin{array}{l}-0.025 \\
{[0.318]}\end{array}$ & $\begin{array}{c}-0.020 \\
{[0.425]}\end{array}$ & $\begin{array}{l}-0.018 \\
{[0.449]}\end{array}$ & $\begin{array}{l}-0.019 \\
{[0.424]}\end{array}$ \\
\hline Baseline Macro Controls & & yes & yes & yes & yes \\
\hline Additional Macro Controls & & & yes & yes & yes \\
\hline Bank Controls & & & & yes & yes \\
\hline Demand-side Controls & & & & & yes \\
\hline Observations & 2,457 & 2,457 & 2,457 & 2,454 & 2,454 \\
\hline Adjusted $\mathrm{R}^{2}$ & 0.167 & 0.120 & 0.180 & 0.182 & 0.186 \\
\hline
\end{tabular}

Note: Rational and irrational sentiment were obtained by cleaning the total sentiment index (z-score) using the individual macroeconomic variables (z-scores) instead of the HOME index à la Hodula et al. (2021). The list of macroeconomic variables used can be found in Table B1. Due to multicollinearity issues in the cleaning estimation we did not employ the third and eighth variables (disposable income and the interest rate on house purchase loans) from Table B1. See also the notes to Table D2 for additional information regarding the data and methodology applied in the estimation. 
Table D5: Sample Heterogeneity - Subsamples of High-Debt and Low-Debt Countries

\begin{tabular}{|c|c|c|c|c|c|}
\hline & \multicolumn{5}{|c|}{ Dependent variable: $\Delta \ln \left(\right.$ Consumer Loans $\left.{ }_{t}\right)$} \\
\hline & $(1)$ & $(2)$ & (3) & $(4)$ & $(5)$ \\
\hline & \multicolumn{5}{|c|}{ High-Debt Countries } \\
\hline RSentiment $_{t-1} \times$ GoodTimes $_{t-1}$ & $\begin{array}{c}\mathbf{0 . 1 1 4} \\
{[0.000]}\end{array}$ & & & & \\
\hline \multirow[t]{2}{*}{ RSentiment $_{t-1} \times$ NormalTimes $_{t-1}$} & 0.136 & & & & \\
\hline & {$[0.000]$} & & & & \\
\hline \multirow{2}{*}{ RSentiment $_{t-1} \times$ BadTimes $_{t-1}$} & 0.103 & & & & \\
\hline & [0.031] & & & & \\
\hline \multirow[t]{2}{*}{ IrSentiment $_{t-1} \times$ GoodTimes $_{t-1}$} & 0.054 & 0.057 & 0.052 & 0.048 & 0.043 \\
\hline & [0.125] & [0.125] & [0.031] & [0.063] & [0.219] \\
\hline \multirow{2}{*}{ IrSentiment $_{t-1} \times$ NormalTimes $_{t-1}$} & 0.059 & 0.051 & 0.020 & 0.018 & 0.015 \\
\hline & [0.344] & [0.469] & [0.688] & {$[0.625]$} & [0.625] \\
\hline \multirow[t]{2}{*}{ IrSentiment $_{t-1} \times$ BadTimes $_{t-1}$} & -0.032 & -0.030 & -0.053 & -0.046 & -0.067 \\
\hline & [0.313] & [0.438] & [0.281] & [0.344] & [0.156] \\
\hline \multicolumn{2}{|l|}{ Baseline Macro Controls } & yes & yes & yes & yes \\
\hline \multicolumn{2}{|l|}{ Additional Macro Controls } & & yes & yes & yes \\
\hline \multicolumn{2}{|l|}{ Bank Controls } & & & yes & yes \\
\hline \multicolumn{2}{|l|}{ Demand-side Controls } & & & & yes \\
\hline \multirow{3}{*}{$\begin{array}{l}\text { Observations } \\
\text { Adjusted } \mathrm{R}^{2}\end{array}$} & 1.015 & 1.015 & 1.015 & 1.012 & 1.012 \\
\hline & 0.271 & 0.213 & 0.300 & 0.305 & 0.314 \\
\hline & & & $\overline{\text { Debt Cou }}$ & & \\
\hline RSentiment $_{t-1} \times$ GoodTimes $_{t-1}$ & $\begin{array}{c}0.076 \\
{[0.281]}\end{array}$ & & & & \\
\hline \multirow[t]{2}{*}{ RSentiment $_{t-1} \times$ NormalTimes $_{t-1}$} & 0.021 & & & & \\
\hline & {$[0.648]$} & & & & \\
\hline \multirow{2}{*}{ RSentiment $_{t-1} \times$ BadTimes $_{t-1}$} & 0.068 & & & & \\
\hline & {$[0.016]$} & & & & \\
\hline \multirow[t]{2}{*}{ IrSentiment $_{t-1} \times$ GoodTimes $_{t-1}$} & $\mathbf{0 . 0 5 8}$ & 0.050 & $\mathbf{0 . 0 5 2}$ & $\mathbf{0 . 0 5 5}$ & $\mathbf{0 . 0 5 3}$ \\
\hline & [0.094] & [0.133] & {$[0.078]$} & [0.086] & [0.047] \\
\hline \multirow{2}{*}{ IrSentiment $_{t-1} \times$ NormalTimes $_{t-1}$} & 0.043 & 0.036 & 0.018 & 0.019 & 0.022 \\
\hline & {$[0.000]$} & [0.039] & [0.234] & [0.211] & [0.102] \\
\hline \multirow[t]{2}{*}{ IrSentiment $_{t-1} \times$ BadTimes $_{t-1}$} & 0.015 & -0.000 & 0.004 & 0.010 & 0.021 \\
\hline & {$[0.328]$} & [0.977] & [0.609] & [0.211] & [0.125] \\
\hline \multicolumn{2}{|l|}{ Baseline Macro Controls } & yes & yes & yes & yes \\
\hline \multicolumn{2}{|l|}{ Additional Macro Controls } & & yes & yes & yes \\
\hline \multicolumn{2}{|l|}{ Bank Controls } & & & yes & yes \\
\hline \multicolumn{2}{|l|}{ Demand-side Controls } & & & & yes \\
\hline Observations & 1.369 & 1.369 & 1.369 & 1.369 & 1.369 \\
\hline Adjusted $\mathrm{R}^{2}$ & 0.099 & 0.086 & 0.133 & 0.137 & 0.167 \\
\hline
\end{tabular}

Note: Individual countries are assigned to the high- and low-debt subsamples based on their credit-to-GDP ratios averaged across 2003:Q1 to 2019:Q2 (credit is represented by total credit granted to households and non-profit institutions serving households). The high-debt countries are DK, NL, GB, PT, SE, ES, DE; the low-debt countries are FI, BE, FR, AT, IT, PL, SK, CZ. p-values (in brackets) are estimated using the wild cluster bootstrap resampling method developed by Cameron et al. (2008). GoodTimes, BadTimes, and NormalTimes denote dummy variables that are equal to 1 if the GDP gap for the given country in the given month $t$ is 0.5 standard deviation above, below, and around its mean, respectively, and 0 otherwise. Estimates in bold determine significance up to the $10 \%$ level. The table lists estimates based on panel data regression with country fixed effects and clusters, weighted by the financial inclusion proxy. See also the notes to Table D1 for additional information regarding the control variables. 


\section{Table D6: Country-Level Baseline Regression}

\begin{tabular}{|c|c|c|c|c|c|c|c|c|c|c|c|c|}
\hline & \multicolumn{12}{|c|}{ Dependent variable: $\Delta \ln \left(\right.$ Consumer Loans $\left.s_{t}^{c}\right)$} \\
\hline & (AT) & (BE) & (CZ) & $(\mathrm{DE})$ & $(\mathrm{DK})$ & (ES) & (FI) & (FR) & (IT) & (NL) & (PT) & (SK) \\
\hline \multicolumn{13}{|c|}{ Panel A: Simple Equation-by-Equation OLS } \\
\hline IrSent $_{t-1}^{c} \times$ GoodTimes $_{t-1}^{c}$ & $\begin{array}{c}0.028^{* * *} \\
(0.014)\end{array}$ & $\begin{array}{c}0.030 \\
(0.018)\end{array}$ & $\begin{array}{c}0.076 \\
(0.061)\end{array}$ & $\begin{array}{c}0.145^{* * *} \\
(0.026)\end{array}$ & $\begin{array}{l}0.059^{*} \\
(0.031)\end{array}$ & $\begin{array}{c}0.034 \\
(0.046)\end{array}$ & $\begin{array}{l}-0.019 \\
(0.019)\end{array}$ & $\begin{array}{c}0.021 \\
(0.013)\end{array}$ & $\begin{array}{c}0.112 * * * \\
(0.016)\end{array}$ & $\begin{array}{c}0.002 \\
(0.075)\end{array}$ & $\begin{array}{c}-0.084^{*} \\
(0.05)\end{array}$ & $\begin{array}{c}0.179^{* * * *} \\
(0.035)\end{array}$ \\
\hline IrSent $_{t-1}^{c} \times$ NormalTimes $_{t-1}^{c}$ & $\begin{array}{l}0.004 \\
(0.015)\end{array}$ & $\begin{array}{l}0.025 \\
(0.015)\end{array}$ & $\begin{array}{l}-0.062 \\
(0.039)\end{array}$ & $\begin{array}{l}-0.020 \\
(0.033)\end{array}$ & $\begin{array}{c}0.085^{* * * *} \\
(0.027)\end{array}$ & $\begin{array}{l}0.038 \\
(0.031)\end{array}$ & $\begin{array}{c}0.024 \\
(0.015)\end{array}$ & $\begin{array}{c}0.034 * * * \\
(0.009)\end{array}$ & $\begin{array}{c}0.064 * * * \\
(0.014)\end{array}$ & $\begin{array}{l}-0.050 \\
(0.056)\end{array}$ & $\begin{array}{c}-0.103^{*} \\
(0.06)\end{array}$ & $\begin{array}{l}0.040 \\
(0.032)\end{array}$ \\
\hline IrSent $_{t-1}^{c} \times$ BadTimes $_{t-1}^{c}$ & $\begin{array}{c}0.016 \\
(0.025)\end{array}$ & $\begin{array}{c}0.020 \\
(0.023)\end{array}$ & $\begin{array}{l}-0.039 \\
(0.039)\end{array}$ & $\begin{array}{l}0.074 * * \\
(0.033)\end{array}$ & $\begin{array}{l}-0.216 * * * \\
(0.057)\end{array}$ & $\begin{array}{c}-0.214 * * * \\
(0.05)\end{array}$ & $\begin{array}{l}-0.021 \\
(0.027)\end{array}$ & $\begin{array}{c}0.072 * * * \\
(0.017)\end{array}$ & $\begin{array}{l}0.065 * * * \\
(0.014)\end{array}$ & $\begin{array}{l}-0.084 \\
(0.076)\end{array}$ & $\begin{array}{c}0.012 \\
(0.039)\end{array}$ & $\begin{array}{c}0.117 * * * \\
(0.043)\end{array}$ \\
\hline All Controls & Y & $\mathrm{Y}$ & $\mathrm{Y}$ & $\mathrm{Y}$ & $\mathrm{Y}$ & $\mathrm{Y}$ & $\mathrm{Y}$ & $\mathrm{Y}$ & $\mathrm{Y}$ & $\mathrm{Y}$ & $\mathrm{Y}$ & $\mathrm{Y}$ \\
\hline Adj. $R^{2}$ & 0.632 & 0.429 & 0.504 & 0.730 & 0.438 & 0.759 & 0.560 & 0.521 & 0.882 & 0.466 & 0.770 & 0.491 \\
\hline \multicolumn{13}{|c|}{ Panel B: Equation-by-Equation OLS with Newey and West (1987) Correction of Standard Errors } \\
\hline IrSent t $_{t-1}^{c} \times$ GoodTimes $_{t-1}^{c}$ & $\begin{array}{l}0.028 \\
(0.02)\end{array}$ & $\begin{array}{c}0.030 \\
(0.029)\end{array}$ & $\begin{array}{c}0.076 \\
(0.134)\end{array}$ & $\begin{array}{c}0.145^{* * * *} \\
(0.033)\end{array}$ & $\begin{array}{c}0.059^{* *} \\
(0.029)\end{array}$ & $\begin{array}{c}0.034 \\
(0.071)\end{array}$ & $\begin{array}{l}-0.019 \\
(0.034)\end{array}$ & $\begin{array}{c}0.021 \\
(0.017)\end{array}$ & $\begin{array}{c}0.112 * * * \\
(0.029)\end{array}$ & $\begin{array}{c}0.002 \\
(0.087)\end{array}$ & $\begin{array}{l}-0.084 \\
(0.069)\end{array}$ & $\begin{array}{c}0.179 * * * * \\
(0.063)\end{array}$ \\
\hline IrSent $_{t-1}^{c} \times$ NormalTimes $_{t-1}^{c}$ & $\begin{array}{c}0.004 \\
(0.028)\end{array}$ & $\begin{array}{c}0.025 \\
(0.042)\end{array}$ & $\begin{array}{l}-0.062 \\
(0.358)\end{array}$ & $\begin{array}{l}-0.020 \\
(0.071)\end{array}$ & $\begin{array}{l}0.085^{*} \\
(0.050)\end{array}$ & $\begin{array}{l}0.038 \\
(0.056)\end{array}$ & $\begin{array}{c}0.024 \\
(0.038)\end{array}$ & $\begin{array}{c}0.034 \\
(0.022)\end{array}$ & $\begin{array}{l}0.064 * * * \\
(0.024)\end{array}$ & $\begin{array}{l}-0.050 \\
(0.068)\end{array}$ & $\begin{array}{l}-0.103 \\
(0.086)\end{array}$ & $\begin{array}{c}0.040 \\
(0.054)\end{array}$ \\
\hline IrSent $t_{t-1}^{c} \times$ BadTimes $_{t-1}^{c}$ & $\begin{array}{c}0.016 \\
(0.035)\end{array}$ & $\begin{array}{c}0.020 \\
(0.035)\end{array}$ & $\begin{array}{l}-0.039 \\
(0.472)\end{array}$ & $\begin{array}{l}0.074^{*} \\
(0.045)\end{array}$ & $\begin{array}{c}-0.216 * * * \\
(0.058)\end{array}$ & $\begin{array}{l}-0.214 * \\
(0.123)\end{array}$ & $\begin{array}{l}-0.021 \\
(0.056)\end{array}$ & $\begin{array}{l}0.072 * * \\
(0.028)\end{array}$ & $\begin{array}{c}0.065^{* * * *} \\
(0.021)\end{array}$ & $\begin{array}{l}-0.084 \\
(0.108)\end{array}$ & $\begin{array}{c}0.012 \\
(0.058)\end{array}$ & $\begin{array}{c}0.117 \\
(0.074)\end{array}$ \\
\hline All Controls & $\mathrm{Y}$ & $\mathrm{Y}$ & $\mathrm{Y}$ & $\mathrm{Y}$ & $\mathrm{Y}$ & $\mathrm{Y}$ & $\mathrm{Y}$ & $\mathrm{Y}$ & $\mathrm{Y}$ & $\mathrm{Y}$ & $\mathrm{Y}$ & $\mathrm{Y}$ \\
\hline Adj. $R^{2}$ & 0.632 & 0.429 & 0.504 & 0.730 & 0.438 & 0.759 & 0.560 & 0.521 & 0.882 & 0.466 & 0.770 & 0.491 \\
\hline \multicolumn{13}{|c|}{ Panel C: Seemingly Unrelated Regression (SUR, Zellner (1962)) } \\
\hline IrSent $_{t-1}^{c} \times$ GoodTimes $_{t-1}^{c}$ & $\begin{array}{l}0.030^{*} \\
(0.012)\end{array}$ & $\begin{array}{l}0.039^{*} \\
(0.016)\end{array}$ & $\begin{array}{c}0.039 \\
(0.051)\end{array}$ & $\begin{array}{l}0.140^{* * *} \\
(0.024)\end{array}$ & $\begin{array}{l}0.076^{* *} \\
(0.029)\end{array}$ & $\begin{array}{l}0.028 \\
(0.034)\end{array}$ & $\begin{array}{l}-0.017 \\
(0.015)\end{array}$ & $\begin{array}{c}0.017 \\
(0.011)\end{array}$ & $\begin{array}{c}0.092^{* * *} \\
(0.014)\end{array}$ & $\begin{array}{c}0.032 \\
(0.054)\end{array}$ & $\begin{array}{c}-0.089^{*} \\
(0.044)\end{array}$ & $\begin{array}{c}0.139^{* * *} \\
(0.032)\end{array}$ \\
\hline IrSent $_{t-1}^{c} \times$ NormalTimes st-1 $_{t-1}^{c}$ & $\begin{array}{l}-0.013 \\
(0.013)\end{array}$ & $\begin{array}{c}0.025 \\
(0.013)\end{array}$ & $\begin{array}{l}-0.032 \\
(0.033)\end{array}$ & $\begin{array}{l}0.004 \\
(0.030)\end{array}$ & $\begin{array}{c}0.085^{* * *} \\
(0.024)\end{array}$ & $\begin{array}{l}0.036 \\
(0.024)\end{array}$ & $\begin{array}{l}0.027^{*} \\
(0.012)\end{array}$ & $\begin{array}{l}0.024^{* *} \\
(0.008)\end{array}$ & $\begin{array}{r}0.040^{* * *} \\
(0.012)\end{array}$ & $\begin{array}{r}-0.040 \\
(0.040)\end{array}$ & $\begin{array}{l}-0.092 \\
(0.053)\end{array}$ & $\begin{array}{c}0.031 \\
(0.029)\end{array}$ \\
\hline IrSent $t_{t-1}^{c} \times$ BadTimes $_{t-1}^{c}$ & $\begin{array}{l}0.009 \\
(0.023)\end{array}$ & $\begin{array}{l}0.044^{*} \\
(0.020)\end{array}$ & $\begin{array}{l}-0.041 \\
(0.033)\end{array}$ & $\begin{array}{l}0.066^{*} \\
(0.029)\end{array}$ & $\begin{array}{c}-0.170^{* *} \\
(0.051)\end{array}$ & $\begin{array}{c}-0.134^{* * *} \\
(0.036)\end{array}$ & $\begin{array}{l}0.019 \\
(0.022)\end{array}$ & $\begin{array}{l}0.055^{* * *} \\
(0.014)\end{array}$ & $\begin{array}{c}0.048^{* * *} \\
(0.012)\end{array}$ & $\begin{array}{l}-0.044 \\
(0.054)\end{array}$ & $\begin{array}{l}-0.018 \\
(0.036)\end{array}$ & $\begin{array}{l}0.091^{*} \\
(0.040)\end{array}$ \\
\hline All Controls & $\mathrm{Y}$ & $\mathrm{Y}$ & $\mathrm{Y}$ & $\mathrm{Y}$ & $\mathrm{Y}$ & $\mathrm{Y}$ & $\mathrm{Y}$ & $\mathrm{Y}$ & $\mathrm{Y}$ & $\mathrm{Y}$ & $\mathrm{Y}$ & $\mathrm{Y}$ \\
\hline Adj. $\mathrm{R}^{2}$ & 0.623 & 0.417 & 0.491 & 0.723 & 0.420 & 0.743 & 0.547 & 0.505 & 0.876 & 0.441 & 0.765 & 0.473 \\
\hline
\end{tabular}

Notes: Standard errors are in parenthesis. Three countries were removed from the country-level analysis because the data on the dependent variable contained fewer observations compared to the other countries in the sample: Poland (data from May 2008 only), Sweden (data from October 2006 only), and the United Kingdom (data from March 2001 to March 2017 only). 


\section{Appendix E: Background of the Harmonized Consumer Surveys}

The European Commission's harmonized survey program has been administered by the DirectorateGeneral for Economic and Financial Affairs (DG ECFIN) since 1961. The program consists of six surveys conducted at monthly frequency in the following areas: manufacturing industry, construction, consumers, retail trade, services, and financial services. All the surveys except for the retail trade one also contain special questions that are included only once a quarter. The surveys themselves are managed by national institutions, most frequently the central banks of the EU member and candidate states. Harmonization across countries is achieved by the use of: (1) the same questionnaires (additional questions or more thorough division into sectors is possible), and (2) common timetable rules for delivering the survey results (for the monthly questions, the fieldwork is carried out in the first two to three weeks of the respective month and the results need to be delivered in the last week of the respective month).

The respondent sample size for each survey and country differs. It is set based on the heterogeneity of the respective economies and on population size. Table E1 lists the sample sizes for the consumer surveys conducted in the countries subject to analysis in this paper. The complete list of sample sizes for each country surveyed and for each survey in the program can be found in European Commission (2018).

Table E1: Consumer Survey - Sample Size per Country

\begin{tabular}{llllll}
\hline \hline AT & 1,500 & ES & 2,000 & PL & 1,020 \\
\hline BE & 1,850 & FI & 1,500 & PT & 1,630 \\
\hline CZ & 1,000 & FR & 3,300 & SK & 1,200 \\
\hline DK & 1,500 & IT & 2,000 & SE & 1,500 \\
\hline DE & 2,000 & NL & 1,660 & UK & 2,000 \\
\hline \hline
\end{tabular}

Source: European Commission (2018)

The sampling scheme for the consumer surveys is derived from a framework which registers all the units in the given population, such as official statistical registers. The unit of observation for the consumer surveys is a single household. Survey participation is voluntary in most of the countries but is mandatory for some or all of the surveys in Spain, France, Italy, the Netherlands, Poland, and Portugal. National institutions and authorities cope with possible non-responsiveness in the consumer surveys either by stratified random sampling or by quota sampling. Stratified sampling is based on separation of the respective population of respondents into stratas - non-overlapping subpopulations that exhibit similar properties as the desired population. The criteria for stratification in the consumer surveys are based on sex, age, education, income, and occupation. Countries that employ quota sampling merely collect the responses of the population until they reach a certain quota of respondents. Compared to stratified sampling, quota samples are not random. This gives rise to several shortcomings when one wants to draw inferences about the population the sample is meant to represent. In this paper, we do not attempt to make any assumptions regarding the population of households, so we do not need to control for this characteristic. 


\section{CNB Working Paper Series (since 2019)}

WP 10/2020

Zuzana Rakovská

Dominika

Ehrenbergerová

Martin Hodula

WP 9/2020 Ivan Sutóris

WP $8 / 2020$

Martin Hodula

Jan Janků

Martin Časta

Adam Kučera

WP 7/2020 František Brázdik Tibor Hlédik Zuzana Humplová Iva Martonosi

Karel Musil

Jakub Ryšánek

Tomáš Šestořád

Jaromír Tonner

Stanislav Tvrz

Jan Žáček

WP 6/2020 Volha Audzei

Jan Brůha

WP 5/2020

Dominika

Ehrenbergerová

Martin Hodula

Zuzana Rakovská

WP 4/2020 Alexis Derviz

WP 3/2020 Milan Szabo

WP 2/2020 Martin Hodula

Ngoc Anh Ngo

WP 1/2020 Michal Franta Ivan Sutóris
The power of sentiment: Irrational beliefs of households and consumer loan dynamics

The intertemporal cost of living and dynamic inflation: The case of the Czech Republic

On the determinants of life and non-life insurance premiums

The g3+ model: An upgrade of the Czech National Bank's core forecasting framework

A model of the Euro Area, China and the United States: Trade links and trade wars

Does capital-based regulation affect bank pricing policy?

Sovereign capital, external balance, and the investment-based Balassa-Samuelson effect in a global dynamic equilibrium

Growth-at-risk:Bayesian approach

Finance, growth and (macro)prudential policy: European evidence

Dynamics of Czech inflation: The role of the trend and the cycle

The elasticity of substitution between domestic and foreign goods:

A quantitative survey

Tomáš Havránek

Zuzana Iršová

Jiří Schwarz

WP 11/2019 Martin Hodula

Simona Malovaná Jan Frait

WP 10/2019 Martin Hodula Simona Malovaná Jan Frait
Too much of a good thing? Households' macroeconomic conditions and credit dynamics

Introducing a new index of households' macroeconomic conditions 


\begin{tabular}{|c|c|c|}
\hline WP 9/2019 & $\begin{array}{l}\text { Jiří Panoš } \\
\text { Petr Polák }\end{array}$ & $\begin{array}{l}\text { How to improve the model selection procedure within a stress testing } \\
\text { framework? }\end{array}$ \\
\hline WP $8 / 2019$ & $\begin{array}{l}\text { Sebastian Gechert } \\
\text { Tomáš Havránek } \\
\text { Zuzana Iršová } \\
\text { Dominika } \\
\text { Kolcunová }\end{array}$ & $\begin{array}{l}\text { Death to the Cobb-Douglas production function? A quantitative survey } \\
\text { of the capital-labor substitution elasticity }\end{array}$ \\
\hline WP $7 / 2019$ & Alexis Derviz & $\begin{array}{l}\text { Coexistence of physical and crypto assets in a stochastic endogenous } \\
\text { growth model }\end{array}$ \\
\hline WP 6/2019 & $\begin{array}{l}\text { Dominika } \\
\text { Ehrenbergerová } \\
\text { Simona Malovaná }\end{array}$ & Introducing macro-financial variables into semi-structural model \\
\hline WP 5/2019 & Martin Hodula & $\begin{array}{l}\text { Monetary policy and shadow banking: Trapped between a rock and } \\
\text { a hard place }\end{array}$ \\
\hline WP 4/2019 & $\begin{array}{l}\text { Simona Malovaná } \\
\text { Žaneta Tesařová }\end{array}$ & $\begin{array}{l}\text { Banks' credit losses and provisioning over the business cycle: } \\
\text { Implications for IFRS } 9\end{array}$ \\
\hline WP 3/2019 & $\begin{array}{l}\text { Aleš Bulî́r } \\
\text { Jan Vlček }\end{array}$ & $\begin{array}{l}\text { Monetary policy is not always systematic and data-driven: Evidence } \\
\text { from the yield curve }\end{array}$ \\
\hline WP 2/2019 & $\begin{array}{l}\text { Dominika } \\
\text { Kolcunová } \\
\text { Simona Malovaná }\end{array}$ & $\begin{array}{l}\text { The effect of higher capital requirements on bank lending: The capital } \\
\text { surplus matters }\end{array}$ \\
\hline WP 1/2019 & $\begin{array}{l}\text { Jaromír Baxa } \\
\text { Tomáš Šestořád }\end{array}$ & The Czech exchange rate floor: Depreciation without inflation? \\
\hline
\end{tabular}

\section{CNB Research and Policy Notes (since 2019)}

\begin{tabular}{|c|c|c|}
\hline RPN 3/2020 & $\begin{array}{l}\text { Simona Malovaná } \\
\text { Martin Hodula } \\
\text { Zuzana Rakovská }\end{array}$ & Researching the research: $A$ central banking edition \\
\hline RPN 2/2020 & $\begin{array}{l}\text { Simona Malovaná } \\
\text { Josef Bajzík } \\
\text { Dominika } \\
\text { Ehrenbergerová } \\
\text { Jan Janků }\end{array}$ & A prolonged period of low interest rates: Unintended consequences \\
\hline RPN 1/2020 & Simona Malovaná & $\begin{array}{l}\text { How to organize research in central banks: The Czech National } \\
\text { Bank's experience }\end{array}$ \\
\hline RPN 4/2019 & $\begin{array}{l}\text { Tomáš Konečný } \\
\text { Lukáš Pfeifer }\end{array}$ & Macroprudential ring-fencing \\
\hline RPN 3/2019 & $\begin{array}{l}\text { Petr Polák } \\
\text { Jiří Panoš }\end{array}$ & Impact of expectations on IFRS 9 loan loss provisions \\
\hline RPN 2/2019 & Jan Filáček & Inflation targeting flexibility: The CNB's reaction function under \\
\hline
\end{tabular}


Ivan Sutóris

RPN 1/2019 Iveta Polášková Luboš Komárek Michal Škoda scrutiny

The contemporary role of gold in central banks' balance sheets 
CZECH NATIONAL BANK

Na Příkopě 28

11503 Praha 1

Czech Republic

ECONOMIC RESEARCH DIVISION

Tel.: +420 224412321

Fax: +420 224412329

http://www.cnb.cz

e-mail: research@cnb.cz

ISSN 1803-7070 